\title{
Supressão Compton na análise por ativação neutrônica instrumental de produtos agrícolas destinados à alimentação humana
}

\section{Luís Gustavo Cofani dos SANTOS}

\author{
Dissertação apresentada ao Centro de Energia \\ Nuclear na Agricultura, Universidade de São Paulo, \\ para obtenção do título de Mestre em Ciências, \\ Área de Concentração: Energia Nuclear na \\ Agricultura
}

\section{PIRACICABA}

Estado de São Paulo - Brasil

Fevereiro - 2004 
Dados Internacionais de Catalogação na Publicação (CIP) Seção Técnica de Biblioteca - CENA/USP

Santos, Luís Gustavo Cofani dos

Supressão Compton na análise por ativação neutrônica instrumental de produtos agrícolas destinados à alimentação humana / Luís Gustavo Cofani dos Santos. - - Piracicaba, 2004.

$86 p$.

Dissertação (mestrado) - - Centro de Energia Nuclear na Agricultura, 2004.

1. Alimentos de origem vegetal 2. Espectrometria 3. Radiação gama 4. Radioisótopos I. Título

CDU 543.53 


\title{
Supressão Compton na análise por ativação neutrônica instrumental de produtos agrícolas destinados à alimentação humana
}

\section{Luís GuSTAVo Cofani dos SANTOS}

Físico

Orientador: Dr. MÁRCIO ARRUDA BACCHI

\author{
Dissertação apresentada ao Centro de Energia \\ Nuclear na Agricultura, Universidade de São Paulo, \\ para obtenção do título de Mestre em Ciências, \\ Área de Concentração: Energia Nuclear na \\ Agricultura
}

\section{PIRACICABA}

Estado de São Paulo - Brasil

Fevereiro - 2004 
Aos meus pais, Roseli e Roberto 


\section{AGRADECIMENTOS}

às instituições:

- Universidade de São Paulo (USP)

- Centro de Energia Nuclear na Agricultura (CENA)

- Coordenação de Aperfeiçoamento de Pessoal de Nível Superior (CAPES)

- Fundação de Amparo à Pesquisa do Estado de São Paulo (FAPESP)

que proporcionaram suporte técnico-científico e financeiro ao trabalho desenvolvido;

à Profa. Dra. Elisabete De Nadai Fernandes, Prof. Dr. Márcio Arruda Bacchi e Profa. Dra. Siu Mui Tsai, pela amizade;

aos integrantes da APG e CPG, em especial ao Prof. Dr. Francisco José Krug e Prof. Dr. Virgílio F. do Nascimento Filho;

à equipe da seção de pós-graduandos e biblioteca;

e aos demais colegas e amigos do Laboratório de Radioisótopos. 
“Talvez não tenhamos conseguido

fazer o melhor, mas lutamos

para que o melhor fosse feito...

Não somos o que deveríamos ser, não somos o que iremos ser, mas, graças a Deus não somos o que éramos.”

Martin Luther King 


\section{SUMÁRIO}

LISTA DE EQUAÇÕES
LISTA DE FIGURAS
LISTA DE TABELAS
RESUMO
SUMMARY
1. INTRODUÇÃO
2. FUNDAMENTOS
2.1. Radiação gama e sua deteç̧ão
2.2. Espalhamento Compton
2.3. Supressão Compton
2.4. Análise por ativação neutrônica
3. REVISÃO DE LITERATURA
3.1. Desempenho de supressores Compton
3.2. Supressão Compton em NAA




\section{LISTA DE EQUAÇÕES}

1 Variação do comprimento de onda, na interação por espalhamento Compton ..... 08

2 Variação do comprimento de onda, na interação por espalhamento Compton utilizando o comprimento de onda Compton ...................................................... 08

3 Energia do fóton Compton em função da energia inicial e do ângulo de

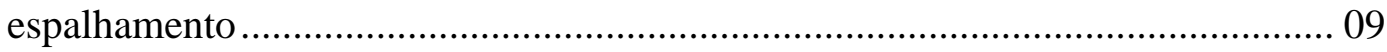

4 Máxima energia de recuo do elétron em função da energia do fóton incidente e do ângulo de espalhamento ................................................................................. 09

5 Formação de radionuclídeo pelo bombardeamento com nêutron ......................... 13

6 Decaimento radioativo por emissão de partícula beta ....................................... 13

7 Quantificação em INAA pelo método multicomparativo ..................................... 15

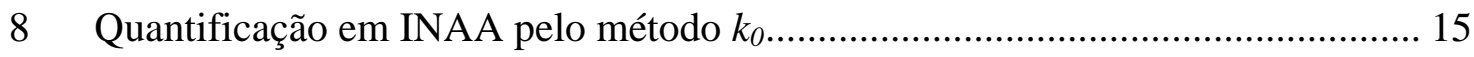

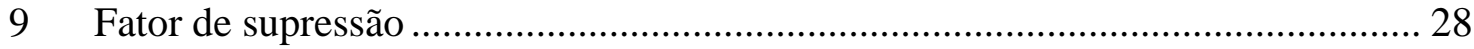

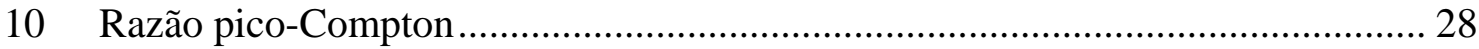

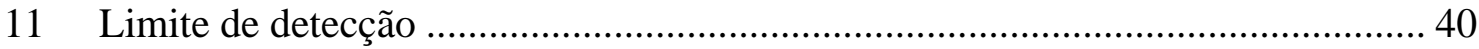




\section{LISTA DE FIGURAS}

1 Ocorrência dos três principais tipos de interação da radiação gama..................... 07

2 Espalhamento Compton antes e depois da interação...........................................08

3 Espectro com e sem supressão Compton .......................................................... 11

4 Diagrama de blocos de um sistema supressor Compton ...................................... 12

5 Classificação da NAA em relação ao tratamento químico de amostras.................14

6 Corte longitudinal do sistema de supressão Compton ........................................24

7 Diagrama de blocos do sistema de supressão Compton.....................................25

8 Distribuição dos materiais para irradiação ......................................................36

$9 \quad$ Fator de supressão para ${ }^{137}$ Cs entre 358 e 382 keV em 20 semanas ..................... 44

10 Fator de supressão para ${ }^{137} \mathrm{Cs}$ medido em diversas energias................................45

11 Fator de supressão para ${ }^{137} \mathrm{Cs}$ medido a diferentes distâncias.............................46

12 Fator de supressão para ${ }^{60} \mathrm{Co}$ em função da taxa de contagem total .....................48

13 Contagem no fotopico do ${ }^{60} \mathrm{Co}$ em função da taxa de contagem total .................49

14 Resultados individuais para amostras de arroz................................................ 53

15 Resultados individuais para amostras de batata ................................................. 55

16 Resultados individuais para amostras de feijão...............................................56

17 Resultados individuais para amostras de ervilha, grão-de-bico e lentilha ............58

18 Razão entre limite de detecção sem e com supressão ........................................62

19 Razão entre os limites de detecção para duas amostras de arroz .........................64

20 Razão entre os limites de detecção para duas amostras de grão-de-bico ..............65

21 Razão entre os limites de detecção para duas amostras de feijão .........................66

22 Razão entre os limites de detecção para materiais de referência certificados ......67 


\section{LISTA DE TABELAS}

1 Módulos eletrônicos do sistema supressor Compton ........................................ 26

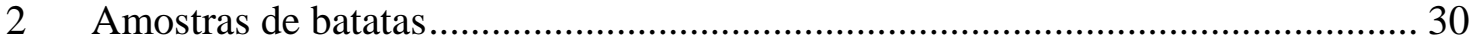

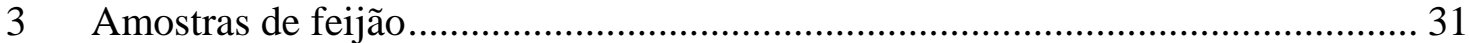

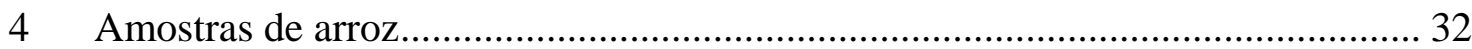

5 Amostras de ervilha, grão-de-bico e lentilha ..................................................... 33

6 Grãos selecionados para análise no segundo lote............................................ 34

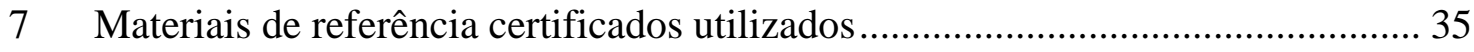

8 Condições típicas observadas na ativação....................................................... 37

9 Condições típicas observadas para cada medição .............................................. 39

10 Radionuclídeos utilizados para a obtenção dos resultados................................ 41

11 Fator de supressão e razão pico-Compton obtidos por diversos autores............... 43

12 Resultados médios para a composição química elementar ................................. 50

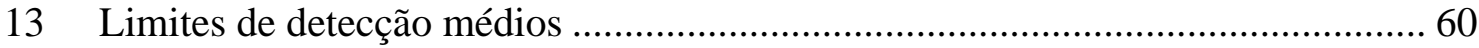




\title{
Supressão Compton na análise por ativação neutrônica instrumental de produtos agrícolas destinados à alimentação humana
}

\author{
Autor: Luís Gustavo Cofani dos Santos \\ Orientador: Márcio Arruda Bacchi
}

\section{RESUMO}

A análise por ativação neutrônica instrumental (INAA) é uma opção para o estudo da composição de alimentos, permitindo determinar simultaneamente diversos elementos. Todavia, a deposição incompleta da energia da radiação gama no detector, devido à interação por espalhamento Compton, dificulta as determinações. O acúmulo de contagens na linha de base do espectro torna-se um problema quando existem na amostra radionuclídeos com emissões gama em energias mais altas do que a de interesse. Nesses casos, os supressores Compton podem aumentar a sensibilidade analítica. Aqui, avalia-se o uso de supressão Compton para o estudo de produtos agrícolas destinados à alimentação humana.

Todas as medições foram realizadas com um detector de germânio hiperpuro com 55 \% de eficiência relativa $\left(1332 \mathrm{keV},{ }^{60} \mathrm{Co}\right)$, circundado por detectores de iodeto de sódio (annulus e plug). Espectros com supressão foram adquiridos a partir da detecção em anti-coincidência. Foram também armazenados os espectros sem supressão.

Inicialmente, testou-se a capacidade do equipamento em reduzir a região Compton, empregando fontes de ${ }^{137}$ Cs. Medindo-se na região entre 358 e $382 \mathrm{keV}$, o melhor fator de supressão foi 5,97, sendo observada variação no valor de acordo com a região Compton escolhida para a medição. Reduções foram notadas no fator de supressão com o aumento da taxa de contagem e da distância fonte-detector. Em verificações realizadas durante 20 semanas, o sistema supressor mostrou-se estável.

Para avaliar o uso de supressão Compton na análise de amostras, foram tomados diversos tipos e marcas comerciais de arroz, batata, feijão, ervilha, grão-de-bico e lentilha. Após secagem e moagem, as amostras foram irradiadas em fluxo de nêutrons 
térmicos de $1 \times 10^{13} \mathrm{~cm}^{-2} \mathrm{~s}^{-1}$ por 8 horas, no reator IEA-R1m do IPEN/CNEN (Instituto de Pesquisas Energéticas e Nucleares). A radioatividade foi medida em quatro oportunidades, em aproximadamente 3, 7, 15 e 40 dias após a irradiação. A análise foi conduzida pelo método $k_{0}$, utilizando o programa Quantu.

Quinze elementos foram estudados, entretanto Cd e Hg apresentaram-se abaixo dos limites de detecção, o que também occoreu para As, Cr, La e Se em várias amostras. Foram notados alguns comportamentos próprios de cada tipo de produto analisado. Arroz integral, parboilizado e polido, por exemplo, apresentaram diferentes concentrações de $\mathrm{K}, \mathrm{Rb}$ e Zn. Dentre os elementos com maior potencial tóxico, a presença de um valor médio de $0,3 \mathrm{mg} \mathrm{kg}^{-1}$ de As em arroz foi a única observação.

Houve influência de $\mathrm{Br}, \mathrm{K}$ e $\mathrm{Na}$ sobre os limites de detecção para os elementos medidos entre 3 e 8 dias após a irradiação. A razão entre os limites de detecção sem e com supressão mostrou que a determinação de Br, Co, La, Na, Sc e Se não foi favorecida pelo uso do supressor. Para As, Ca, Cd, Cr, Fe, Hg, K, Rb e Zn, observou-se ganho de sensibilidade fortemente dependente da composição do material e das condições experimentais. Os resultados demonstraram que o desempenho do supressor Compton em INAA deve ser individualmente testado para cada tipo de amostra. 


\title{
Instrumental neutron activation analysis with Compton suppression for the evaluation of foodstuff composition
}

Author: Luís Gustavo Cofani dos Santos

Adviser: Márcio Arruda Bacchi

\begin{abstract}
SUMMARY
Instrumental neutron activation analysis (INAA) is a good option for studying chemical composition of food, allowing the simultaneous determination of several elements. However, the incomplete deposition of gamma-ray energies in the detector crystal due to Compton scatter can elevate the spectrum baseline making difficult the determination of some elements. The problem is particularly important for samples having high activities of radionuclides emitting gamma-rays with energies higher than those to be measured. For such cases, the use of a Compton suppression system can improve the detection limits.

Here, the application of a suppression system for the analysis of foodstuff is evaluated. Measurements were carried out with a hyperpure germanium detector with $55 \%$ relative efficiency for the photopeak $1332 \mathrm{keV}$ of ${ }^{60} \mathrm{Co}$, working in anti-coincidence with two sodium iodine guard detectors (annulus and plug). Suppressed and unsuppressed spectra were simultaneously acquired.

Initially, the overall system performance on the reduction of the Compton region was tested using ${ }^{137}$ Cs. Measuring between 358 and $382 \mathrm{keV}$, the higher suppression factor was 5.97, being observed a large variation according to the energy region selected for the determination. Reductions were noticed for the suppression factor resulting from increases on counting rate and source-detector distance. The suppression system showed to be stable during twenty weeks of periodic verifications.

To evaluate the system performance on real sample analysis, several types and commercial brands of rice, potatoes, beans, peas, chickpeas and lentil were taken. After drying and grinding, samples were irradiated at a thermal neutron flux of $1 \times 10^{13} \mathrm{~cm}^{-2} \mathrm{~s}^{-1}$
\end{abstract}


for 8 hours, in the nuclear research reactor IEA-R1m from IPEN/CNEN (Instituto de Pesquisas Energéticas e Nucleares). Each sample was measured after decay periods of about 3, 7, 15 and 40 days. Analysis was conducted by the $k_{0}$ method using the software package Quantu.

Fifteen elements were assessed, however $\mathrm{Cd}$ and $\mathrm{Hg}$ were below detection limits, as well as As, Cr, La e Se for several samples. The content of some elements were noticed to vary according to the product analyzed or its particular type. Different results, for instance, were obtained for $\mathrm{K}, \mathrm{Rb}$ and $\mathrm{Zn}$ in integral, parboiled and polish rice. Among the elements with potentially high toxicity for humans, the only observation was a mean As content of $0.3 \mathrm{mg} \mathrm{kg}^{-1}$ in rice.

There was a significant influence of $\mathrm{Br}, \mathrm{K}$ and $\mathrm{Na}$ on the detection limits for elements measured from 3 to 8 days after the irradiation. The ratio between the detection limits calculated for unsuppressed and suppressed spectra showed that the determination of Br, Co, La, Na, Sc and Se was not improved by using the Compton suppression system. For As, $\mathrm{Ca}, \mathrm{Cd}, \mathrm{Cr}, \mathrm{Fe}, \mathrm{Hg}, \mathrm{K}, \mathrm{Rb}$ and $\mathrm{Zn}$, an enhancement in the analytical sensitivity was noted, which was strongly dependent on sample composition and experimental conditions. The results demonstrated that the suppression system performance for INAA should be individually evaluated for each type of matrix to be analyzed. 


\section{INTRODUÇÃO}

A produção de alimentos no Brasil tem alcançado níveis inéditos nos últimos anos. Em 2003, dentre dezenove produtos agrícolas avaliados pelo Instituto Brasileiro de Geografia e Estatística (IBGE), treze obtiveram resultado positivo em relação ao ano anterior. A produção nacional de cereais, leguminosas e oleaginosas na safra 2002/2003 totalizou cerca de 122 milhões de toneladas, aproximadamente $26 \%$ superior à safra 2001/2002. A cultura do trigo, nesse mesmo período, mostrou um aumento de aproximadamente $90 \%$. No ano de 2004, observando-se somente o grupo dos cereais, leguminosas e oleaginosas, espera-se colher 127 milhões de toneladas, cerca de $4 \%$ mais do que em 2003 (IBGE, 2004).

Contudo, no desenvolvimento da agricultura não deve haver preocupação apenas com mecanismos que proporcionem aumento de produtividade, mas também atentar para a qualidade do alimento. A sociedade brasileira, acompanhando uma tendência mundial, está ficando mais exigente em relação aos produtos consumidos em sua alimentação.

Uma alimentação adequada é essencial ao bom funcionamento do organismo de um indivíduo saudável. Segundo Lehninger (1990), mesmo com todo o conhecimento que há sobre nutrição, estima-se que um oitavo da população mundial seja desnutrida. Opostamente ao esperado, muitas pessoas dos países ricos são malnutridas, não pela falta de comida, mas pela alimentação inadequada.

Os alimentos são fontes de substâncias nutritivas indispensáveis, porém podem ser também fonte de substâncias tóxicas que ocasionam os mais diversos malefícios à saúde. Resíduos de agrotóxicos e toxinas produzidas por microorganismos são dois dos grupos de substâncias presentes em alimentos que normalmente são associadas a 
problemas de saúde. Todavia, não se deve negligenciar outros tipos de contribuições danosas, como elementos químicos absorvidos em excesso pelas plantas, resultado de concentração natural elevada no solo, de poluição ou outra forma de desequilíbrio ecológico causado pela ação humana. Embora seja bem conhecido que diversos elementos são essenciais à saúde humana, é também verdade que muitos têm sido apontados como causadores diretos ou indiretos de enfermidades.

Alguns vegetais acumulam elementos químicos em níveis tóxicos ao consumo humano, sem que haja qualquer manifestação de fitotoxicidade. Carbonell-Barrachina et al. (1999) mencionam que rabanete, crescendo sob exposição a grande quantidade de As, acumula esse elemento em concentrações inaceitáveis para o consumo humano ou de animais, mesmo que as plantas se desenvolvam normalmente.

Na maioria das vezes, os efeitos nocivos não são imediatos ou pelo menos, não são notados a curto prazo. Senesi et al. (1999) relatam que grande parte da população mundial considerada saudável pode estar sofrendo envenenamento por elementos químicos sem que seja percebido. É comum que os elementos acumulem-se gradativamente no organismo e só a partir de determinados níveis passem a produzir o efeito danoso.

Inúmeros autores têm estudado os efeitos tóxicos de elementos químicos. Iyengar \& Nair (2000), por exemplo, relatam que As, $\mathrm{Hg}$ e $\mathrm{Pb}$, ao entrarem na cadeia alimentar, podem esgotar seriamente as reservas de Fe, vitamina $\mathrm{C}$ e outros nutrientes do corpo, levando à diminuição das defesas imunológicas, entre outros danos. Por sua vez, Ishihara et al. (2001) afirmam que na bacia do Rio Jinzu, Japão, o crescimento de problemas renais na população rural, com conseqüente aumento da mortalidade, foi relacionado à elevada concentração de Cd no arroz cultivado na região. Alguns trabalhos de revisão têm procurado compilar as informações disponíveis sobre elementos considerados tóxicos, como As (Jain \& Ali, 2000) e Cd (Waalkes, 2000).

A crescente percepção da importância dos elementos químicos para a saúde, na condição de agentes nutricionais benéficos e maléficos, tem levado à constante busca por aprimoramento nas técnicas e métodos de análise de alimentos. O controle da 
segurança alimentar requer resultados com a melhor exatidão possível e também a quantificação de concentrações cada vez mais baixas.

Nesse sentido, progresso significativo tem sido alcançado principalmente com o grande avanço das técnicas de análise instrumental, como as espectrometrias de absorção atômica, emissão atômica e massas. Porém, há ainda lacunas a serem preenchidas, especialmente considerando os efeitos da globalização. O comércio internacional de alimentos exige que os resultados produzidos em um laboratório brasileiro sejam metrologicamente comparáveis aos dos demais países, de modo a serem aceitos sem restrições.

Por prescindir de qualquer tratamento químico de amostras, possuindo fontes de incerteza bem conhecidas e completamente distintas de outras técnicas, a análise por ativação neutrônica instrumental (INAA) é uma opção interessante para a determinação de elementos químicos em alimentos, sobretudo quando se necessita de um elevado rigor metrológico. Adicionalmente, o seu caráter multielementar possibilita um estudo amplo da composição química do material analisado, o que é bastante útil nas situações de triagem, quando há suspeita de contaminação ou acúmulo de elementos químicos em alimentos.

Naturalmente, a INAA também apresenta limitações quando comparada a outras técnicas analíticas, citando-se, por exemplo, a dependência de reatores nucleares de pesquisa e tempos normalmente longos para obtenção de resultados. Como qualquer outra técnica instrumental multielementar, está também sujeita a problemas de interferência, em que a presença de um elemento de alguma forma afeta negativamente a determinação de outro.

A INAA consiste basicamente na irradiação de amostras com nêutrons para induzir a formação de radionuclídeos, detectando-se os raios gama emitidos no decaimento. Dentre vários fatores, a sensibilidade analítica pode ser prejudicada pela presença de elevada linha de base no espectro de radiação gama, formada principalmente pela deposição incompleta da energia dos fótons ao interagirem com o detector por espalhamento Compton. Quanto maior a presença de radionuclídeos emissores de raios gama de alta energia, mais elevada será essa linha de base, ou região Compton, portanto 
menor será a sensibilidade para detecção de radionuclídeos que emitem raios gama em energias mais baixas.

A utilização de técnicas de supressão Compton aplicadas à INAA surge como alternativa para a redução da linha de base, tendo como conseqüência direta um aumento na sensibilidade para determinação de vários elementos (Landsberger, 1994). A aplicação de supressão é recomendada apenas para elementos quantificados por meio de radionuclídeos que não emitem raios gama em cascata. Elementos com grande importância como contaminantes de alimentos, tais como As, Cd, Cr e Hg, podem ter a determinação beneficiada pelo uso da supressão.

Inserido no contexto apresentado, este trabalho tem como objetivo consolidar a implementação de supressão Compton em INAA aplicada ao estudo de matrizes biológicas, com ênfase em produtos agrícolas destinados à alimentação humana. Para isso, avaliou-se inicialmente o desempenho geral do equipamento supressor com fontes radioativas de ${ }^{137} \mathrm{Cs}$ e ${ }^{60} \mathrm{Co}$. Em seguida, testou-se a utilização do equipamento na análise de amostras de arroz e feijão, que são dois constituintes básicos da dieta brasileira, além de batata, ervilha, grão-de-bico e lentilha. Diversos materiais de referência certificados, de matrizes similares às das amostras, foram adicionados às séries analíticas para controle de qualidade e avaliação complementar do desempenho do sistema supressor Compton na análise de diferentes matrizes. 


\section{FUNDAMENTOS}

\subsection{Radiação gama e sua detecção}

A radiação gama é uma radiação eletromagnética de origem nuclear, altamente energética (da ordem de $1 \mathrm{MeV}$ ) e com grande potencial de penetração. Ela é originada pela emissão de energia de um núcleo em estado excitado, que passa para um estado de energia mais baixa.

A emissão de raios gama geralmente ocorre em decorrência de um decaimento radioativo, por exemplo após a emissão de partículas alfa ou beta. Ao emitir partículas alfa ou beta, na maioria da vezes, um núcleo decai para um estado excitado do núcleo descendente, que então alcançará seu estado fundamental pela liberação de um ou mais raios gama. Considerando que esses raios gama são característicos do decaimento de cada radionuclídeo e têm suas energias e intensidades conhecidas, torna-se possível fazer a identificação e a quantificação de um ou mais radionuclídeos presentes em um determinado material por meio de espectrometria de radiação gama.

Ao longo de aproximadamente um século, o homem desenvolveu instrumentos e mecanismos específicos para detecção e contagem da radiação gama. O princípio da detecção consiste em absorver a energia dos fótons (ou parte dela) em um meio capaz de convertê-la em uma forma que possa, de alguma maneira, transformar-se em um sinal mensurável. Há diversos tipos de detectores compreendendo os estados sólido, líquido e gasoso. Porém, dada a sua estrutura física que propicia maior eficiência, os detectores de estado sólido são usados quase na totalidade dos experimentos de quantificação de radiação gama. 
Os primeiros detectores de estado sólido eram de $\mathrm{NaI}(\mathrm{Tl})$ (iodeto de sódio dopado com tálio), porém com o tempo surgiram detectores de Ge(Li) e de HPGe (germânio hiperpuro), que possibilitaram a quantificação simultânea de diversos radionuclídeos, diminuindo a necessidade de separações químicas. Hoje, graças ao aprimoramento tecnológico, o emprego de detectores de HPGe, considerados de alto poder de resolução, tornou-se relativamente comum em espectrometria gama em comparação a algumas décadas atrás. Em análise por ativação neutrônica, a utilização de detectores de germânio, aliada à grande disponibilidade de computadores, tornou praticável a realização de determinações multielementares por método puramente instrumental (INAA).

Para que a radiação gama seja detectada é necessário que o fóton emitido interaja com o detector, seja de $\mathrm{NaI}(\mathrm{Tl})$, HPGe ou qualquer outro material. As três principais formas de interação da radiação gama com a matéria são o efeito fotoelétrico, o espalhamento Compton e a formação de par. Simplificadamente, a formação de par ocorre na proximidade de um núcleo atômico e envolve a transformação de parte da energia da radiação incidente em um par pósitron-elétron que carrega o restante da energia na forma de energia cinética. No efeito fotoelétrico e no espalhamento Compton, a interação ocorre com um elétron que recebe energia da radiação incidente. A diferença é que no efeito fotoelétrico toda a energia da radiação é transferida e no espalhamento Compton parte é espalhada ainda na forma de radiação eletromagnética, que é a radiação Compton.

A probabilidade de ocorrência desses três tipos de interação depende da energia da radiação incidente e do material em que há a interação. Pela Figura 1, observa-se que o efeito fotoelétrico ocorre mais freqüentemente para raios gama de baixas energias e absorvedores de elevado número atômico, enquanto a formação de pares predomina em altas energias, dependendo de uma energia limiar mínima de $1022 \mathrm{keV}$, referente à energia de formação do par pósitron-elétron. O espalhamento Compton, por sua vez, é mais comum para absorvedores com baixo número atômico, sem grande influência da energia da radiação. 


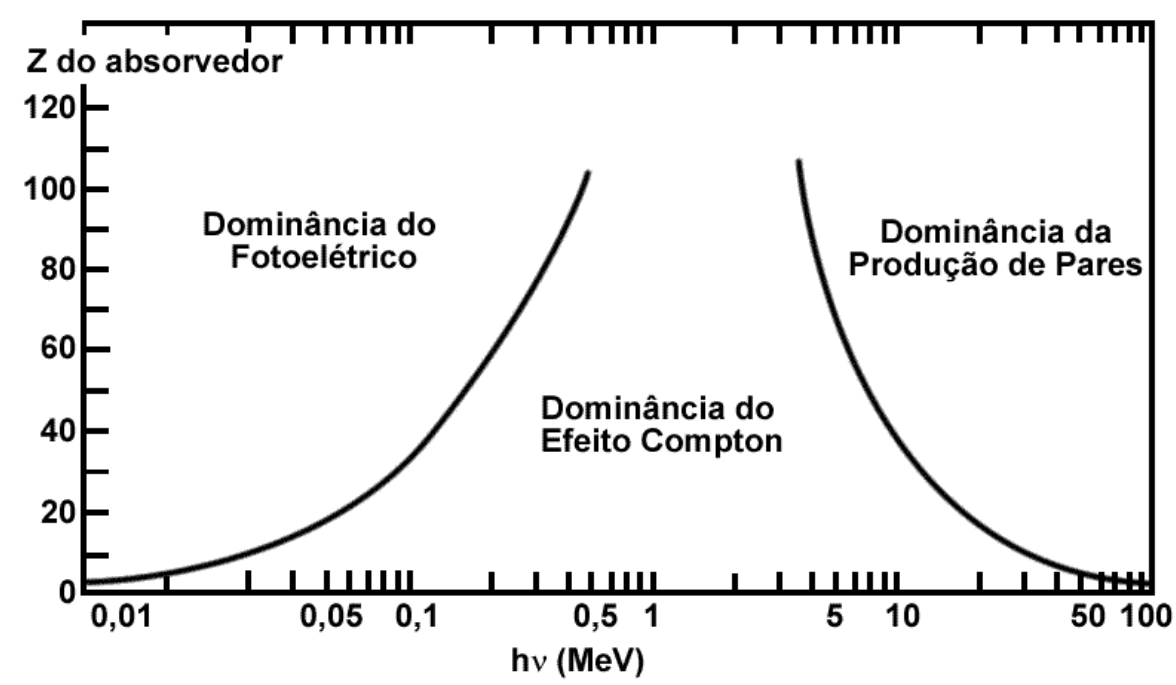

Figura 1 - Probabilidade de ocorrência dos três tipos principais de interação da radiação gama com a matéria em função do número atômico do absorvedor e da energia do raio gama. Adaptado de Evans (1955)

Em espectrometria de radiação gama, considerando as três formas de interação, o efeito fotoelétrico é o mais desejável para o processo de deteç̧ão, pois há uma probabilidade muito maior de toda a energia da radiação ser depositada no material detector, contribuindo para a formação do fotopico relativo à emissão em questão. No espalhamento Compton e na formação de pares, é bastante provável que parte da energia do fóton inicialmente considerado se perca na forma de radiação eletromagnética, que por possuir alto poder de penetração pode atravessar o material detector sem que haja nova interação. Assim, a deposição incompleta da energia causaria a adição de um evento no espectro, porém não no fotopico correspondente ao radionuclídeo de interesse.

\subsection{Espalhamento Compton}

Conforme explicado no item anterior (2.1), no espalhamento Compton parte da energia do fóton incidente é transferida para o elétron e parte é espalhada na forma de radiação eletromagnética. A Figura 2 ilustra o espalhamento Compton, mostrando as condições existentes antes e após a ocorrência da interação de um fóton com um elétron do material absorvedor, como o cristal de um detector, por exemplo. 

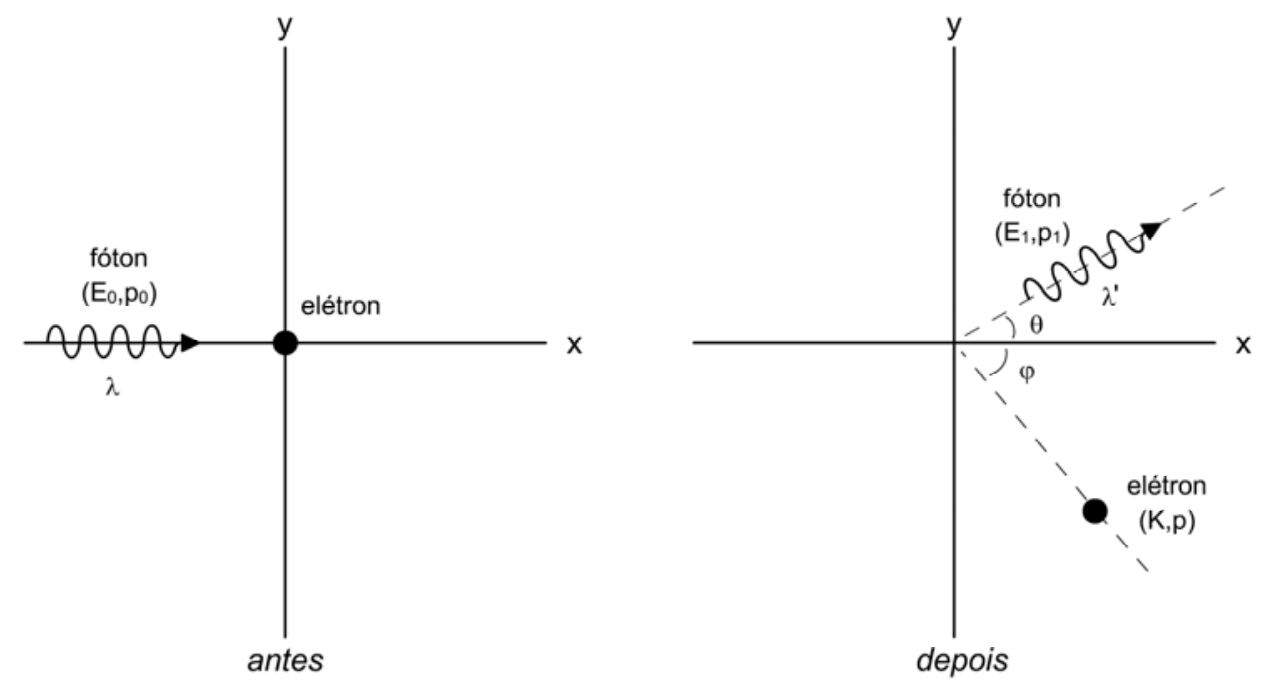

Figura 2 - Ilustração do espalhamento Compton, antes e depois da interação entre um fóton incidente e um elétron

Considerando o princípio da conservação da energia e do momento, e utilizando-se de ferramentas matemáticas, chega-se à eq.(1), que estabelece a diferença entre o comprimento de onda da radiação incidente $(\lambda)$ e da radiação Compton espalhada $\left(\lambda^{\prime}\right)$ após a interação. Por essa equação, onde $h$ é a constante de Planck, $m_{0}$ é a massa inercial do elétron e $c$ é a velocidade da luz no vácuo, percebe-se que a diferença entre os comprimentos de onda varia de acordo com o ângulo de desvio da radiação $(\theta)$.

$$
\lambda^{\prime}-\lambda=\frac{h}{m_{0} c}(1-\cos \theta)
$$

Pelo fato de serem constantes, $h, m_{0}$ e $c$ podem ser substituídas por apenas um valor, conhecido por comprimento de onda Compton $\left(\lambda_{C}\right)$, que é da ordem de $2,43 \times 10^{12} \mathrm{~m}$. Assim, reescrevendo a eq.(1), tem-se:

$$
\lambda^{\prime}-\lambda=\lambda_{C}(1-\cos \theta)
$$


Observando-se a eq.(1) ou a eq.(2), percebe-se que a diferença entre os comprimentos de onda $\left(\lambda^{\prime}-\lambda\right)$ chega a um máximo de $2 \lambda_{C}$ para $\theta$ igual a $180^{\circ}$. Neste caso, o comprimento de onda da radiação Compton seria máximo, ou seja, $\lambda+2 \lambda_{C}$. Desenvolvimento detalhado do assunto pode ser obtido em literatura específica (Eisberg \& Resnick, 1979).

Considerando-se que em espectrometria de radiação gama a identificação é realizada pela energia da radiação, que é inversamente proporcional ao comprimento de onda, a visualização fica facilitada quando se observa a eq.(3), extraída de Landsberger (1994). Nessa equação, $E_{0}$ é a energia do fóton incidente e $E_{1}$ é a energia da radiação Compton espalhada.

$$
E_{1}=\frac{E_{0}}{1+\frac{E_{0}}{m_{0} c^{2}}(1-\cos \theta)}
$$

Analisando-se a eq. 3, nota-se que a energia da radiação espalhada pode assumir um valor máximo igual a $E_{0}$, quando o ângulo de desvio é $0^{\circ}$ e na verdade não houve qualquer interação, e um valor mínimo, quando o ângulo de desvio é máximo, ou seja, $180^{\circ}$. O termo $m_{0} c^{2}$ corresponde à energia inercial do elétron $(511 \mathrm{keV})$.

$\mathrm{Na}$ prática, caso após uma interação por efeito Compton a radiação espalhada não interaja com o detector, só a energia cinética de recuo do elétron contribuirá para o sinal gerado, que portanto terá energia menor do que a da radiação incidente $\left(E_{0}\right)$. A energia de recuo pode ser obtida pela diferença de energia entre o fóton incidente e o fóton espalhado $\left(E_{0}-E_{1}\right)$, variando desde zero, quando o ângulo de desvio é $0^{\circ}$, a até um valor máximo dependente de $E_{0}$. A máxima energia de recuo do elétron $\left(R_{\max }\right)$, também conhecida como energia de corte Compton, é dada pela eq.(4) e corresponde a um ângulo de desvio de $180^{\circ}$.

$$
R_{\max }=E_{0}-\frac{E_{0}}{1+\frac{2 E_{0}}{511}}
$$




\subsection{Supressão Compton}

Um grande problema em muitas análises que envolvem o uso de espectrometria gama é a presença de uma elevada linha de base no espectro de radiação, causada pela contagem de eventos em regiões outras que não dos fotopicos. Este acúmulo indesejável de contagens pode prejudicar sensivelmente a detecção dos fotopicos de interesse, dificultando a quantificação ou mesmo impedindo a identificação dos radionuclídeos. A formação dessa linha de base pode ser atribuída principalmente a deposição incompleta da energia dos fótons emitidos pelos radionuclídeos presentes na amostra, radiação cósmica e radiação proveniente de isótopos radioativos contidos no ambiente de detecção. Radionuclídeos emissores de radiação beta de alta energia também podem contribuir intensivamente para o acúmulo de contagens nas regiões de mais baixa energia do espectro, devido à ocorrência de radiação de freamento (Bremsstrahlung) proveniente da interação da partícula beta com a matéria.

A supressão Compton é uma alternativa para diminuir a altura da linha de base dos espectros, pela rejeição de eventos provenientes da deposição incompleta da energia do fóton no detector. Os supressores Compton são normalmente compostos de um detector principal de germânio que é circundado por um ou mais detectores secundários, geralmente de cristais de $\mathrm{NaI}(\mathrm{Tl})$ (iodeto de sódio dopado com tálio) ou BGO (germanato de bismuto). Os fótons Compton que escapam do detector principal têm alta probabilidade de interagir com um detector secundário, cujos sinais determinam a contagem ou não do sinal do detector principal. $\mathrm{O}$ sistema funciona em anti-coincidência, ou seja, quando há ocorrência de sinais simultâneos no detector

principal e em um detector secundário ocorre a rejeição do pulso, que não será acumulado no espectro em aquisição. Exemplo da redução que pode ser obtida na altura da linha de base é mostrado na Figura 3. 


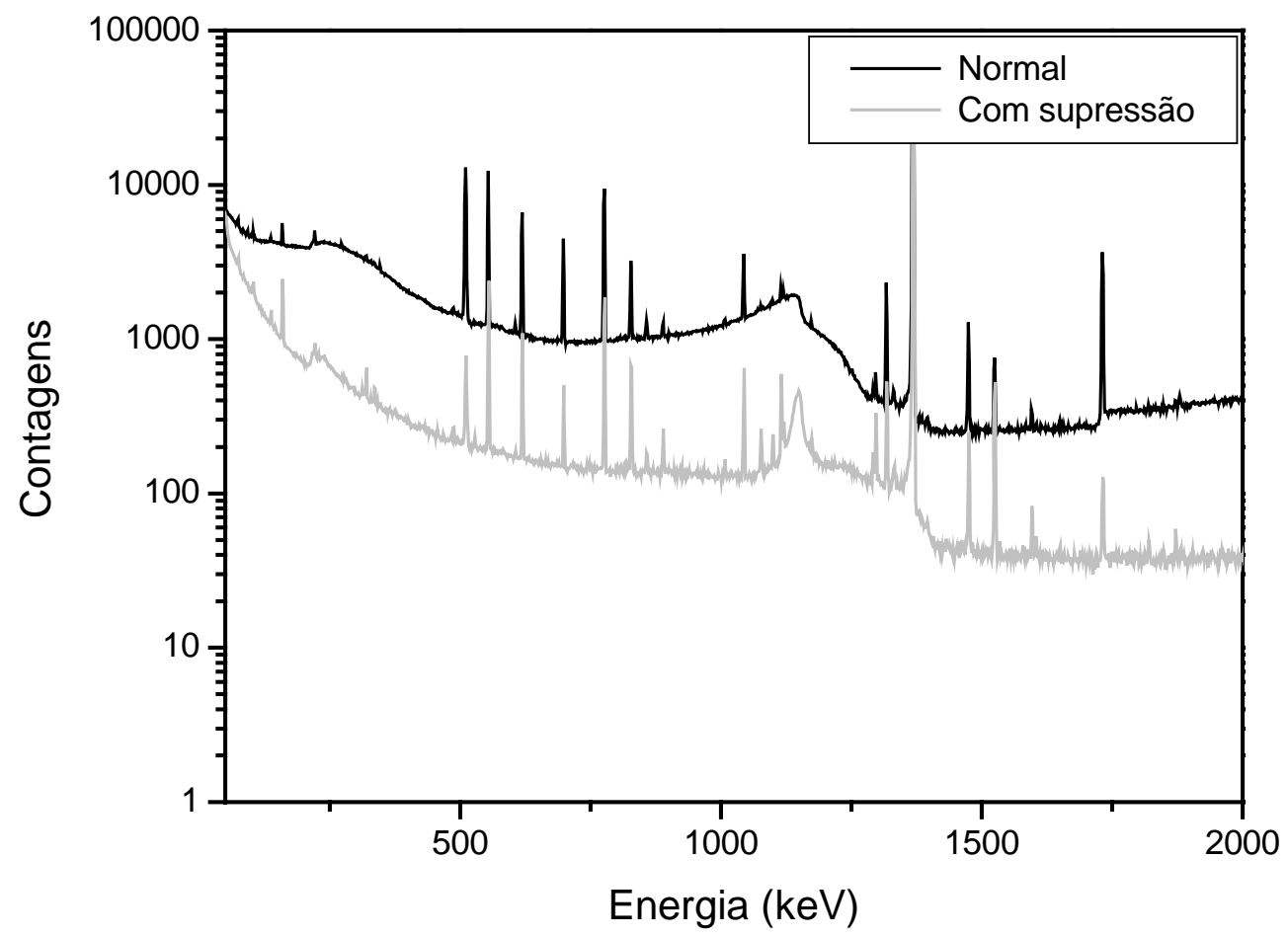

Figura 3 - Espectros sem supressão (normal) e com supressão Compton adquiridos simultaneamente, demonstrando a redução na altura da linha de base

Em um supressor Compton ocorre também a rejeição de outros eventos coincidentes, como por exemplo a detecção simultânea no detector principal e no secundário de dois ou mais raios gama emitidos em cascata. Assim, os fotopicos correspondentes serão reduzidos no espectro com supressão, o que pode ser notado para alguns picos dos espectros da Figura 3. Por esse motivo, em geral os sistemas são configurados para que seja possível armazenar dois espectros (com e sem supressão) para posterior análise das informações. O diagrama de blocos da Figura 4 apresenta simplificadamente o mecanismo de obtenção dos espectros com e sem supressão em um sistema supressor Compton. 


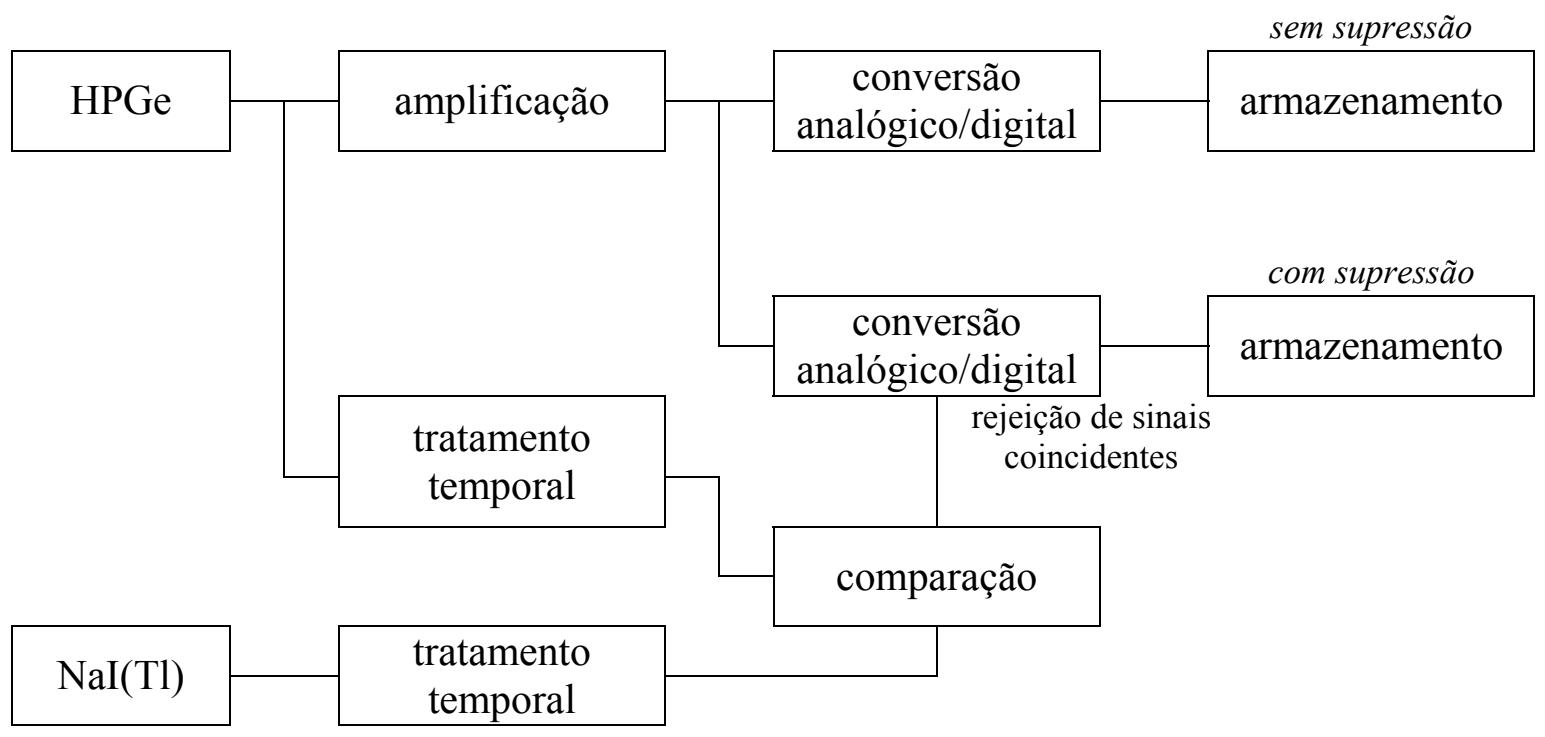

Figura 4 - Diagrama de blocos mostrando o funcionamento de um sistema supressor Compton, com possibilidade de armazenamento de espectros de radiação gama com e sem supressão

\subsection{Análise por ativação neutrônica}

Desde a primeira aplicação, em 1936, a análise por ativação neutrônica (NAA) vem amadurecendo como técnica para determinações elementares, chegando ao seu auge durante as décadas de 70 e 80 . Dois grande impulsos marcam a sua história, o primeiro nas décadas de 50 e 60, com o surgimento e disseminação pelo mundo da tecnologia de reatores nucleares, e o segundo com a popularização dos detectores de germânio na década de 70, que tornou a NAA definitivamente uma técnica multielementar, como conhecida atualmente.

Em geral, a NAA consiste na utilização de reações nucleares para produção de radionuclídeos, ou estados excitados de nuclídeos estáveis, a partir do bombardeamento das amostras com nêutrons. Quando um nêutron colide com um núcleo, diversos tipos de reações podem ocorrer, tais como espalhamento elástico $(n, n)$, espalhamento inelástico $\left(n, n^{\prime}\right)$, captura radioativa $(n, \gamma)$, reações com liberação de partículas $(n, \alpha),(n, p)$ e $(n, 2 n)$, e fissão $(n, f)$. Contudo, a mais encontrada em NAA é a captura radioativa, que pode ser 
escrita como na eq.(5), onde ${ }^{\mathrm{A}} Z$ é o núcleo alvo e ${ }^{\mathrm{A}+1} \mathrm{Z}$ é o núcleo gerado que está inicialmente em estado excitado, sendo que como parte de sua estabilização nuclear ocorre emissão de raios gama prontos (Alfassi, 1994a).

$$
n+{ }^{\mathrm{A}} \mathrm{Z} \rightarrow{ }^{\mathrm{A}+1} \mathrm{Z}^{*} \rightarrow{ }^{\mathrm{A}+1} \mathrm{Z}+\gamma
$$

Nos casos mais comuns de determinação por NAA, o nuclídeo formado $\left({ }^{\mathrm{A}+1} \mathrm{Z}\right)$ é radioativo e está sujeito a decaimento, seguido de emissão de radiação gama. É pela detecção e quantificação dos raios gama emitidos no decaimento que se realiza a determinação dos elementos presentes na amostra. $\mathrm{Na}$ eq.(6) há um exemplo de decaimento radioativo por emissão de partícula beta negativa em que há emissão de radiação gama.

$$
{ }^{\mathrm{A}+1} \mathrm{Z} \rightarrow{ }^{\mathrm{A}+1} \mathrm{X}+\beta^{-}+\gamma
$$

Alguns cuidados precisam ser observados em NAA, pois um mesmo radionuclídeo pode ser originado de diferentes reações nucleares. Por exemplo, a formação de ${ }^{28} \mathrm{Al}$ pode se dar a partir de três fontes distintas $\left({ }^{27} \mathrm{Al},{ }^{28} \mathrm{Si},{ }^{31} \mathrm{P}\right)$, dependendo da energia do nêutron que interage com os núcleos alvos. Esta possibilidade pode gerar interferências nas determinações elementares. Além disso, dois radionuclídeos podem emitir raios gama em energias muito próximas, dificultando ou mesmo impossibilitando a sua resolução. Em alguns casos, é necessário recorrer a separações químicas para superar essas interferências.

Dependendo da existência ou não de tratamento químico, a técnica de ativação neutrônica pode ser dividida em três tipos (Figura 5). Não havendo qualquer tratamento é chamada análise por ativação neutrônica instrumental (INAA - instrumental neutron activation analysis). Se ocorrer tratamento antes da irradição, tem-se a análise por ativação neutrônica química (CNAA - chemical neutron activation analysis). Se o tratamento for após a irradiação, tem-se a análise por ativação neutrônica radioquímica (RNAA - radiochemical neutron activation analysis) (Ehmann \& Vance, 1991). 


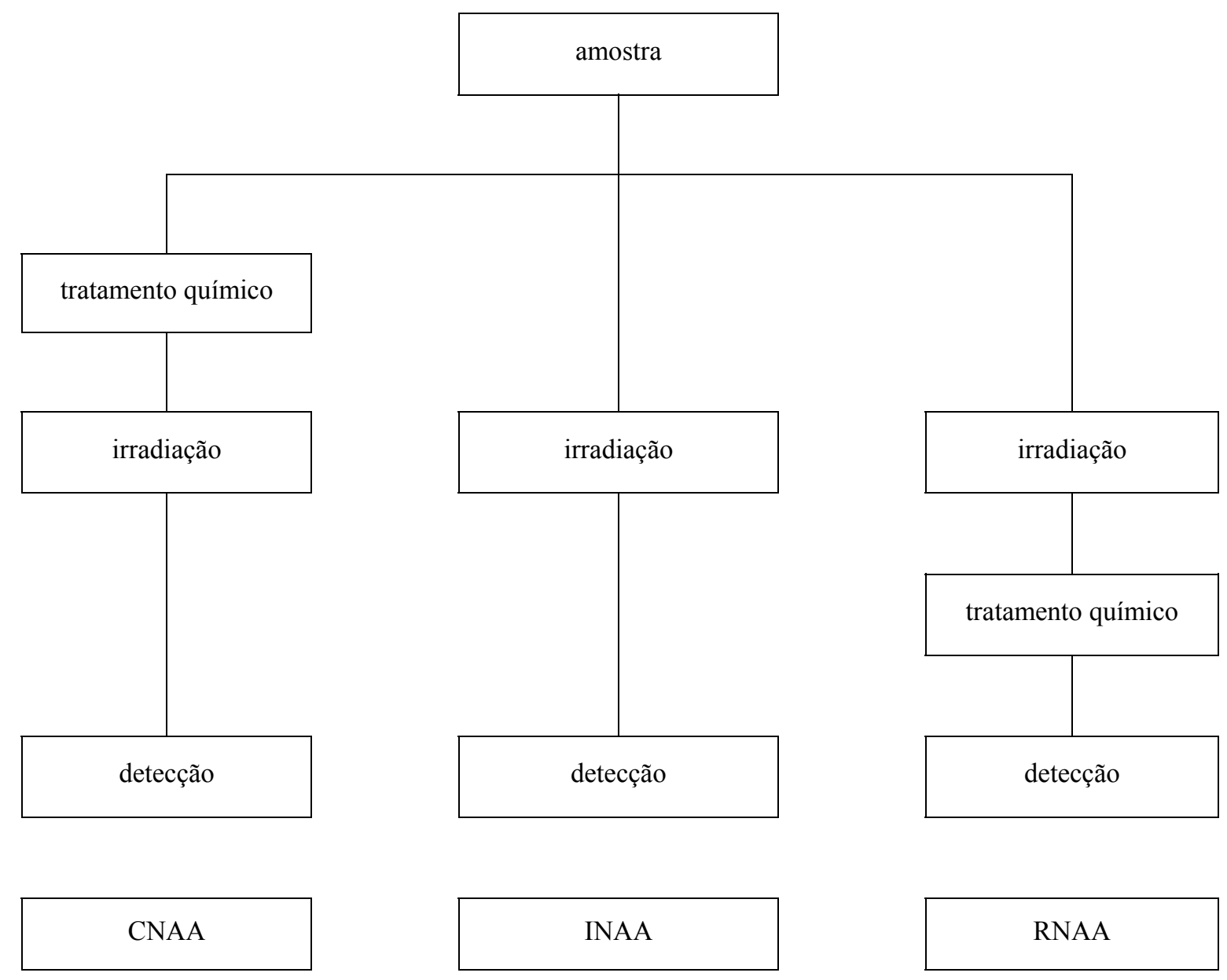

Figura 5 - Classificação da NAA em relação ao tratamento químico dispensado às amostras antes ou depois da irradiação

A NAA também pode ser classificada de acordo com a energia dos nêutrons utilizados. Normalmente, a ativação é feita com nêutrons térmicos (energia de aproximadamente $0,025 \mathrm{eV}$ ), quando se tem a maior quantidade de reações e também maior probabilidade de geração de radionuclídeos. Porém, existem aplicações específicas em que são empregados nêutrons epitérmicos (energia entre $0,1 \mathrm{eV}$ e $1 \mathrm{MeV}$ ) e rápidos (energia acima de $1 \mathrm{MeV}$ ) (Alfassi, 1994b).

A quantificação elementar em NAA pode ser realizada pelo uso de sua equação fundamental, em um método conhecido como paramétrico ou "absoluto" (Parry, 1991). 
Porém, esse método não é muito utilizado devido à dificuldade de determinação exata de todos os parâmetros nucleares envolvidos.

O método comparativo, em que juntamente com as amostras se irradiam padrões para todos os elementos de interesse, é o mais usado na determinação da composição elementar. Assumindo-se condições de irradiação e detecção similares para amostras e padrões, o método comparativo, segundo Ehmann \& Vance (1991), poderia ser descrito como na eq.(7), onde $\lambda, R, W, T$ representam respectivamente a constante de decaimento, a taxa de contagem, a massa do elemento e o tempo de decaimento, enquanto os índices são referentes a padrão (std) e amostra (sam).

$$
\frac{\mathrm{R}_{\text {std }}}{\mathrm{R}_{\mathrm{sam}}}=\frac{\mathrm{W}_{\text {std }}\left(\mathrm{e}^{-\lambda \mathrm{T} s t d}\right)_{\text {std }}}{\mathrm{W}_{\text {sam }}\left(\mathrm{e}^{-\lambda \mathrm{Tsam}}\right)_{\mathrm{sam}}}
$$

A utilização de um fator simples que pudesse substituir os parâmetros nucleares envolvidos sempre foi um atrativo. Diversos métodos surgiram em que se empregava padrão para um único elemento, recorrendo-se à equação fundamental da ativação a fim de obter resultados para os demais elementos de interesse. Foi a partir dos métodos de comparador único que surgiu o método $k_{0}$ em que um fator $\left(k_{0}\right)$ substituiu quatro constantes nucleares, ou seja, massa molar, abundância isotópica, seção de choque e intensidade de emissão gama.

Na publicação em que reapresenta as origens do método $k_{0}$, De Corte (2001) escreve simplificadamente a equação geral para obtenção da concentração de um elemento $\left(\rho_{a}\right)$ conforme a adaptação mostrada na eq.(8).

$$
\rho_{a}=\frac{(N / W t S D C)_{a}}{A_{A u}} \frac{1}{k_{0, A u}(a)}\left(\frac{f+Q_{0, A u}(\alpha)}{f+Q_{0, a}(\alpha)}\right) \frac{\varepsilon_{A u}}{\varepsilon_{a}}
$$

onde:

$$
\begin{aligned}
& a=\text { índice que representa o analito } \\
& A u=\text { índice que representa o comparador (ouro) }
\end{aligned}
$$




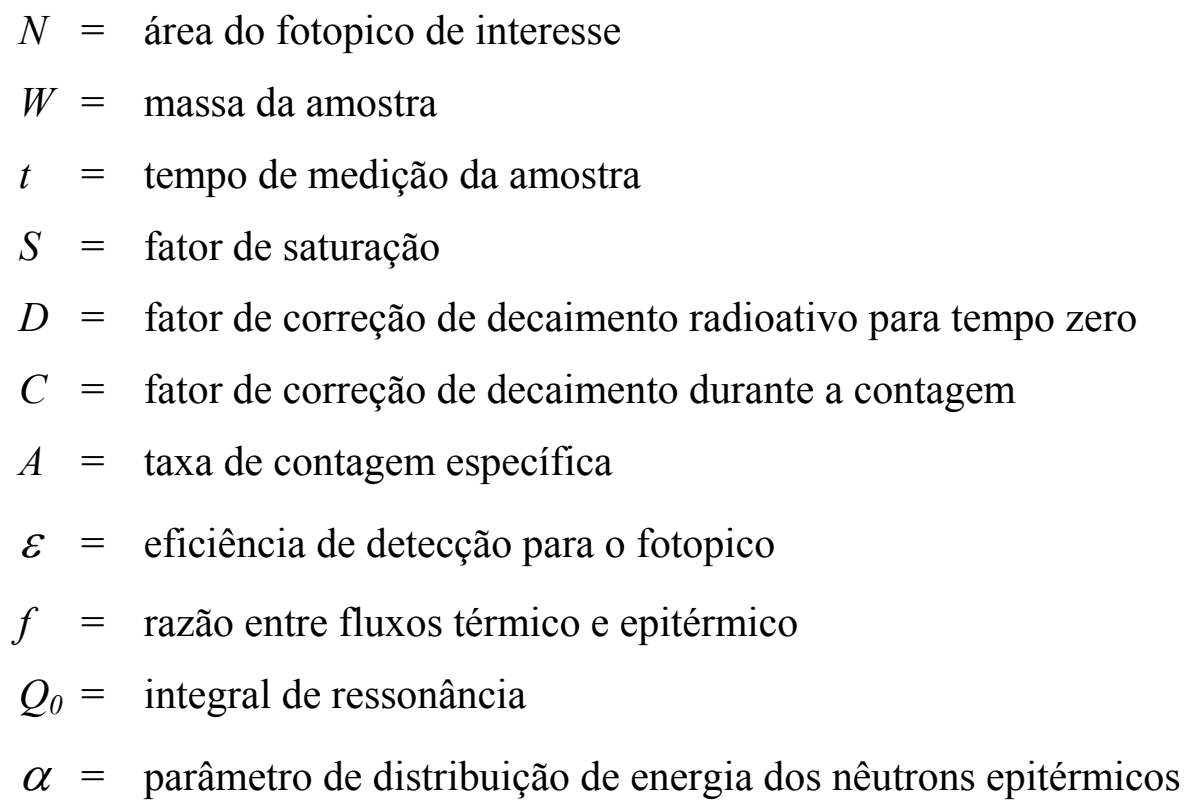

Os fatores $k_{0}$ para muitos nuclídeos foram determinados e publicados por pesquisadores do "Activation Analysis Laboratory of the Central Research Institute for Physics" (Budapeste, Hungria) e "Institute for Nuclear Science" (Gent, Bélgica) usando o ouro como elemento comparador. Hoje, o método $k_{0}$ é muito utilizado em NAA, embora os métodos comparativos ainda sejam os mais comuns.

Mesmo a observação da eq.(8), em que alguns parâmetros são omitidos objetivando simplificação, permite concluir que os cálculos para quantificação pelo método $k_{0}$ são muito mais complexos do que os de um método comparativo, representados na eq.(7). Porém, há que se considerar que no método $k_{0}$ tem-se a grande vantagem de eliminar a aquisição e preparo de diversos padrões, o que diminui o custo da análise e a quantidade de operações realizadas em laboratório. Além disso, com a utilização de software adequado e dos microcomputadores PC disponíveis no mercado, pode-se resolver todos os cálculos envolvidos na análise de uma amostra em fração de minuto. 


\section{REVISÃO DE LITERATURA}

\subsection{Desempenho de supressores Compton}

Os radionuclídeos ${ }^{137} \mathrm{Cs}$ e ${ }^{60} \mathrm{Co}$ são comumente utilizados para estudar o desempenho de supressores Compton (Parus et al., 2003). Em trabalhos científicos descrevendo o desenvolvimento e a aplicação de sistemas anti-Compton, diversos autores têm apresentado números baseados em medição de fontes radioativas desses dois radionuclídeos, para avaliar e/ou demonstrar a capacidade de supressão. Esses números são muito importantes para balizar o trabalho de configuração dos equipamentos, na busca de um desempenho otimizado. Contudo, é importante salientar que um equipamento pode ser muito eficiente na diminuição da região Compton gerado por um determinado radionuclídeo e não ser adequado para a medição de um outro, principalmente quando se trata da mistura de diversos radionuclídeos (Cooper, 1970).

O parâmetro de avaliação mais comumente determinado é o fator de supressão, que pode ser obtido pela divisão entre as razões pico-Compton em espectros com e sem supressão (Parus et al., 2003). Entretanto, outros parâmetros têm sido avaliados. Carpenter et al. (1994) utilizaram a razão de contagem pico-total para ${ }^{60} \mathrm{Co}$ como parâmetro para testar diversas configurações de supressores Compton. Os valores obtidos entre 0,26 e 0,74 demonstraram claramente qual a melhor configuração. Todavia, cabe ressaltar que, em geral, o cálculo de razão pico-total não é recomendado por ser sensível a ajustes no conversor analógico-digital, principalmente pelo corte na aquisição de energias baixas (Wahl et al., 1996).

Na determinação do fator de supressão, nota-se a utilização de diversos

procedimentos de cálculo para obter a razão pico-Compton. Para ${ }^{137} \mathrm{Cs}$, freqüentemente 
se divide a contagem máxima no fotopico $662 \mathrm{keV}$ pela média das contagens acumuladas nos canais compreendidos na faixa de 358 a $382 \mathrm{keV}$ (região plana ou plateau), sendo em alguns casos utilizada a faixa de 475 a $481 \mathrm{keV}$ (região de borda ou edge), conforme estabelecido pela norma ANSI/IEEE 325-1986 (ANSI,1986). Para ${ }^{60} \mathrm{Co}$, segue-se procedimento semelhante, utilizando a máxima contagem no fotopico $1332 \mathrm{keV}$ e a região entre 1040 e $1096 \mathrm{keV}$.

Ao calcularem as razões pico-Compton para ${ }^{137} \mathrm{Cs}$ com o sistema anti-Compton ativado e desativado, Harbottle \& Cumming (1994) estiveram muito próximos de determinar o fator de supressão, porém não há qualquer informação sobre as condições em que esses valores foram medidos. Por sua vez, Hien (1996) utilizou parâmetro que também poderia ser definido como fator de supressão, encontrando respectivamente 4,2 e 6 para ${ }^{137} \mathrm{Cs}$ e ${ }^{60} \mathrm{Co}$, entretanto também não forneceu informação sobre os cálculos.

Embora tenha determinado o fator de supressão para ${ }^{137} \mathrm{Cs}$, Landsberger (1994) calculou a razão pico-Compton a partir da área líquida do fotopico $662 \mathrm{keV}$ e das contagens acumuladas em uma área de igual largura situada em algum ponto não definido da região Compton. O autor comparou o valor obtido $(7,8)$ com dados extraídos de literatura, havendo boa concordância, exceto por um valor compilado $(18,0)$ que mostrou-se discrepante.

Mauerhofer et al. (1996) também utilizaram um algoritmo diferente para obter o fator de supressão, recorrendo à área líquida dos fotopicos de interesse e às contagens acumuladas em intervalos de $\pm 10 \mathrm{keV}$ tomados em diversas energias da região Compton. O fator de supressão variou, de acordo com a energia, entre 2 e 7,8 para ${ }^{137} \mathrm{Cs}$ e entre 2,5 e 8,7 para ${ }^{60} \mathrm{Co}$, evidenciando a necessidade de se definir também a energia tomada para comparar fatores de supressão.

A confusão de algoritmos e terminologia existente em literatura parece ter levado alguns autores a misturar, em uma mesma avaliação, o critério definido na norma ANSI/IEEE 325-1986 (ANSI,1986) com cálculos equivalentes aos relatados por Landsberger (1994). Dessa forma, o entendimento dos procedimentos realizados por Satoh et al. (1995) e Fukuda et al. (1996) fica comprometido. 
Além dos procedimentos de cálculo, as condições experimentais também devem ser cuidadosamente observadas. Voigt et al. (1995) obtiveram fator de supressão 10,1 para ${ }^{137} \mathrm{Cs}$ e 6,4 para ${ }^{60} \mathrm{Co}$. Esses valores, significativamente superiores à maioria encontrada em literatura, foram calculados de acordo com as definições da ANSI/IEEE 325-1986 (ANSI,1986). Entretanto, os próprios autores ressaltaram que foi empregado um arranjo fonte-detector favorável à obtenção de bom desempenho na supressão, inclusive com uso de colimador.

Fukuda et al. (1996) exploraram a diferença de comportamento de um supressor Compton para fontes colocadas dentro ou fora do limite definido pelo detector secundário (poço), o que reforça a necessidade de definir as condições experimentais utilizadas na medição do fator de supressão. Também é sabido que a taxa de contagem influencia o desempenho de um supressor, principalmente pela perda de contagem no fotopico de interesse. Westphal et al. (1999) discutiram detalhadamente a perda de desempenho a elevadas taxas de contagem, apresentando um espectrômetro em que o problema foi bastante minimizado pela adoção de um sistema eletrônico de correção.

\subsection{Supressão Compton em NAA}

Um dos trabalhos científicos pioneiros em sistemas de detecção de radiação gama com capacidade de rejeitar o efeito do espalhamento Compton foi realizado por Sever \& Lippert (1965), seguindo-se vários outros artigos. Alguns anos depois, surgiram as referências pioneiras sobre a possibilidade de aplicar a supressão Compton em análise por ativação neutrônica (Cooper \& Brownell, 1967) e em radioquímica (Cooper, 1970). Entretanto, há um período em que não são encontradas publicações sobre supressão em NAA, sendo que os trabalhos parecem ter sido retomados cerca de duas décadas mais tarde, em artigos como Petra et al. (1990) e Rossbach et al. (1990).

Landsberger et al. (1993) apresentaram um dos primeiros trabalhos em que um problema analítico específico foi resolvido pela aplicação de supressão Compton em NAA. Os autores determinaram Cd em filtros de ar para avaliar a influência da fumaça 
de cigarro e, pela ativação com nêutrons epitérmicos e supressão, conseguiram reduzir o limite de detecção em cerca de duas ordens de grandeza. Na mesma época, Landsberger et al. (1994) trataram da determinação de Si em amostras biológicas, observando que o limite de deteç̧ão para o SRM 1567a (Wheat Flour) foi reduzido de 47 para $25 \mathrm{mg} \mathrm{kg}^{-1}$ pelo uso de supressão.

Um interessante apanhado sobre a aplicação de supressão Compton com ênfase para estudos ambientais é apresentado por Landsberger (1994). O autor salienta que, até aquela época, havia pouca demonstração de resultados práticos, embora já existissem alguns grupos trabalhando com o assunto e inclusive artigos científicos sobre o desenvolvimento e avaliação de supressores para NAA. Alguns resultados obtidos pelo seu grupo de pesquisa, sediado nos Estados Unidos, foram apresentados para demostrar a melhoria da sensibilidade analítica e da precisão para a determinação de I, Hg e Zn em solos, além de Cd em materiais biológicos.

Continuando os estudos da influência da fumaça de cigarros na qualidade do ar, Landsberger \& Wu (1995) notaram que a supressão Compton, combinada com a irradiação com nêutrons epitérmicos, era fator responsável pela melhoria das condições para a determinação de cinco elementos. O benefício pôde ser observado especialmente para As, Cd e Sb, conseguindo-se atingir limites de detecção de 0,2, 2 e 0,03 ng, respectivamente. Em avaliação realizada por Cornett et al. (1995), o uso de supressão melhorou as condições de determinação de $\mathrm{Hg}$ em tecidos humanos, entretanto um método radioquímico testado paralelamente mostrou-se mais adequado por atingir melhor sensibilidade analítica.

Mauerhofer (1996) apresentou uma abordagem mais teórica, em que descreve os ganhos que podem ser conseguidos na estatística de contagem e no limite de detecção pelo uso de supressão. Em outra publicação no mesmo ano (Mauerhofer et al., 1996), um supressor Compton construído para uso em NAA é descrito, sendo apresentada a avaliação de seu desempenho.

Em uma avaliação generalizada, Bode (1997) comparou o uso de diferentes tipos de espectrômetros e arranjos amostra-detector quanto à sensibilidade alcançável em NAA, concluindo que em algumas situações particulares o uso de supressor pode ser 
vantajoso. Ainda segundo o autor, reduções máximas de quatro vezes devem ser esperadas em limites de deteç̧ão para amostras colocadas diretamente sobre o detector.

Um novo sistema supressor Compton dedicado à NAA foi apresentado por Lin et al. (1997), demonstrando boa capacidade de supressão até baixas energias (15 keV). Os autores testaram o sistema pela avaliação de treze elementos em amostras biológicas e ambientais, discutindo as vantagens e desvantagens para cada determinação. Deibel et al. (1997) desenvolveram método para determinação de $\mathrm{Cu}$ em tecidos do cérebro humano, conseguindo reduzir a influência de $\mathrm{Na}$ e $\mathrm{Cl}$ pela utilização de nêutrons epitérmicos e supressor Compton.

Um supressor Compton para trabalhar a elevadas taxas de contagem foi desenvolvido por Westphal (1998), atendendo a um sistema pneumático de irradiação, de modo a realizar NAA com radionuclídeos de meias-vidas curtas. O mesmo espectrômetro foi apresentado com maiores detalhes em Westphal et al. (1999), quando alguns resultados experimentais demonstraram o bom desempenho do equipamento a taxas de até 180 mil contagens por segundo. Trabalho de Landsberger \& Wu (1999) investigou o uso de nêutrons térmicos e epitérmicos, conjuntamente com supressão Compton, objetivando melhorar as condições para determinação de As, Cd, Hg e Sb, de modo a diminuir a interferência por $\mathrm{Br}, \mathrm{Cl}$ e $\mathrm{Na}$.

Riedel et al. (2000) determinaram Th e U em amostras de náilon, empregando supressão principalmente para diminuir a influência de ${ }^{82} \mathrm{Br}$. Por outro lado, a supressão foi útil também na determinação de Br e I em aerosóis da Região Ártica, alcançando-se, respectivamente, limites de detecção de 0,023 e 0,002 $\mu \mathrm{g}$, com uso de nêutrons epitérmicos (Landsberger et al., 2001).

A possibilidade de empregar espectrometria gama multidimensional em INAA foi apresentada por Hatsukawa et al. (2001 e 2002). Para testar a técnica proposta, os autores utilizaram um espectrômetro (GEMINI) composto por doze detectores de germânio hiperpuro, dotados de supressão Compton pelo uso de detectores de germanato de bismuto em anti-coincidência. Analisaram alguns materiais de referência geológicos ativados com nêutrons térmicos, conseguindo a determinação de até 30 elementos, em 
condições analíticas que consideraram melhores do que a medição em espectrômetro com um único detector de germânio.

Finalmente, os dois mais recentes exemplos encontrados para o uso de supressor Compton em NAA abordaram a determinação de I em amostras biológicas, após irradiação em fluxo de nêutrons epitérmicos. Yonezawa et al. (2003) apresentaram resultados para cinco materiais de referência, destacando que o uso de supressão contribuiu para reduzir a influência de ${ }^{24} \mathrm{Na}$ e ${ }^{38} \mathrm{Cl}$ na detecção do ${ }^{128} \mathrm{I}$, respectivamente em 3,7 e 4,6 vezes. Por outro lado, Serfor-Armah et al. (2003) analisaram alimentos conseguindo limites de detecção de até $20 \mu \mathrm{g} \mathrm{kg}^{-1}$, o que, combinado com a boa recuperação de valores certificados para materiais de referência, demonstra a adequação do método proposto. 


\section{MATERIAIS E MÉTODOS}

\subsection{Supressor Compton}

\subsubsection{Descrição e funcionamento}

Foi utilizado espectrômetro de radiação gama adquirido com recursos do Projeto PRONEX-086/96 “Desenvolvimento de métodos automatizados e isotópicos em química analítica”. Fabricado e integrado pela empresa ORTEC (Oak Ridge, Estados Unidos), o sistema é dotado de um detector principal e de dois detectores secundários (Figura 6). Simplificadamente, pode-se dizer que o detector principal é responsável pela identificação da energia dos fótons, ao passo que os detectores secundários são responsáveis pelo aproveitamento ou não dos sinais obtidos pelo detector principal, realizando a função de blindagem ativa da radiação Compton.

O detector principal é coaxial, constituído de cristal semicondutor de germânio hiperpuro (tipo N), modelo GMX50220 com $257 \mathrm{~cm}^{3}$ (6,4 cm de diâmetro e 8,0 cm de altura), acomodado em proteção de alumínio de 1,5 mm de espessura e ligado a criostato vertical. A janela superior é composta por camada de 0,5 mm de berílio, objetivando minimizar o efeito de atenuação das radiações gama de baixa energia. De acordo com medições realizadas pelo fabricante em novembro de 1999, o detector principal tem 55 \% de eficiência relativa e alcança 2,04 keV de resolução (FWHM) para o fotopico $1332 \mathrm{keV}$ do ${ }^{60} \mathrm{Co}$, tendo sido observada uma razão pico-Compton igual a 62.

Os detectores secundários são dois cristais cintiladores sólidos de $\mathrm{NaI}(\mathrm{Tl})$, um anular circundando o detector principal, tipo annulus com 9x9 polegadas, e um cilíndrico padrão de 3x3 polegadas, denominado plug, colocado na parte superior do sistema. Devido às suas grandes dimensões, o detector annulus está acoplado a seis células fotomultiplicadoras, enquanto o plug possui uma única célula. 


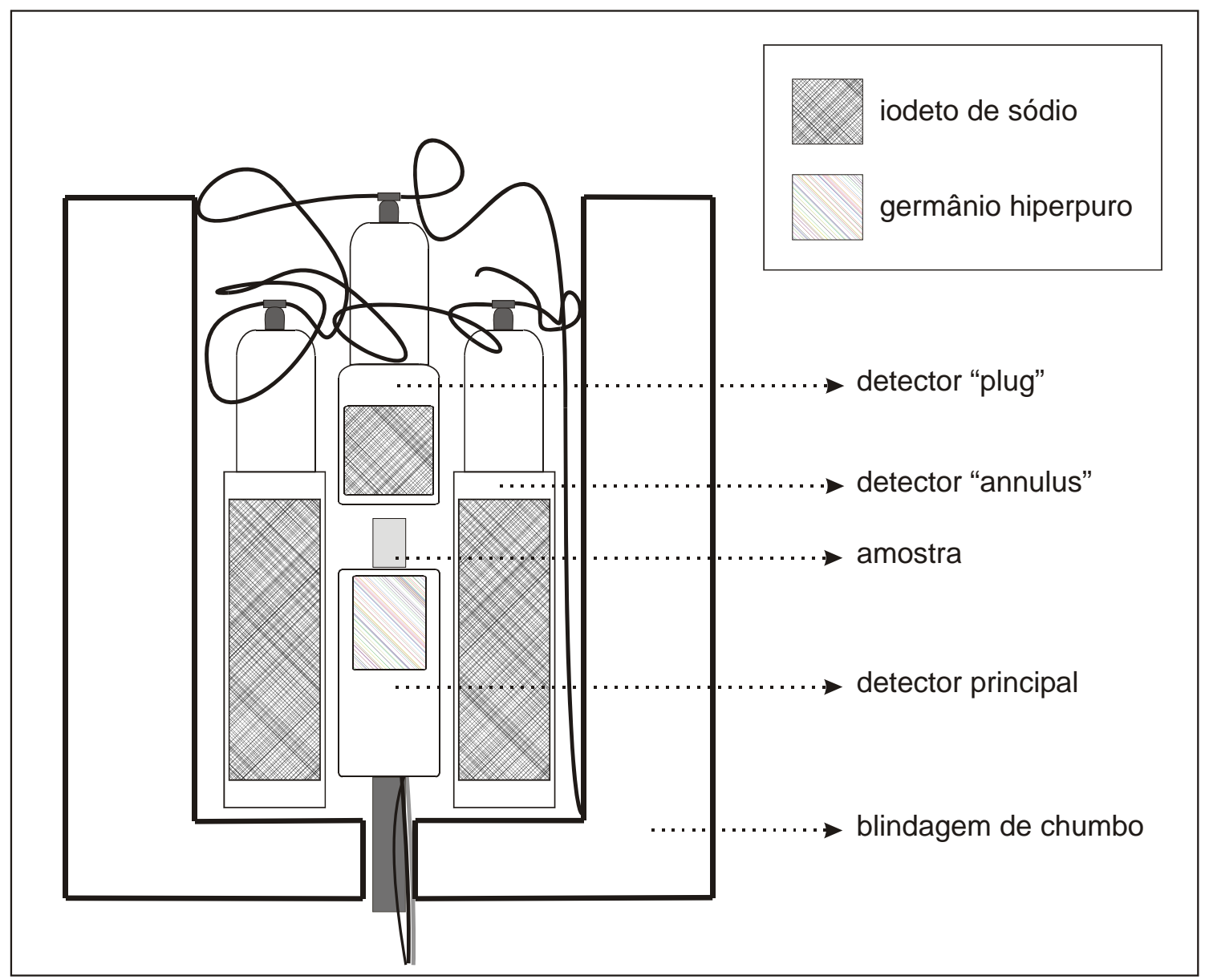

Figura 6 - Esquema mostrando um corte longitudinal do sistema supressor Compton, permitindo a visualização do posicionamento dos detectores

Além de um módulo pré-amplificador (modelo 137), que se localiza junto ao detector principal, o espectrômetro possui diversos módulos eletrônicos construídos no padrão NIM (Nuclear Instrumentation Methods), representados no diagrama de blocos da Figura 7. Um espectrômetro de radiação gama sem supressão Compton seria normalmente composto por uma fonte de tensão de polarização (659), um pré-amplificador (137), um amplificador de sinal (672) e um analisador multicanal (919E). Os módulos 416A, 463, 556, 567, 579 e 583 são, portanto, de alguma forma empregados na supressão Compton, ou seja, para definir se há ou não simultaneidade entre eventos registrados pelo detector principal e por um dos detectores secundários. A função de cada tipo de módulo eletrônico está sumarizada na Tabela 1. 


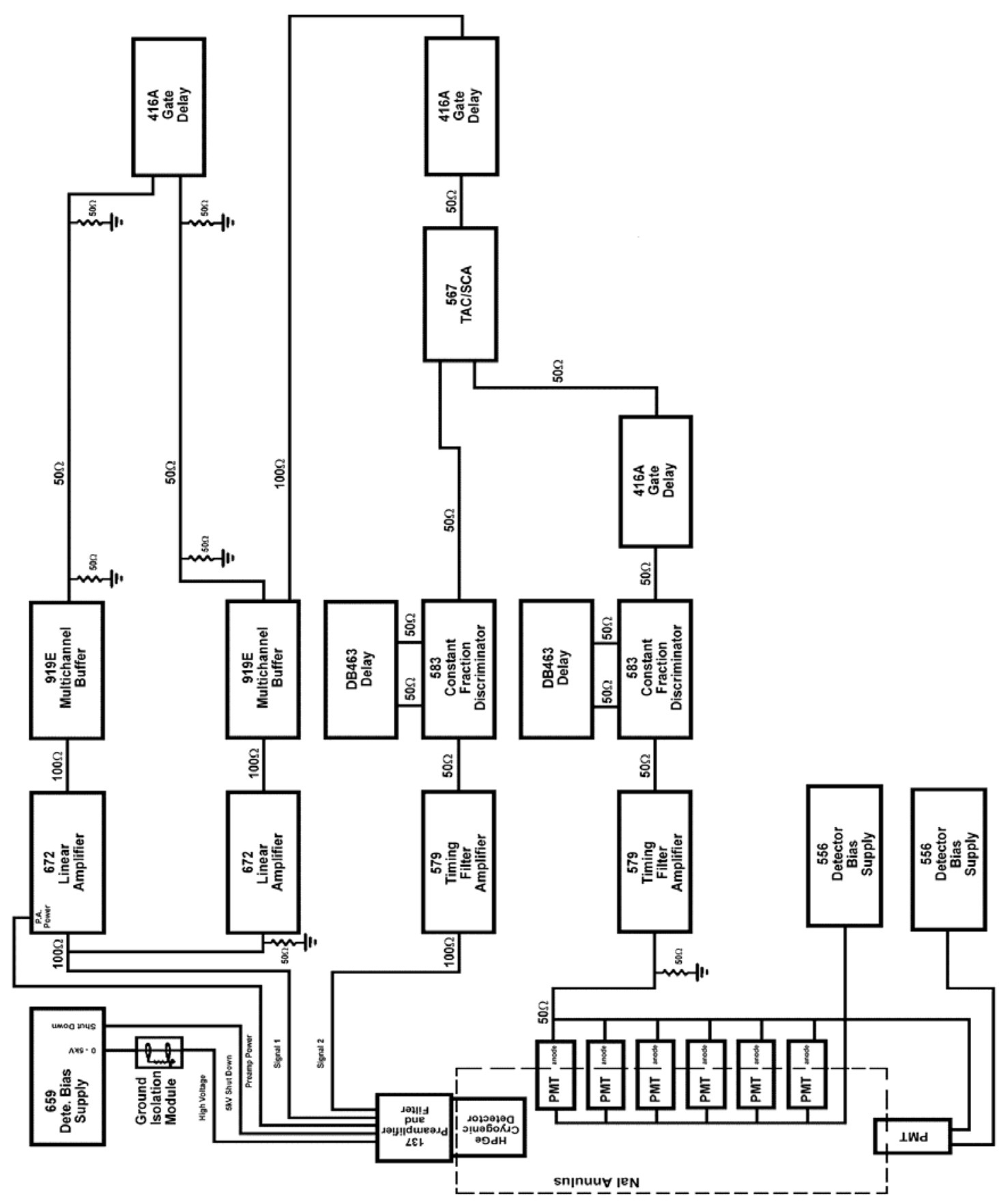

Figura 7 - Diagrama de blocos representando o espectrômetro de radiação gama com supressão Compton utilizado neste trabalho. Fonte: empresa ORTEC, EUA 
Tabela 1. Módulos eletrônicos do sistema supressor Compton e suas respectivas funções nos subsistemas de espectrometria de energia e de tempo

\begin{tabular}{|c|c|c|}
\hline Modelo & Nome & Função \\
\hline 137 & pré-amplificador & $\begin{array}{c}\text { amplifica o sinal do detector principal e filtra a } \\
\text { tensão de polarização }\end{array}$ \\
\hline $416 \mathrm{~A}$ & gerador de atraso & $\begin{array}{l}\text { gera pulso lógico, atrasado em até } 110 \text { s, a partir } \\
\text { de um pulso de entrada, permitindo seleção de } \\
\text { amplitude, polaridade e largura do sinal de saída }\end{array}$ \\
\hline 463 & caixa de atraso & $\begin{array}{c}\text { atrasa o pulso de entrada em até } 64 \text { ns, não } \\
\text { alterando suas características }\end{array}$ \\
\hline 556 & fonte de tensão & $\begin{array}{c}\text { fornece a tensão (1 e } 1,2 \mathrm{kV} \text { ) para a polarização } \\
\text { das fotomultiplicadoras dos detectores de iodeto } \\
\text { de sódio }\end{array}$ \\
\hline 567 & $\begin{array}{l}\text { conversor } \\
\text { tempo/amplitude }\end{array}$ & $\begin{array}{c}\text { gera um pulso lógico de } 5 \mathrm{~V} \text { a partir da } \\
\text { ocorrência de simultaneidade entre dois pulsos de } \\
\text { entrada, permitindo ajustes na janela de tempo } \\
\text { pretendida }\end{array}$ \\
\hline 579 & $\begin{array}{l}\text { amplificador } \\
\text { com filtro de tempo }\end{array}$ & $\begin{array}{l}\text { amplifica os sinais dos detectores de germânio e } \\
\text { de iodeto de sódio, produzindo sinais analógicos } \\
\text { (0 a } 5 \text { V) com constantes de tempo controláveis }\end{array}$ \\
\hline 583 & $\begin{array}{l}\text { discriminador } \\
\text { diferencial }\end{array}$ & $\begin{array}{l}\text { gera um pulso lógico negativo para pulsos de } \\
\text { entrada com amplitude compreendida em uma } \\
\text { janela definida por dois discriminadores }\end{array}$ \\
\hline 659 & fonte de tensão & $\begin{array}{l}\text { fornece tensão }(-4,0 \mathrm{kV}) \text { para a polarização do } \\
\text { detector de germânio }\end{array}$ \\
\hline 672 & $\begin{array}{l}\text { amplificador } \\
\text { espectroscópico }\end{array}$ & $\begin{array}{l}\text { amplifica os sinais provenientes do } \\
\text { pré-amplificador do detector principal, } \\
\text { ajustando-os para a faixa de trabalho do } \\
\text { analisador multicanal }\end{array}$ \\
\hline $919 \mathrm{E}$ & analisador multicanal & $\begin{array}{c}\text { converte sinais analógicos entre } 0 \text { e } 10 \mathrm{~V} \\
\text { provenientes do amplificador } 672 \text { em sinais } \\
\text { digitais e acumula as contagens em canais (8192) }\end{array}$ \\
\hline
\end{tabular}


Didaticamente, o espectrômetro pode ser dividido em dois subsistemas, um realiza espectrometria de energia e outro de tempo. A espectrometria de energia trabalha apenas com o sinal gerado pelo detector principal, amplificando-o para gerar um sinal de saída adequado e ajustado à faixa de trabalho do conversor analógico-digital (0 a $10 \mathrm{~V})$. Por sua vez, a espectrometria de tempo trabalha sinais gerados pelo detector principal e pelos detectores secundários. Nesse subsistema, além de amplificação, os sinais analógicos são transformados em pulsos lógicos que são, então, comparados de acordo com sua ocorrência temporal.

Na espectrometria de tempo, há também necessidade de tratar os sinais de modo a compensar variações nas constantes de tempo dos sinais de entrada, ocasionadas por características intrínsecas de cada tipo de detector (germânio ou iodeto de sódio). Os módulos de atraso (416A e 463) são responsáveis por este tratamento temporal dos sinais, gerando pequenas defasagens entre os sinais de entrada e saída, e fazendo com que ocorra a sincronização necessária entre os sinais detectados em coincidência. A saída do subsistema de tempo é um sinal lógico de $5 \mathrm{~V}$ e $4 \mu$ s gerado a cada detecção simultânea de eventos no detector principal e em um dos detectores secundários.

Para realizar a supressão Compton, o analisador multicanal (módulo 919E) realiza a aquisição do sinal analógico proveniente do subsistema de energia em anti-coincidência com o sinal lógico do subsistema de tempo. Dessa forma, são acumulados no espectro apenas os eventos percebidos pelo detector principal sem ocorrência de evento simultâneo nos detectores secundários, condição que é estabelecida pelo sinal lógico proveniente da espectrometria de tempo.

No sistema (Figura 7) verifica-se duplicidade quanto aos módulos amplificador (672) e conversor analógico-digital (919E), o que permite a aquisição concomitante de espectros com e sem supressão. No armazenamento dos espectros sem supressão só há participação do subsistema de energia, enquanto na obtenção do espectro com supressão Compton há participação dos dois subsistemas. 


\subsubsection{Avaliação}

As medições para avaliação de desempenho do supressor envolveram a utilização de duas fontes radioativas de ${ }^{137} \mathrm{Cs}$, com atividades de $392 \mathrm{kBq}$ (Fonte 1) e 9 kBq (Fonte 2) em 30/06/1985, além de uma fonte radioativa de ${ }^{60}$ Co (Fonte 3), com atividade certificada de $453 \mathrm{kBq}$ na mesma data. As três fontes são disciformes com 25 mm de diâmetro e altura variável entre 2 e 4 mm.

Inicialmente, a Fonte $2\left({ }^{137} \mathrm{Cs}\right)$ foi centrada diretamente sobre o topo do detector principal, com o detector plug colocado sobre ela. A radioatividade foi contada por 300 s, realizando-se seis medições em dias consecutivos para possibilitar a avaliação da repetitividade dos resultados.

O fator de supressão $(F)$ foi calculado segundo a eq. (9), onde $P C$ é a razão pico-Compton para os espectros com e sem efeito de supressão.

$$
F=\frac{P C_{\text {supressão }}}{P C_{\text {normal }}}
$$

As razões pico-Compton foram obtidas pela eq. (10), em que $P$ é o total de eventos acumulados no canal de máxima contagem do fotopico de interesse, $C$ é o total de eventos acumulados em uma faixa qualquer tomada na região Compton e $N$ é o número de canais compreendidos nessa faixa escolhida.

$$
P C=\frac{P}{C / N}
$$

A norma ANSI/IEEE-325 (ANSI, 1986) estabelece duas regiões de interesse para ${ }^{137} \mathrm{Cs}$, uma entre 358 e $382 \mathrm{keV}$ (região plana) e outra de 475 a $481 \mathrm{keV}$ (região de borda). Considerando que a maior parte dos artigos encontrados em literatura relata fatores de supressão medidos na região plana, adotou-se aqui apenas a faixa entre 358 e $382 \mathrm{keV}$, que foi comparada ao canal de máximo acúmulo no fotopico $662 \mathrm{keV}$. 
Em seguida, repetiu-se o procedimento da primeira etapa, porém em intervalos aproximados de sete dias durante um total de vinte semanas, a fim de verificar a estabilidade do equipamento com o decorrer do tempo. Ainda nesta etapa, a partir de quatro medições realizadas em semanas consecutivas, foram também calculados os fatores de supressão em intervalos de $50 \mathrm{keV}$, entre 50 e $550 \mathrm{keV}$, de modo a observar a variação do fator medido em diferentes energias. Para cada uma das energias, foi tomada uma faixa abrangendo $\pm 10 \mathrm{keV}$.

Para determinar a influência da posição da fonte no desempenho do equipamento, o fator de supressão para ${ }^{137} \mathrm{Cs}$ na região plana (358-382 keV) foi medido para várias distâncias entre 0 e $210 \mathrm{~mm}$ do topo do detector principal, em intervalos de $30 \mathrm{~mm}$. Nesta etapa, o detector plug não foi utilizado, uma vez que o fechamento da blindagem não seria possível para distâncias maiores que $150 \mathrm{~mm}$. A Fonte 1, com maior atividade, foi empregada entre 60 e $210 \mathrm{~mm}$, enquanto a Fonte 2 foi utilizada para posições mais próximas (entre 0 e $120 \mathrm{~mm}$ ). Os tempos de detecção foram estipulados de modo a acumular cerca de 10 mil eventos no canal de máxima contagem do fotopico $662 \mathrm{keV}$.

Finalmente, em um último experimento, a Fonte $3\left({ }^{60} \mathrm{Co}\right)$ foi fixada de modo a fornecer uma taxa de contagem total de $5 \times 10^{2}$ cps (contagens por segundo). Variou-se, então, a taxa de contagem total até $5 \times 10^{3}$ cps pela aproximação da Fonte $1\left({ }^{137} \mathrm{Cs}\right)$. O comportamento do supressor foi medido nas diferentes taxas de contagem, tomando-se as áreas líquidas do fotopico $1332 \mathrm{keV}$ dos espectros com e sem supressão e também o fator de supressão para ${ }^{60} \mathrm{Co}$, considerando o fotopico $1332 \mathrm{keV}$ e a região entre 1040 e $1096 \mathrm{keV}$ (ANSI, 1986). 


\subsection{Amostras}

\subsubsection{Obtenção}

Foram tomadas amostras de arroz, batata, ervilha, feijão, grão-de-bico e lentilha, de diversos tipos, variedades e marcas comerciais. Com exceção da batata, as demais foram adquiridas no mercado consumidor de Piracicaba.

As batatas foram coletadas em um campo experimental ${ }^{1}$ localizado em Batatais, São Paulo, em que se comparou cultivo convencional e orgânico. Para este trabalho foram selecionadas as variedades achat, bintje, slaney e monalisa cultivadas sob condições convencionais. Coletaram-se cinco tubérculos representativos do tamanho médio obtido para cada variedade. Considerando que eram esperadas diferenças significativas entre a composição da casca e da polpa, os tubérculos foram descascados manualmente, tomando-se separadamente casca e polpa, perfazendo um total de oito amostras (Tabela 2).

Tabela 2. Amostras de batata coletadas em campo experimental de Batatais-SP, mostrando número de identificação, variedade e parte do tubérculo

\begin{tabular}{ccc}
\hline Número & Variedade & Parte \\
\hline 01 & achat & polpa \\
02 & achat & casca \\
03 & bintje & polpa \\
04 & bintje & casca \\
05 & slaney & polpa \\
06 & slaney & casca \\
07 & monalisa & polpa \\
08 & monalisa & casca \\
\hline
\end{tabular}

1 Campo experimental implantado por meio do Projeto FAPESP "Inovação Tecnológica - Parceria Universidade/Empresa” (n. ${ }^{\circ}$ 97/13244-0), coordenado pela Dra. Siu Mui Tsai (CENA/USP). 
Para a coleta das demais amostras, diversos estabelecimentos comerciais foram visitados, buscando-se adquirir produtos de tipos e marcas comerciais diferentes, de modo a possibilitar a identificação de possíveis diferenças na composição química elementar. Ao final do trabalho, foram acumuladas 49 amostras de grãos, sendo 30 de feijão (Tabela 3), 9 de arroz (Tabela 4), além de 2 de ervilha, 4 de grão-de-bico e 4 de lentilha (Tabela 5).

Tabela 3. Amostras de feijão coletadas no mercado consumidor de Piracicaba-SP, mostrando número de identificação, tipo e marca comercial

\begin{tabular}{|c|c|c|c|c|c|}
\hline Número & Tipo & Marca & Número & Tipo & Marca \\
\hline 01 & adzuki & Super Grão & 16 & carioca & Ki Grão \\
\hline 02 & bolinha & D'Guste & 17 & carioca & Marcon \\
\hline 03 & bolinha & Grão de Campo & 18 & carioca & Pantera \\
\hline 04 & branco & Angélica & 19 & carioca & Vencedor \\
\hline 05 & branco & Camil & 20 & carioca & Zamunér \\
\hline 06 & branco & Grão de Campo & 21 & fradinho & Camil \\
\hline 07 & branco & Hikari & 22 & jalo & Camil \\
\hline 08 & branco & Kodilar & 23 & jalo & Grão de Campo \\
\hline 09 & branco & Super Grão & 24 & jalo & Super Cook \\
\hline 10 & branco & Yoki & 25 & manteiga & Super Grão \\
\hline 11 & carioca & Bico de Ouro & 26 & mulatinho & Super Grão \\
\hline 12 & carioca & Broto Legal & 27 & preto & Camil \\
\hline 13 & carioca & Camil & 28 & preto & Namorado \\
\hline 14 & carioca & Carrefour & 29 & rosinha & Grão de Campo \\
\hline 15 & carioca & Grão de Campo & 30 & roxo & Super Cook \\
\hline
\end{tabular}


Tendo em vista a sua importância para a dieta básica do brasileiro e a conseqüente farta disponibilidade no mercado, foi priorizada a coleta de arroz e feijão. Em particular, o grande número de amostras de feijão se justifica pela oferta de inúmeros tipos, com características morfológicas e culinárias bastante distintas. Assim, a princípio supôs-se que os diferentes tipos de feijão apresentariam composição química variada. Cabe ressaltar que, com exceção do feijão adzuki que é da espécie Phaseolus angularis, todos os demais feijões são provenientes da espécie Phaseolus vulgaris.

De cada amostra foi adquirido um pacote contendo 0,5 ou $1 \mathrm{~kg}$, dependendo dos tamanhos de embalagem disponíveis nos estabelecimentos visitados. Da mesma forma que para as batatas, a identificação de cada amostra foi realizada por meio de códigos numéricos seqüenciais estabelecidos separadamente para cada tipo de material. Assim, as amostras de feijão, por exemplo, foram numeradas de 01 a 30, enquanto as de lentilha receberam códigos entre 01 e 04.

Tabela 4. Amostras de arroz coletadas no mercado consumidor de Piracicaba-SP, mostrando número de identificação, tipo e marca comercial

\begin{tabular}{ccc}
\hline Número & Tipo & Marca \\
\hline 01 & integral & Ásia Lee \\
02 & parboilizado & Carrefour \\
03 & parboilizado & Super Coradini \\
04 & parboilizado & Uncle Beans \\
05 & polido & Carrefour \\
06 & polido & Coradini \\
07 & polido & Delta \\
08 & polido & Prato Fino \\
09 & polido & Tio João \\
\hline
\end{tabular}


Tabela 5. Amostras de ervilha, grão-de-bico e lentilha coletadas no mercado consumidor de Piracicaba-SP, mostrando número de identificação e marca comercial

\begin{tabular}{ccc}
\hline Número & Grão & Marca \\
\hline 01 & ervilha & Hikari \\
02 & ervilha & Yoki \\
01 & grão-de-bico & Camil \\
02 & grão-de-bico & Hikari \\
03 & grão-de-bico & Kodilar \\
04 & grão-de-bico & Yoki \\
01 & lentilha & Camil \\
02 & lentilha & Hikari \\
03 & lentilha & Kodilar \\
04 & lentilha & Yoki \\
\hline
\end{tabular}

\subsubsection{Tratamento}

Após lavagem com água destilada, os tubérculos de batata foram separados em casca e polpa, sendo então liofilizados. Uma vez secas, as amostras foram desintegradas até granulometria menor que $1 \mathrm{~mm}$, separando-se porções de $5 \mathrm{~g}$ para a análise.

Antes de iniciar o preparo dos grãos para análise, homogeneizou-se cuidadosamente cada amostra, retirando uma porção de $100 \mathrm{~g}$. Estas subamostras foram acondicionadas em sacos plásticos e guardadas em separado, possibilitando a realização de eventuais repetições futuras das análises, em caso de dúvidas nos resultados obtidos.

Para uma avaliação inicial dos grãos, escolheu-se aleatoriamente um exemplar de cada tipo, sem levar em consideração a marca comercial, tomando-se 17 amostras (Tabela 6) das 49 disponíveis. Uma porção de 100 g de cada uma das 17 amostras foi submetida a secagem a $60{ }^{\circ} \mathrm{C}$ em estufa com circulação de ar, até massa constante, sendo 
então reduzida em moinho orbital com cubas de alumina, modelo Tecnal TE365, por 6 minutos. Posteriormente, de cada uma das demais 32 amostras de grãos, foi tomada uma porção de 100 g, que também foi seca a $60{ }^{\circ} \mathrm{C}$ em estufa com circulação de ar, até massa constante. Houve, então, redução do material por 3 minutos em moinho planetário, modelo Fritsch Pulverisette 14. Todas as amostras de grão, já devidamente secas e moídas, foram acondicionadas em recipientes plásticos.

Tabela 6. Amostras de grãos selecionadas para análise no segundo lote

\begin{tabular}{ccc}
\hline Identificação & Tipo & Marca \\
\hline arroz-01 & integral & Ásia Lee \\
arroz-04 & parboilizado & Uncle Beans \\
arroz-08 & polido & Prato Fino \\
ervilha-01 & - & Hikari \\
feijão-01 & adzuki & Super Grão \\
feijão-02 & bolinha & D’Guste \\
feijão-10 & branco & Yoki \\
feijão-12 & carioca & Broto Legal \\
feijão-21 & fradinho & Camil \\
feijão-22 & jalo & Camil \\
feijão-25 & manteiga & Super Grão \\
feijão-26 & mulatinho & Super Grão \\
feijão-28 & preto & Namorado \\
feijão-29 & rosinha & Grão de Campo \\
feijão-30 & roxo & Super Cook \\
grão-de-bico-04 & - & Yoki \\
lentilha-03 & - & Kodilar \\
\hline
\end{tabular}




\subsection{Determinação por INAA}

\subsubsection{Preparo}

As amostras foram analisadas em três ocasiões distintas. Em um primeiro lote foram incluídas as 8 amostras de batata. Na seqüência, foram avaliadas as 17 amostras de grãos listadas na Tabela 6. Finalmente, o terceiro lote correspondeu as demais 32 amostras de grãos. Nos três lotes foram incluídos materiais de referência certificados (Tabela 7) para controle da qualidade analítica e para uma avaliação mais abrangente do sistema supressor Compton.

Tabela 7. Materiais de referência certificados utilizados, listando código de identificação, nome, sigla do produtor e lote em que foi empregado

\begin{tabular}{cccc}
\hline Código & Nome & Produtor & Lote \\
\hline A-11 & Milk Powder & IAEA & 1 \\
V-10 & Hay Powder & IAEA & 2 e 3 \\
TL-1 & Tea Leaves & INCT & 3 \\
SRM 1515 & Apple Leaves & NIST & 1 e 2 \\
SRM 1547 & Peach Leaves & NIST & 2 e 3 \\
SRM 1570a & Spinach Leaves & NIST & 1 , 2 e 3 \\
SRM 1573a & Tomato Leaves & NIST & 2 e 3 \\
RM 8433 & Corn Bran & NIST & 1 , 2 e 3 \\
\hline
\end{tabular}

Na escolha dos materiais de referência procurou-se composição matricial semelhante às amostras, tentando também atender todos os elementos químicos de interesse. Foram empregados materiais de referência do NIST (National Institute of Standards and Technology, Estados Unidos), IAEA (International Atomic Energy Agency, Áustria) e INCT (Institute of Nuclear Chemistry and Technology, Polônia). 
Porções analíticas de 100 a 500 mg de amostras e materiais de referência foram acondicionadas em cápsulas de polietileno de alta pureza fabricadas pela Vrije Universiteit, Amsterdam, Holanda. A umidade residual de cada material foi determinada em porções de 0,5 a $1 \mathrm{~g}$, em estufa a $60{ }^{\circ} \mathrm{C}$ até massa constante. Para o primeiro lote, foram utilizadas cápsulas com $9 \mathrm{~mm}$ de altura e $9 \mathrm{~mm}$ de diâmetro, enquanto para os demais lotes as cápsulas tinham $12 \mathrm{~mm}$ de altura. Em cada lote foi adicionada uma cápsula vazia, tomada como branco analítico. Todas as cápsulas foram lacradas com bastão de quartzo incandescente, sendo então distribuídas em recipientes de alumínio (“coelhos”), conforme exemplo da Figura 8. Pedaços de $10 \mathrm{mg}$ de fios de liga Ni-Cr, com concentração de 19,6 \% de Cr (França et al., 2003), foram colocados na parte superior e inferior de cada cápsula como monitores de fluxo de nêutrons térmicos.

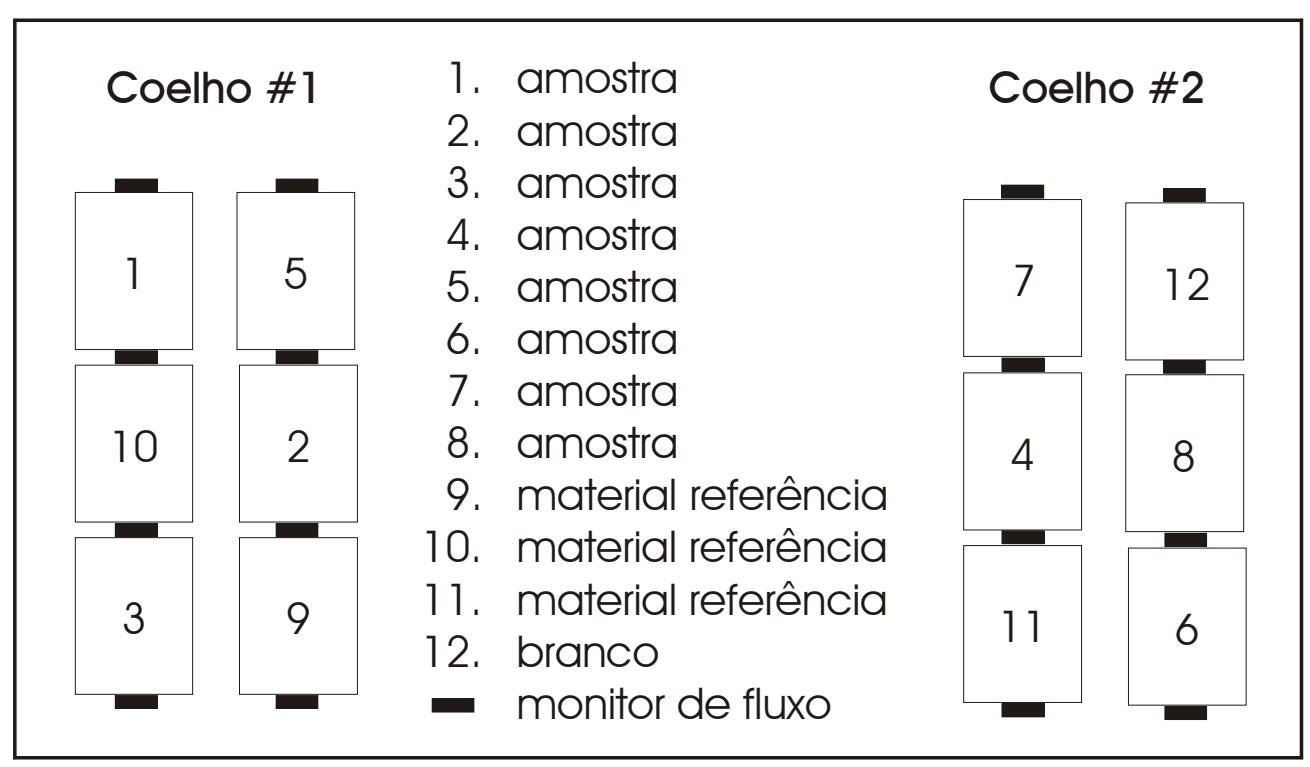

Figura 8 - Exemplo de distribuição de amostras, materiais de referência certificados, branco e monitores de fluxo de nêutrons nos recipientes de irradiação

\subsubsection{Ativação}

Para a ativação neutrônica, as amostras foram irradiadas no reator nuclear de pesquisa IEA-R1m do IPEN/CNEN (Instituto de Pesquisas Energéticas e Nucleares), localizado na cidade de São Paulo. As irradiações dos três lotes analíticos foram 
realizadas por 8 horas, sob condições de fluxo de nêutrons com pequenas variações (Tabela 8). As posições 24A e 24B, utilizadas para as irradiações, são tubos verticais dispostos na matriz do núcleo do reator, cada um com capacidade para irradiação simultânea de até oito "coelhos" (prateleiras 1 a 8).

Tabela 8. Posições do reator nuclear de pesquisa IEA-R1m, do IPEN/CNEN utilizadas para irradiação das amostras dos três lotes, mostrando também o fluxo de nêutrons térmicos nominal, fornecido pelo controle do reator

\begin{tabular}{|c|c|c|c|c|}
\hline Lote & Data & Posição & Prateleira & Fluxo $\left(\times 10^{13} \mathrm{~cm}^{-2} \mathrm{~s}^{-1}\right)$ \\
\hline \multirow[t]{4}{*}{1} & \multirow[t]{4}{*}{$25 / 03 / 2002$} & \multirow[t]{4}{*}{$24 \mathrm{~A}$} & 4 & 1,2 \\
\hline & & & 5 & 1,5 \\
\hline & & & 6 & 1,7 \\
\hline & & & 7 & 1,4 \\
\hline \multirow[t]{4}{*}{2} & \multirow[t]{4}{*}{ 27/08/2002 } & \multirow[t]{3}{*}{$24 \mathrm{~A}$} & 3 & 0,9 \\
\hline & & & 4 & 1,2 \\
\hline & & & 8 & 1,1 \\
\hline & & $24 B$ & 4 & 0,8 \\
\hline \multirow[t]{5}{*}{3} & \multirow[t]{5}{*}{$17 / 03 / 2003$} & \multirow[t]{2}{*}{$24 \mathrm{~A}$} & 3 & 0,9 \\
\hline & & & 4 & 1,3 \\
\hline & & \multirow[t]{3}{*}{$24 \mathrm{~B}$} & 4 & 0,8 \\
\hline & & & 5 & 1,1 \\
\hline & & & 6 & 1,1 \\
\hline
\end{tabular}

Tanto quanto possível, procurou utilizar apenas as prateleiras 4 a 7 , onde a variação espacial do fluxo de nêutrons térmicos é menor. A posição 24A é um pouco mais próxima ao centro do núcleo, apresentando fluxo de nêutrons maior e ligeiramente menos termalizado, sendo 40 e 47 as razões entre fluxo de nêutrons térmico e epitérmico (f), respectivamente nas posições 24A e 24B ( $\alpha=0,067$ em ambas). 


\subsubsection{Detecção}

Após a irradiação, as amostras permaneceram no IPEN/CNEN por um período aproximado de 3 dias, para que a atividade geral do material abaixasse a limites de segurança para manuseio e transporte até o CENA/USP. Assim, as determinações envolveram radionuclídeos com meias-vidas superiores a 12 horas.

A detecção da radioatividade das amostras, materiais de referência e brancos foi sempre realizada no espectrômetro com supressão Compton detalhadamente descrito no item 4.1. Para possibilitar a quantificação de radionuclídeos com meias-vidas bastante variadas, realizaram-se quatro medições para cada lote, com tempos de decaimento após a irradiação variando entre 3 e 51 dias. A distância amostra-detector e o tempo de contagem foram estabelecidos para cada medição de acordo com a atividade das amostras na ocasião. Assim, em geral, a distância era reduzida a cada medição e o tempo de contagem era aumentado de modo a buscar a otimização das condições para detecção dos radionuclídeos de interesse. A Tabela 9 sumariza as condições em que se realizaram as medições, apresentando valores típicos para tempo de decaimento, distância amostra-detector e tempo de contagem.

Para os monitores de fluxo, em que havia interesse em um único radionuclídeo $\left({ }^{51} \mathrm{Cr}, \mathrm{T}=27,7\right.$ dias$)$, foram realizadas apenas duas medições de radioatividade, com períodos de decaimento de aproximadamente 30 e 60 dias e tempos de contagem de 300 s. Neste caso, apenas os espectros sem supressão foram armazenados, tendo em vista que não havia emissões gama de alta energia que causassem dificuldades na detecção do fotopico $320 \mathrm{keV}$ do ${ }^{51} \mathrm{Cr}$. 
Tabela 9. Condições típicas observadas para cada medição de radioatividade realizada para os três lotes analíticos, mostrando tempo de decaimento, distância amostra-detector e tempo de contagem

\begin{tabular}{ccccc}
\hline Lote & Medição & Decaimento (dias) & Distância (mm) & Tempo (s) \\
\hline 1 & 1 & $3-4$ & 210 & 1500 \\
& 2 & $6-8$ & 87 & 1800 \\
& 3 & $15-17$ & 10 & 3600 \\
& 4 & $37-44$ & 10 & 7200 \\
2 & 1 & $3-4$ & 200 & 1800 \\
& 2 & $6-8$ & 54 & 3600 \\
& 3 & $17-21$ & 9 & 7200 \\
& 4 & $35-40$ & 9 & 7200 \\
3 & 1 & $3-4$ & 54 & 1800 \\
& 2 & $6-8$ & 22 & 1800 \\
& 3 & $14-17$ & 2 & 3600 \\
& 4 & $42-51$ & 9 & 3600 \\
\hline
\end{tabular}

\subsubsection{Cálculos}

Os resultados foram obtidos pelo método $k_{0}$ de padronização, apresentado no Capítulo 2, seguindo procedimentos relatados por Bacchi et al. (2000a e 2000b). Para realização dos cálculos, foi utilizado o software Quantu (Bacchi \& Fernandes, 2003), desenvolvido no CENA/USP especificamente para a condução de INAA pelo método $k_{0}$.

Todos os espectros foram avaliados pelo programa Quantu-MCA, usando seu procedimento de análise totalmente automática. Assim, para cada série de medições, o trabalho de avaliação espectral constituiu basicamente na calibração dos parâmetros energia e largura dos picos, a partir da qual o programa procedeu à procura de picos e ajuste de curvas Gaussianas em todos os espectros selecionados. 
Com o programa Quantu-INAA, foram feitos os cálculos de fluxo de nêutrons térmicos, concentração dos elementos e incerteza padrão associada a cada resultado. $\mathrm{Na}$ Tabela 10, estão listados os radionuclídeos utilizados nas determinações, com suas respectivas meias-vidas e parâmetros $k_{0}$. Embora essa compilação apresente apenas as linhas de emissão gama mais intensas para cada radionuclídeo, o programa Quantu trabalha com até quatro linhas. Nos casos em que os resultados eram obtidos a partir de diversas linhas e espectros, foi utilizada média ponderada, calculada pelo programa considerando a incerteza de cada valor individual.

Ainda por meio do programa Quantu-INAA, foram calculados os limites de deteç̧ão para cada amostra, segundo critério extraído de Alfassi (1994a) e representado na eq.(11), onde $N_{P}$ é o menor número de contagens detectável no fotopico característico e $N_{B}$ é o número de contagens do background da região de interesse. Para estes cálculos, os espectros com e sem supressão foram considerados separadamente, de modo a permitir a determinação da influência do supressor Compton na redução dos limites de deteç̧ão.

$$
N_{P} \geq 3 \sqrt{N_{B}}
$$

Há que se ressaltar a gande confusão existente em relação à expressão "limite de detecção" e outros termos relacionados com a capacidade de um procedimento analítico (Currie, 1999), tais como "limite de quantificação" e "limite de determinação". Porém, apesar de algumas pequenas divergências, o critério utilizado neste trabalho não difere significativamente das práticas mais comuns em espectrometria de radiação gama. 
Tabela 10. Radionuclídeos utilizados para a obtenção dos resultados, apresentando suas meias-vidas (dias), além da energia (keV) e do parâmetro $k_{0}$ para as linhas de emissão gama mais importantes. Fonte: programa Quantu

\begin{tabular}{|c|c|c|c|c|}
\hline Elemento & Radionuclídeo & Meia-vida & Energia & $k_{0}$ \\
\hline As & ${ }^{76}$ As & 1,097 & 559,08 & $4,83 \times 10^{-2}$ \\
\hline \multirow[t]{2}{*}{$\mathrm{Br}$} & ${ }^{82} \mathrm{Br}$ & 1,4708 & 554,30 & $2,38 \times 10^{-2}$ \\
\hline & & & 776,50 & $2,76 \times 10^{-2}$ \\
\hline $\mathrm{Ca}$ & ${ }^{47} \mathrm{Ca}$ & 4,536 & 1297,06 & $9,54 \times 10^{-7}$ \\
\hline $\mathrm{Cd}$ & ${ }^{115 m}$ In & 2,228 & 336,20 & $7,73 \times 10^{-4}$ \\
\hline \multirow[t]{2}{*}{ Co } & ${ }^{60} \mathrm{Co}$ & 1925 & 1173,24 & $1,32 \times 10^{+0}$ \\
\hline & & & 1332,50 & $1,32 \times 10^{+0}$ \\
\hline $\mathrm{Cr}$ & ${ }^{51} \mathrm{Cr}$ & 27,7 & 320,08 & $2,62 \times 10^{-3}$ \\
\hline \multirow[t]{2}{*}{$\mathrm{Fe}$} & ${ }^{59} \mathrm{Fe}$ & 44,496 & 1099,25 & $7,77 \times 10^{-5}$ \\
\hline & & & 1291,60 & $5,93 \times 10^{-5}$ \\
\hline $\mathrm{Hg}$ & ${ }^{203} \mathrm{Hg}$ & 46,612 & 279,20 & $1,10 \times 10^{-2}$ \\
\hline $\mathrm{K}$ & ${ }^{42} \mathrm{~K}$ & 0,515 & 1524,58 & $9,46 \times 10^{-4}$ \\
\hline \multirow[t]{2}{*}{$\mathrm{La}$} & ${ }^{140} \mathrm{La}$ & 1,678 & 487,02 & $6,37 \times 10^{-2}$ \\
\hline & & & 1596,54 & $1,34 \times 10^{-1}$ \\
\hline $\mathrm{Na}$ & ${ }^{24} \mathrm{Na}$ & 0,624 & 1368,60 & $4,62 \times 10^{-2}$ \\
\hline $\mathrm{Rb}$ & ${ }^{76} \mathrm{Rb}$ & 18,66 & 1076,69 & $7,65 \times 10^{-4}$ \\
\hline \multirow[t]{2}{*}{ Sc } & ${ }^{46} \mathrm{Sc}$ & 83,82 & 889,25 & $1,22 \times 10^{+0}$ \\
\hline & & & 1120,51 & $1,22 \times 10^{+0}$ \\
\hline Se & ${ }^{75} \mathrm{Se}$ & 119,77 & 264,66 & $7,11 \times 10^{-3}$ \\
\hline $\mathrm{Zn}$ & ${ }^{65} \mathrm{Zn}$ & 244,1 & 1115,52 & $5,72 \times 10^{-3}$ \\
\hline
\end{tabular}




\section{RESULTADOS E DISCUSSÃO}

\subsection{Desempenho do supressor Compton}

A primeira série de medições de desempenho apontou um fator de supressão médio de 5,97 $\pm 0,11$ (desvio padrão, $\mathrm{n}=6$ ) para ${ }^{137} \mathrm{Cs}$, tomando-se as contagens na região plana do continuum Compton, ou seja, de 358 a $382 \mathrm{keV}$. A média obtida foi semelhante a valores relatados por alguns autores (Tabela 11), embora existam supressores com desempenho aparentemente bem melhor.

Muitas vezes, a utilização de um detector principal de pequenas dimensões, e portanto com baixa razão pico-Compton, resulta na obtenção de um fator de supressão elevado ao se utilizar um sistema supressor. Assim, embora os fatores de supressão sejam normalmente utilizados para a avaliação de desempenho, é importante considerar também as razões pico-Compton. A razão pico-Compton conseguida no espectro com supressão parece um parâmetro que possibilita uma melhor avaliação da real capacidade do sistema em seu todo e não apenas da atuação da blindagem ativa anti-Compton. $\mathrm{O}$ fator de supressão medido neste trabalho corresponde a uma razão pico-Compton para ${ }^{137}$ Cs de 133 nos espectros sem supressão e de 795 nos espectros com supressão, portanto o terceiro maior valor entre os listados na Tabela 11.

Não se deve negligenciar que as razões pico-Compton e os fatores de supressão compilados não foram necessariamente medidos na mesma faixa de energia, o que pode causar grandes diferenças nos resultados, principalmente para a razão pico-Compton. Ainda mais, alguns cálculos consideram a área do fotopico $662 \mathrm{keV}$, e não as contagens no canal de maior acúmulo, para obter o fator de supressão, o que pode resultar em pequenas diferenças. Neste caso, por exemplo, o fator de supressão medido seria $6,07 \pm 0,12$. 
Tabela 11. Fatores de supressão e razão pico-Compton $(\mathrm{P} / \mathrm{C})$ no espectro com supressão, obtidos por diversos autores para ${ }^{137} \mathrm{Cs}$, empregando diferentes procedimentos de medição e cálculo

\begin{tabular}{cccc}
\hline Fator & P/C & Região do espectro & Fonte \\
\hline 5,97 & 795 & $358-382 \mathrm{keV}$ & este trabalho \\
5 & 300 & não especificada & Harbottle \& Cumming (1994) \\
7,8 & $*$ & próximo a borda & Landsberger (1994) \\
5,3 & 364 & não especificada & Satoh et al. (1995) \\
10,1 & 1410 & $358-382 \mathrm{keV}$ & Voigt et al. (1995) \\
5,9 & 480 & não especificada & Sudarti et al. (1997) \\
8,0 & $*$ & não especificada & Peerani et al. (2002) \\
$5,8-8,2$ & 515 & não especificada & Yonezawa et al. (2003) \\
7,6 & 950 & $358-382 \mathrm{keV}$ & Parus et al. (2003) \\
\hline
\end{tabular}

* valores não disponíveis

Ainda em relação aos dados da Tabela 11, as condições experimentais empregadas pelos diversos autores foram bastante variáveis, quanto a fatores como atividade da fonte e distância fonte-detector, o que também pode interferir significativamente nos resultados. Como ilustração, os maiores valores foram obtidos por Voigt et al. (1995) utilizando as contagens no canal de máximo acúmulo e a região de 358 a $382 \mathrm{keV}$. Porém, a medição foi realizada em condições experimentais bastante favoráveis, inclusive com uso de colimador que, segundo os autores, resultou em melhoria significativa no desempenho.

Neste trabalho, também buscou-se medir o fator de supressão em condição otimizada, ou seja, com fonte colocada sobre o detector principal e com o detector plug posicionado sobre ela, de modo a obter uma configuração próxima a $4 \pi$ para detecção da radiação Compton. Adicionalmente, dentre duas fontes de ${ }^{137} \mathrm{Cs}$ disponíveis no laboratório, foi utilizada a de menor atividade $(9 \mathrm{kBq})$, o que proporcionou uma taxa de contagem total da ordem de $1,1 \times 10^{3}$ cps. 
Para as medições realizadas ao longo de vinte semanas (Figura 9), o fator de supressão médio foi $5,88 \pm 0,11$ (desvio padrão, $\mathrm{n}=20$ ), portanto perfeitamente concordante com o fator de supressão inicialmente obtido. A dispersão dos resultados mostrou-se compatível com a incerteza combinada, que foi calculada com base na estatística de contagem para cada resultado individual, apresentando valores entre 0,17 e 0,18 . O desvio padrão igual ao observado para a primeira série de medidas, além de todos os resultados compreendidos no intervalo de \pm 2 desvios padrões, não deixa dúvidas quanto a estabilidade do sistema supressor durante o período em questão.

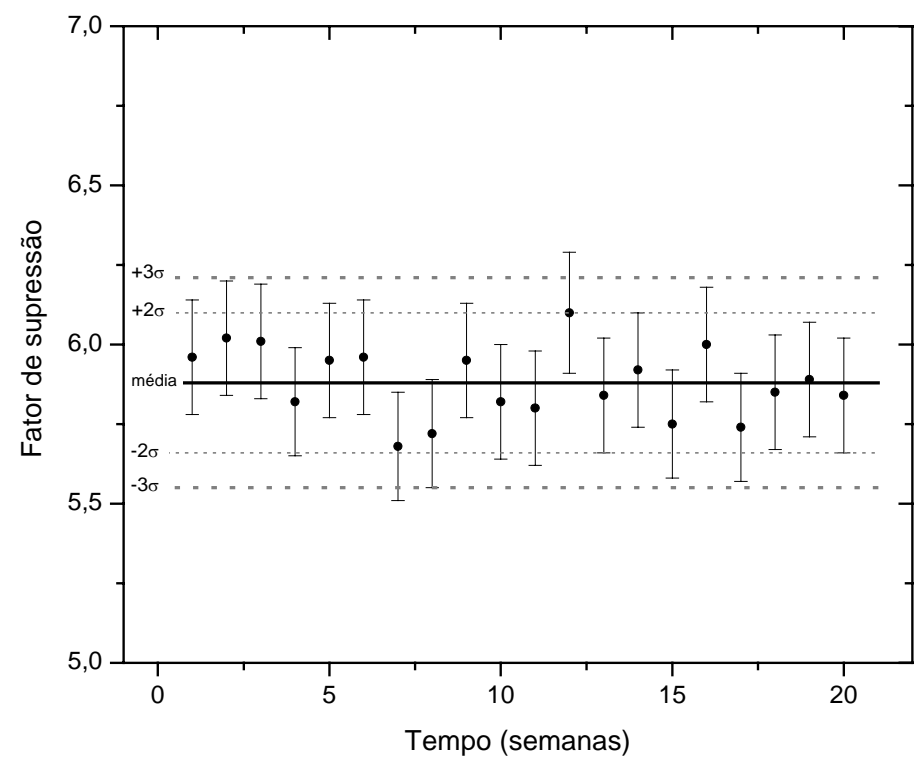

Figura 9 - Fator de supressão para ${ }^{137} \mathrm{Cs}$ medido entre 358 e $382 \mathrm{keV}$. Resultados individuais e incertezas combinadas para vinte medições semanais, comparados à média $(5,88)$ e desvio padrão $(1 \sigma=0,11)$

Confirmando expectativa, o fator de supressão mostrou-se bastante variável em função da faixa de energia tomada para o cálculo (Figura 10), apresentando um comportamento semelhante ao observado por Mauerhofer et al. (1996) e também por Parus et al. (2003). Os valores apresentados foram calculados a partir de faixas de $\pm 10 \mathrm{keV}$ em relação às energias plotadas no gráfico, com óbvia exceção das regiões $358-382 \mathrm{keV}$ e $475-481 \mathrm{keV}$. Cabe salientar que os dados da Figura 10 são provenientes de apenas quatro medições tomadas aleatoriamente da série de vinte, o que 
explica um fator de supressão ligeiramente diferente para a região plana em relação aos resultados anteriormente obtidos. Pelo gráfico, percebe-se valor máximo de $8,4 \pm 0,2$ (desvio padrão, $n=4$ ) obtido na região de $450 \mathrm{keV}$, enquanto Mauerhofer et al. (1996) encontraram um valor máximo de 7,6 em $400 \mathrm{keV}$ e Parus et al. (2003) acharam máximo de 12 em $475 \mathrm{keV}$. Nota-se, ainda, que o fator de supressão é maior na região de borda do que na região plana, o que é comum à maioria dos supressores Compton.

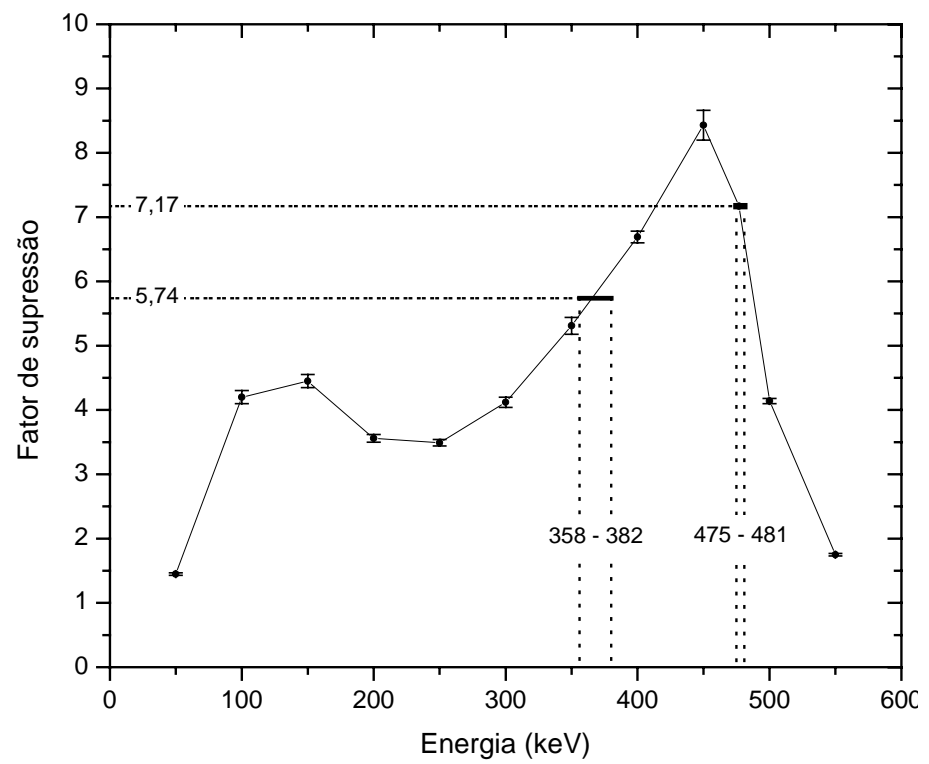

Figura 10 - Fator de supressão para ${ }^{137}$ Cs medido em diversas energias. Cada ponto corresponde à média de quatro repetições realizadas em dias distintos e a barra de erros representa o desvio padrão

Ainda pela observação da Figura 10, nota-se a grande variação que o fator de supressão apresenta na faixa de 250 a $450 \mathrm{keV}$, que de maneira geral pode ser considerada como região plana do continuum Compton. Esse comportamento variável ilustra a dificuldade de comparação entre fatores de supressão calculados para diferentes regiões do espectro, reforçando a importância de se empregar procedimentos normalizados, como o fixado pela ANSI (1986), a fim de produzir resultados comparáveis. Mesmo assim, deve-se ressaltar que a variação do fator de supressão com a energia depende do equipamento, conforme observado em Mauerhofer et al. (1996) em que curvas diferentes foram obtidas para duas configurações testadas. Assim, em uma 
condição extrema, um supressor pode ter um desempenho ruim na região entre 358 e $382 \mathrm{keV}$ se comparado com outros equipamentos, mas apresentar um elevado fator de supressão em outras energias.

A determinação do fator de supressão para ${ }^{137} \mathrm{Cs}$ a varias distâncias do detector principal (Figura 11) demonstrou que há clara redução no desempenho do equipamento com o afastamento da fonte. Na faixa testada, entre 0 e $210 \mathrm{~mm}$, o comportamento foi linear, sendo que o ajuste de uma reta (coeficiente angular de 0,0039 $\pm 0,0003$ ) apontou uma redução de aproximadamente $2 \%$ a cada $30 \mathrm{~mm}$ ou um total de $15 \%$ para os $210 \mathrm{~mm}$. A perda de desempenho com a distância é compatível com dados relatados por Parus et al. (2003), que encontraram redução de $40 \%$ para distância de até $650 \mathrm{~mm}$. Considerando a extrapolação do comportamento linear, a redução de 40 \% ocorreria a $550 \mathrm{~mm}$ para o espectrômetro testado neste trabalho.

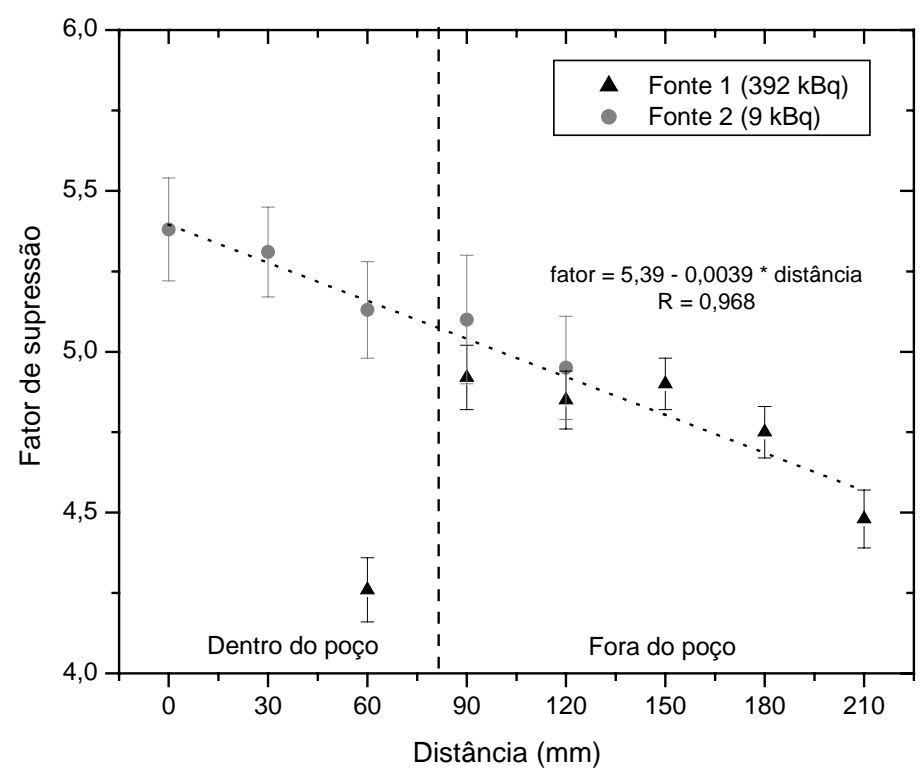

Figura 11 - Fator de supressão para ${ }^{137}$ Cs na região plana $(358$ - $382 \mathrm{keV})$ medido a diferentes distâncias do detector principal, sem o uso do detector plug. Barras de erro representam as incertezas combinadas calculadas a partir da estatística de contagem 
Todas as determinações que originaram a Figura 11 foram realizadas sem a utilização do detector plug, o que justifica o valor mais baixo 5,38 \pm 0,16 (incerteza combinada) encontrado para o fator de supressão medido sobre o detector. A redução de $10 \%$ em relação ao fator determinado com posicionamento do detector plug concorda perfeitamente com a diminuição também de $10 \%$ observada por Parus et al. (2003), que avaliaram o fator de supressão na região plana para diversas configurações de um sistema supressor.

A utilização de duas fontes com atividades distintas, na avaliação do desempenho com a distância, evidencia claramente o efeito negativo da elevada taxa de contagem sobre o fator de supressão. O valor medido a $60 \mathrm{~mm}$ com a Fonte 1 (de maior atividade) é $18 \%$ menor do que o observado com a Fonte 2. Essa diferença se deve principalmente à redução das contagens no pico de ${ }^{137} \mathrm{Cs}$ por coincidência entre eventos ocorridos no detector principal e no detector annulus. Na realidade, a redução do pico $662 \mathrm{keV}$ também foi da ordem de $18 \%$, e corrigindo-se esta perda, obtem-se 4,96, valor muito próximo ao medido com a Fonte $2(5,13)$. Mesmo nos valores determinados a 90 e $120 \mathrm{~mm}$ já se nota uma pequena diminuição na supressão devido à maior atividade da Fonte 1. Como se trata de coincidência ocasional, há uma relação direta entre a taxa de contagem e a redução no fotopico, por isso para a fonte de menor atividade não se observa o problema. Como a eficiência de detecção no cristal annulus é consideravelmente maior para posições dentro do poço, a redução no fotopico, e portanto no fator de supressão, torna-se bem mais visível para distâncias menores do que $80 \mathrm{~mm}$.

O efeito da taxa de contagem foi investigado pela utilização da Fonte 3, de ${ }^{60} \mathrm{Co}$, em distância $(300 \mathrm{~mm})$ que fornecia um total de $5 \times 10^{2} \mathrm{cps}$ no detector principal, seguido do aumento gradativo da taxa de contagem pela aproximação da Fonte 1, de ${ }^{137}$ Cs. Na faixa estudada (Figura 12), de até $5 \times 10^{3} \mathrm{cps}$, a redução no fator de supressão para ${ }^{60} \mathrm{Co}$ mostrou-se linear, correspondendo a uma perda entre 3 e $4 \%$ para cada aumento de $1 \times 10^{3} \mathrm{cps}$. 


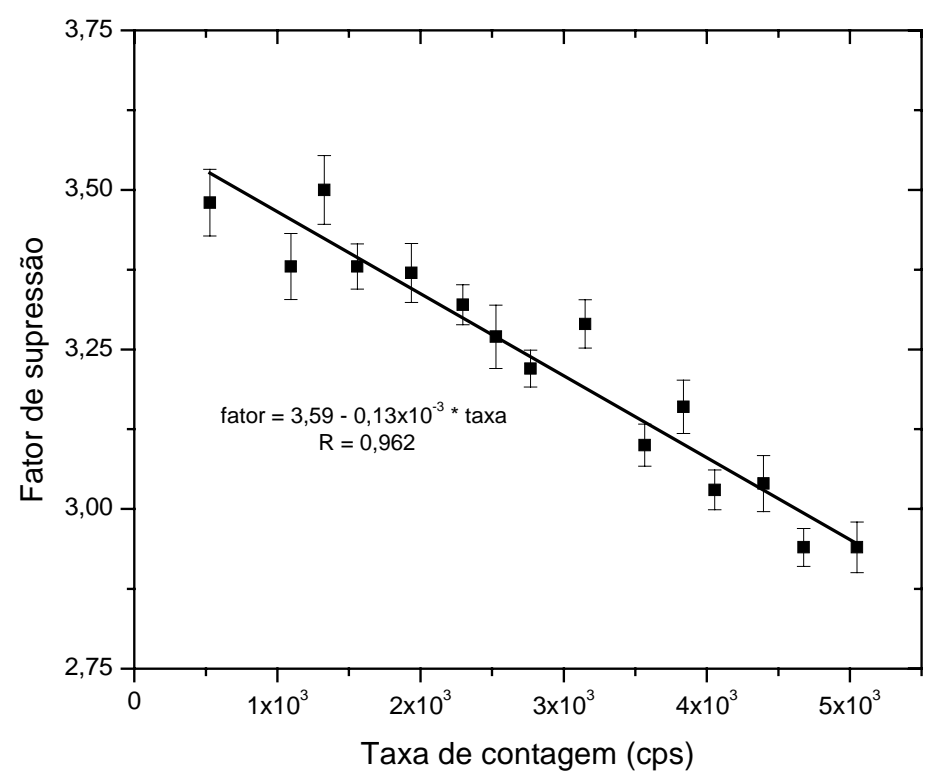

Figura 12 - Fator de supressão medido para ${ }^{60} \mathrm{Co}$ na região entre 1040 e $1096 \mathrm{keV}$ em função da taxa de contagem total observada no detector principal. Barras de erro representam a incerteza combinada das determinações individuais, calculada a partir da estatística de contagem

Na Figura 13, observa-se uma nítida perda de contagens no fotopico $1332 \mathrm{keV}$ no espectro com supressão em função do aumento da taxa de contagem total, enquanto no espectro sem supressão os valores se concentram em torno de um valor médio de 5,38. Apenas nas condições de taxa de contagem mais elevadas, nota-se pequena redução no fotopico também no espectro sem supressão. Neste caso, as contagens são perdidas por ocorrência de eventos simultâneos no próprio detector principal.

A redução de $3 \%$ notada na área do fotopico mesmo a $5 \times 10^{2} \mathrm{cps}$ (Figura 13) se deve ao efeito de coincidência verdadeira, uma vez que no decaimento do ${ }^{60} \mathrm{Co}$ ocorre emissão de dois raios gama em cascata (1173 e $1332 \mathrm{keV})$. Neste caso, a perda é independente da taxa de contagem, mas se agrava em situações de elevada eficiência. Assim, em posições dentro do poço do supressor, onde é grande a probabilidade de detecção simultânea de eventos em cascata, a redução nos fotopicos do ${ }^{60}$ Co seria muito maior. 


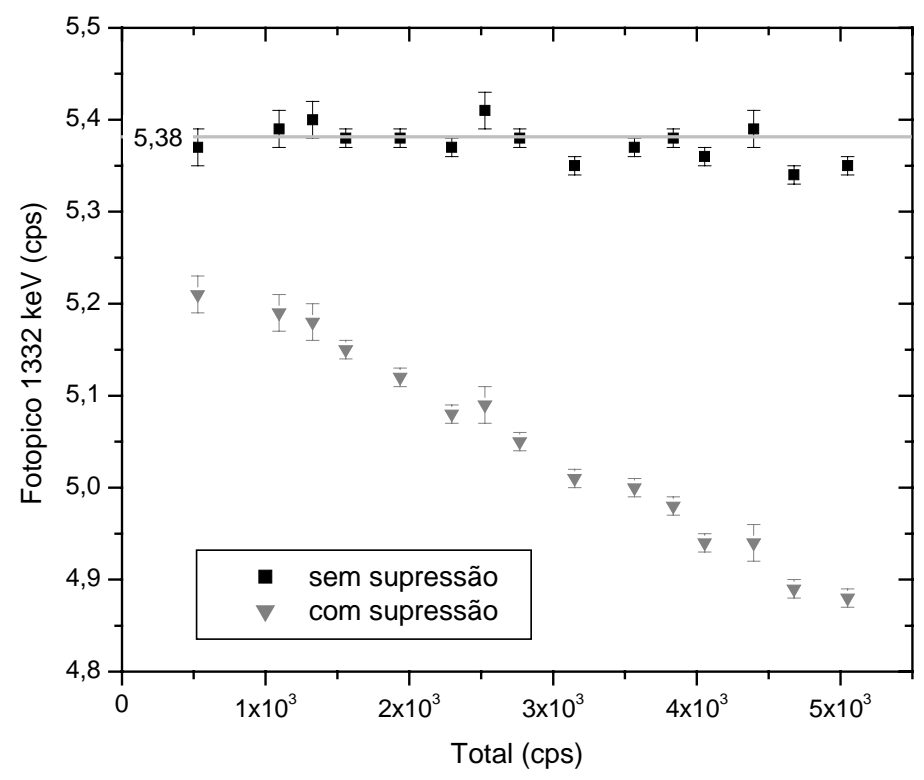

Figura 13 - Taxa de contagem no fotopico $1332 \mathrm{keV}$ do ${ }^{60} \mathrm{Co}$ para espectros com e sem supressão em função da taxa de contagem total no detector principal

\subsection{Composição química elementar}

Os resultados individuais obtidos para cada amostra encontram-se no Apêndice 1. Para proporcionar uma avaliação generalizada da composição química determinada para arroz, batata, ervilha, feijão, grão-de-bico e lentilha, tabularam-se os valores médios das concentrações obtidas para quinze elementos em cada produto (Tabela 12). Pelos dados, observa-se que Br, Ca, Co, Fe, K, Na, Rb, Sc e Zn foram mais freqüentemente determinados, sendo que $\mathrm{Br}, \mathrm{Co}, \mathrm{K}, \mathrm{Rb}$ e $\mathrm{Zn}$ puderam ser quantificados em todas as amostras. Por outro lado, As, Cr, La e Se apresentaram-se abaixo do limite de detecção em diversas amostras, enquanto $\mathrm{Cd}$ e $\mathrm{Hg}$ não foram encontrados em nenhum material.

Dentre os elementos que mostraram muitos resultados abaixo do limite de detecção, percebe-se a tendência de maior concentração em um determinado produto. As nove amostras de arroz, por exemplo, foram as únicas em que a quantificação de As foi possível. Também $\mathrm{Cr}$ apareceu com maior freqüência no arroz, enquanto Se não foi detectado em arroz e batata, sendo mais encontrado em ervilha, grão-de-bico e especialmente em lentilha, onde as concentrações foram bem mais elevadas. 
Tabela 12. Resultados médios de concentração expressos em $\mathrm{mg} \mathrm{kg}^{-1}$ base seca ( $\mathrm{Sc}$ em $\mu \mathrm{g} \mathrm{kg}^{-1}$ ) com seus desvios padrões relativos (DPR) e número de amostras

\begin{tabular}{|c|c|c|c|c|c|c|c|c|}
\hline & & Arroz & & & ervilha & feiião & grão-de- & lentilha \\
\hline & & Alloz & polpa & casca & & IEIjau & & \\
\hline & média & 0,30 & & & & & & \\
\hline As & DPR & 40 & $<0,051$ & $<0,066$ & $<0,029$ & $<0,025$ & $<0,15$ & $<0,029$ \\
\hline & $\mathrm{n}$ & 9 & & & & & & \\
\hline & média & 1,18 & 1,26 & 3,28 & 1,23 & 1,03 & 16,1 & 6,36 \\
\hline $\mathrm{Br}$ & DPR & 46 & 31 & 19 & 9,2 & 119 & 39 & 42 \\
\hline & $\mathrm{n}$ & 9 & 4 & 4 & 2 & 30 & 4 & 4 \\
\hline & média & 183 & 334 & 834 & 572 & 1390 & 1170 & 675 \\
\hline $\mathrm{Ca}$ & DPR & 16 & 14 & 31 & 25 & 29 & 7,5 & 11 \\
\hline & $\mathrm{n}$ & 2 & 1 & 4 & 2 & 30 & 4 & 4 \\
\hline & média & & & & & & & \\
\hline $\mathrm{Cd}$ & $\begin{array}{c}\text { DPR } \\
\mathrm{n}\end{array}$ & $<0,11$ & $<0,47$ & $<0,57$ & $<0,22$ & $<0,22$ & $<0,40$ & $<0,20$ \\
\hline & média & 0,042 & 0,02 & 0,04 & 0,078 & 0,20 & 0,13 & 0,10 \\
\hline $\mathrm{Co}$ & DPR & 71 & 63 & 49 & 36 & 68 & 23 & 9,6 \\
\hline & $\mathrm{n}$ & 9 & 4 & 4 & 2 & 30 & 4 & 4 \\
\hline & média & 1,13 & $<0,56$ & $<0,63$ & 1,27 & $<0,43$ & $<0,43$ & $<0,39$ \\
\hline $\mathrm{Cr}$ & DPR & 26 & - & $-0,03$ & 14 & $-0,+3$ & $-0,4 J$ & - 0,03 \\
\hline & $\mathrm{n}$ & 4 & & & 1 & & & \\
\hline & média & 11,8 & 25,7 & 139 & 63,3 & 73,2 & 57,9 & 88,8 \\
\hline $\mathrm{Fe}$ & DPR & 47 & 7,8 & 39 & 13 & 19 & 4,8 & 6,8 \\
\hline & $\mathrm{n}$ & 6 & 4 & 4 & 2 & 30 & 4 & 4 \\
\hline & média & & & & & & & \\
\hline $\mathrm{Hg}$ & $\begin{array}{c}\text { DPR } \\
n\end{array}$ & $<0,013$ & $<0,014$ & $<0,019$ & $<0,019$ & $<0,024$ & $<0,020$ & $<0,022$ \\
\hline & média & 1160 & 22500 & 31400 & 10500 & 15500 & 11700 & 11100 \\
\hline $\mathrm{K}$ & DPR & 60 & 9,0 & 4,8 & 4,7 & 7,0 & 2,5 & 3,5 \\
\hline & $\mathrm{n}$ & 9 & 4 & 4 & 2 & 30 & 4 & 4 \\
\hline & média & & & 0,08 & 0,026 & 0,02 & 0,014 & 0,01 \\
\hline $\mathrm{La}$ & DPR & $<0,0018$ & $<0,010$ & 19 & 5,9 & 73 & 9,7 & 50 \\
\hline & $\mathrm{n}$ & & & 3 & 1 & 19 & 1 & 4 \\
\hline & média & 11,9 & 13,5 & 37,6 & 36,8 & 3,98 & 138 & 9,56 \\
\hline $\mathrm{Na}$ & DPR & 75 & 54 & 61 & 33 & 213 & 30 & 73 \\
\hline & $\mathrm{n}$ & 9 & 4 & 4 & 2 & 16 & 4 & 4 \\
\hline & média & 11,9 & 13,1 & 19,2 & 7,9 & 12,8 & 7,17 & 5,09 \\
\hline $\mathrm{Rb}$ & DPR & 51 & 19 & 17 & 50 & 83 & 33 & 22 \\
\hline & $\mathrm{n}$ & 9 & 4 & 4 & 2 & 30 & 4 & 4 \\
\hline & média & 0,91 & 1,37 & 37,1 & 1,73 & 3,87 & 3,49 & 5,05 \\
\hline $\mathrm{Sc}$ & DPR & 48 & 24 & 43 & 4,0 & 116 & 42 & 64 \\
\hline & $\mathrm{n}$ & 2 & 4 & 4 & 1 & 30 & 4 & 4 \\
\hline & média & & & & 0,17 & 0,27 & 0,20 & 1,18 \\
\hline $\mathrm{Se}$ & DPR & $<0,044$ & $<0,033$ & $<0,055$ & 4,3 & 25 & 20 & 6,3 \\
\hline & $\mathrm{n}$ & & & & 2 & 9 & 4 & 4 \\
\hline & média & 13,8 & 20,9 & 23,1 & 39,8 & 32,6 & 33,5 & 44,7 \\
\hline $\mathrm{Zn}$ & DPR & 31 & 9,8 & 21 & 1,1 & 12 & 4,3 & 4,5 \\
\hline & $\mathrm{n}$ & 9 & 4 & 4 & 2 & 30 & 4 & 4 \\
\hline
\end{tabular}


Como um elemento bastante ligado à presença de terra, La apareceu em maior proporção na casca das batatas, porém também foi determinado em amostras de ervilha, feijão, grão-de-bico e lentilha. Analisando mais cuidadosamente as médias da Tabela 12, nota-se que a casca da batata tem os maiores valores para cinco elementos, entre os quais $\mathrm{Fe}$ e $\mathrm{Sc}$, que apresentaram elevada correlação $\left(\mathrm{R}^{2}=0,9969\right)$ para essas amostras. Assim, mesmo tendo passado por lavagem, há evidências da existência de vestígios de terra, uma vez que esses dois elementos podem ser empregados como rastreadores da presença de terra em material vegetal (Fernandes, 1993).

Considerando que $\mathrm{Br}$ e $\mathrm{Co}$ foram determinados em todas as amostras, houve especial atenção quanto à possível interferência de $\mathrm{Br}$ na quantificação de $\mathrm{Co}$, devido à formação de picos soma do ${ }^{82} \mathrm{Br}$ em $1173,4 \mathrm{keV}(554,3+619,1)$ e $1330,8 \mathrm{keV}$ $(554,3+776,5)$, portanto muito próximos aos fotopicos do ${ }^{60} \mathrm{Co}$. A observação de um período de decaimento mínimo de 35 dias antes da quarta medição garantiu a ausência dessa interferência, tendo em vista a meia-vida do ${ }^{82} \mathrm{Br}$ (1,47 dias).

Outra interferência importante observada nas análises realizadas, é a emissão de raios gama de ${ }^{75} \mathrm{Se} \mathrm{e}{ }^{203} \mathrm{Hg}$ em $279 \mathrm{keV}$. Neste caso, avaliou-se a coerência entre os resultados obtidos para Se individualmente por meio das linhas 264 e $279 \mathrm{keV}$, procedendo-se a correção dos resultados de $\mathrm{Hg}$ quando necessário.

Alguns elementos apareceram na análise das cápsulas vazias, sendo $\mathrm{Br}, \mathrm{Cr}, \mathrm{Na}$ e $\mathrm{Zn}$ os mais freqüentes. Após os devidos descontos do branco analítico, apenas os resultados de $\mathrm{Cr}$ foram substancialmente alterados. A presença de $\mathrm{Cr}$ nas cápsulas elevou os limites de deteç̧ão em aproximadamente uma ordem de grandeza. Assim, limites de detecção bem inferiores aos reportados na Tabela 12 podem ser alcançados retirando-se as amostras da cápsula de irradiação antes de proceder a medição.

Finalmente, vale ressaltar que $\mathrm{Br}, \mathrm{K}$ e $\mathrm{Na}$ devem contribuir mais intensamente para a formação da região Compton nas duas primeiras medições. Da mesma forma, Co e $\mathrm{Zn}$ devem contribuir para a elevação da linha de base na terceira e quarta contagens. Por isso, amostras que apresentam elevada concentração desses elementos são, a princípio, mais beneficiadas pelo uso do equipamento supressor, como o grão-de-bico que tem elevadas concentrações de $\mathrm{Br}$ e $\mathrm{Na}$. 


\subsubsection{Arroz}

Para observação individual de cada amostra, optou-se por plotar em gráficos de barra apenas os resultados para os elementos que foram efetivamente medidos em todas as amostras de um determinado produto. Assim, para arroz foram construídos gráficos para As, Br, Co, K, Na, Rb e Zn (Figura 14).

Observando os dados, é possível diferenciar as amostras de arroz integral (01), parboilizado (02 a 04) e polido (05 a 09), principalmente pelas variações nos teores de $\mathrm{K}, \mathrm{Rb}$ e Zn. Seguindo a expectativa, os teores dos três elementos são mais elevados no arroz integral. As amostras de arroz parboilizado são mais ricas em $\mathrm{K}$ e $\mathrm{Rb}$ em relação a arroz polido, porém para Zn observa-se um comportamento inverso. Considerando que o processo de parboilização objetiva a manutenção de nutrientes no arroz, os resultados apontam que para as amostras tomadas o processo não parece eficiente para a manutenção de Zn, elemento com reconhecida importância nutricional.

Além da separação dos três tipos de arroz, nota-se também uma diferença na composição das amostras 08 e 09. Ambas mostram teores de As menores e de Co mais elevados do que todas as demais avaliadas. Tentou-se associar esse comportamento com a origem geográfica ou empresa produtora, entretanto a informação contida nas embalagens não permitiu que se encontrasse qualquer relação.

É fundamental avaliar com maior atenção os teores de As encontrados em arroz, visto que dentre os elementos potencialmente tóxicos foi a única ocorrência relevante. A concentração média encontrada $\left(0,30 \mathrm{mg} \mathrm{kg}^{-1}\right)$ foi praticamente o dobro do valor máximo determinado por Nriagu \& Lin (1995), porém assemelha-se aos valores máximos relatados por diversos autores (Roychowdhury et al., 2002; D'llio et al., 2002; Pizarro et al., 2003; Lamont, 2003). Alguns valores muito elevados, acima de $1,8 \mathrm{mg} \mathrm{kg}^{-1}$, já foram encontrados por Meharg \& Rahman (2003) em um levantamento realizado em Bangladesh. Embora os valores obtidos neste trabalho estejam todos abaixo de $1,0 \mathrm{mg} \mathrm{kg}^{-1}$, que é o nível máximo em grãos estabelecido pela Portaria 685 (27/08/1998) do Ministério da Saúde, parece importante que seja realizado um estudo mais detalhado, uma vez que os níveis medidos estão relativamente próximos do limite legal. 

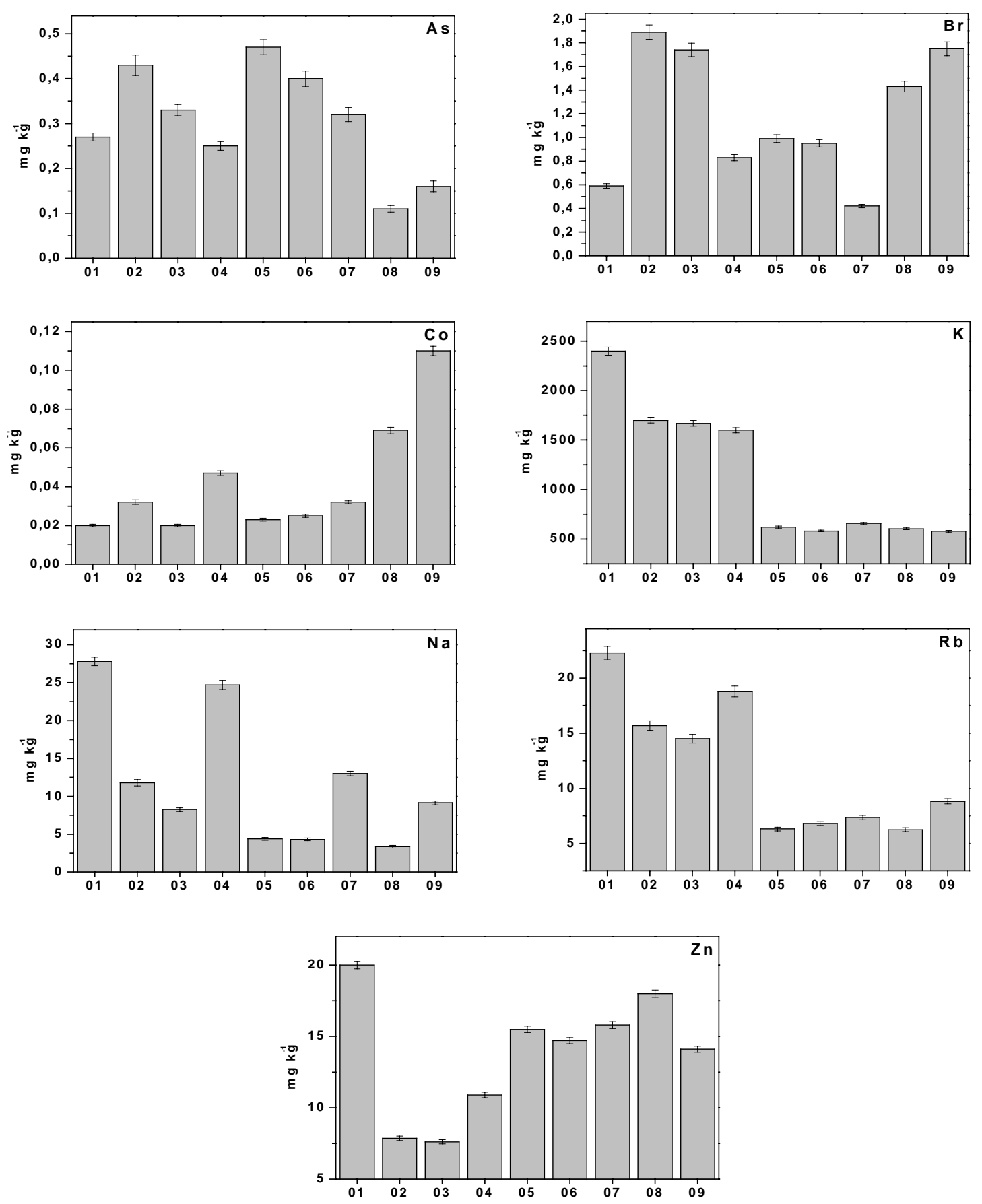

Figura 14 - Resultados individuais para os sete elementos químicos que foram determinados em todas as amostras de arroz. Barras de erros representam as incertezas combinadas dos valores obtidos 


\subsubsection{Batata}

Oito elementos ( $\mathrm{Br}, \mathrm{Co}, \mathrm{Fe}, \mathrm{K}, \mathrm{Na}, \mathrm{Rb}, \mathrm{Sc}$ e $\mathrm{Zn}$ ) foram determinados em todas as amostras de batata, tanto na polpa quanto na casca (Figura 15). Os resultados permitiram uma perfeita separação entre as amostras de polpa (números ímpares) e de casca (números pares). As maiores diferenças são vistas para $\mathrm{Fe}$ e Sc, justificadas pela presença de contaminação superficial com terra, conforme já discutido anteriormente. Entretanto, a mesma tendência foi também claramente notada para $\mathrm{Br}, \mathrm{K}$ e $\mathrm{Rb}$, além de Co e Na em menor proporção, demonstrando um óbvio acúmulo de elementos na casca.

Quanto às quatro variedades, a principal diferença notada foram as maiores concentrações de Co e Rb na polpa e casca da batata achat (01 e 02). A atribuição desse resultado a um comportamento da variedade depende de confirmação, uma vez que a amostragem realizada foi simples e não contemplava este propósito. Contudo, há que se considerar que as amostras foram tomadas de um mesmo campo experimental, em que as condições de cultivo foram controladas e iguais para todas as quatro variedades.

\subsubsection{Feijão}

O feijão foi a matriz alimentar que apresentou os mais elevados desvios padrões relativos (Tabela 12) para a maioria dos elementos determinados, o que demonstra uma composição química bastante variável. A análise de diferentes tipos de feijão contribuiu para essa dispersão observada nos resultados, uma vez que é bastante provável que a composição química seja, em alguma proporção, dependente desse fator.

Foi possível a determinação de oito elementos $(\mathrm{Br}, \mathrm{Ca}, \mathrm{Co}, \mathrm{Fe}, \mathrm{K}, \mathrm{Rb}, \mathrm{Sc}$ e Zn) em todas as amostras de feijão (Figura 16). Alguns resultados destacam-se por serem bastante diferentes da maioria. É o caso da concentração de Br para a amostra feijão-26 (mulatinho, Super Grão) que foi mais de seis vezes superior à média $(1,03)$. Entre vários outros dados, também merecem comentário as elevadas concentrações de Ca na amostra feijão-01 (adzuki, Super Grão), Co nas amostras 11, 22 e 26, além de Rb nas amostras 11 e 30. Entretanto, aparentemente não foi encontrada qualquer associação dessa composição diferenciada com o tipo de feijão. 

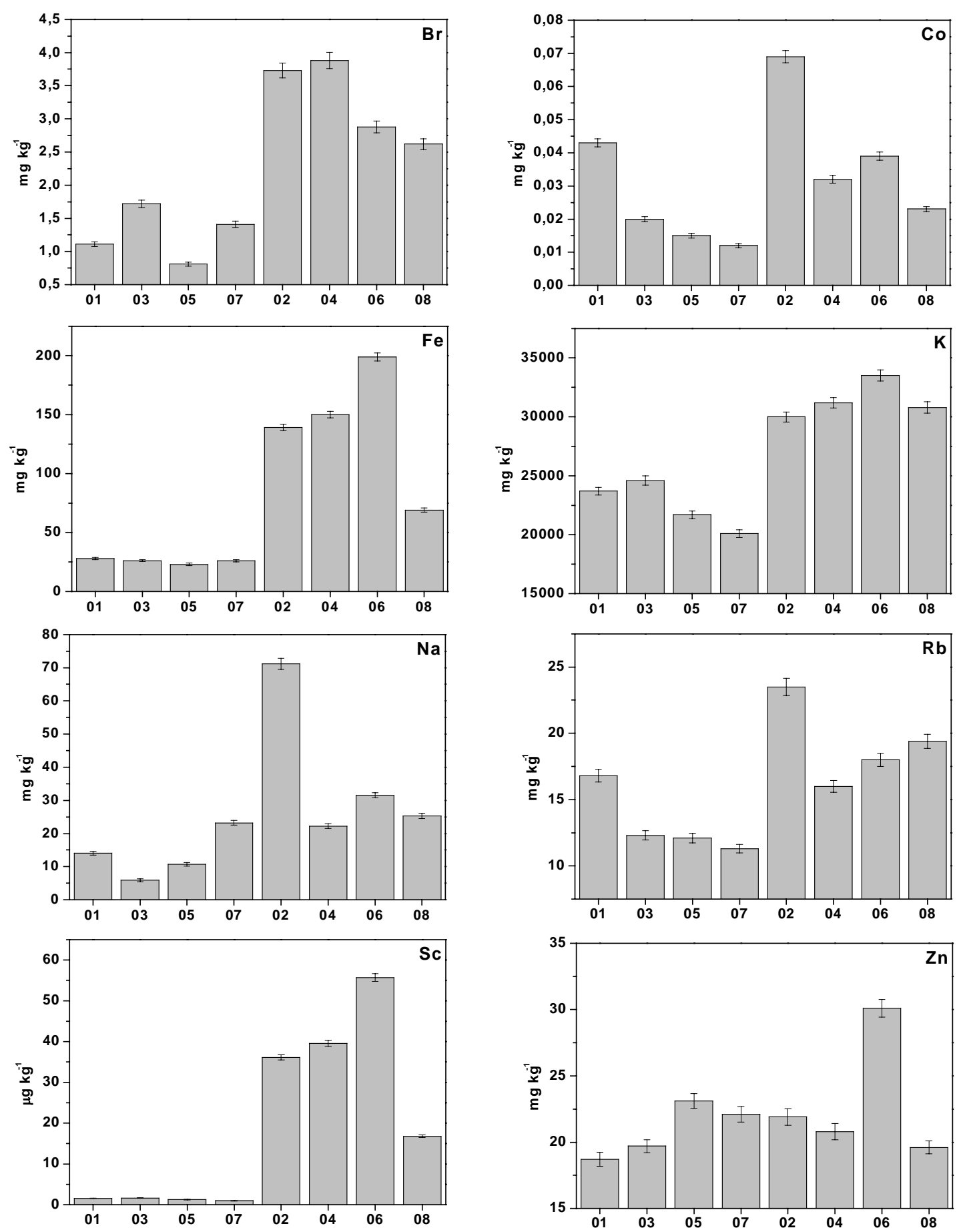

Figura 15 - Resultados individuais para os oito elementos químicos que foram determinados em todas as amostras de batata. Barras de erros representam as incertezas combinadas dos valores obtidos 

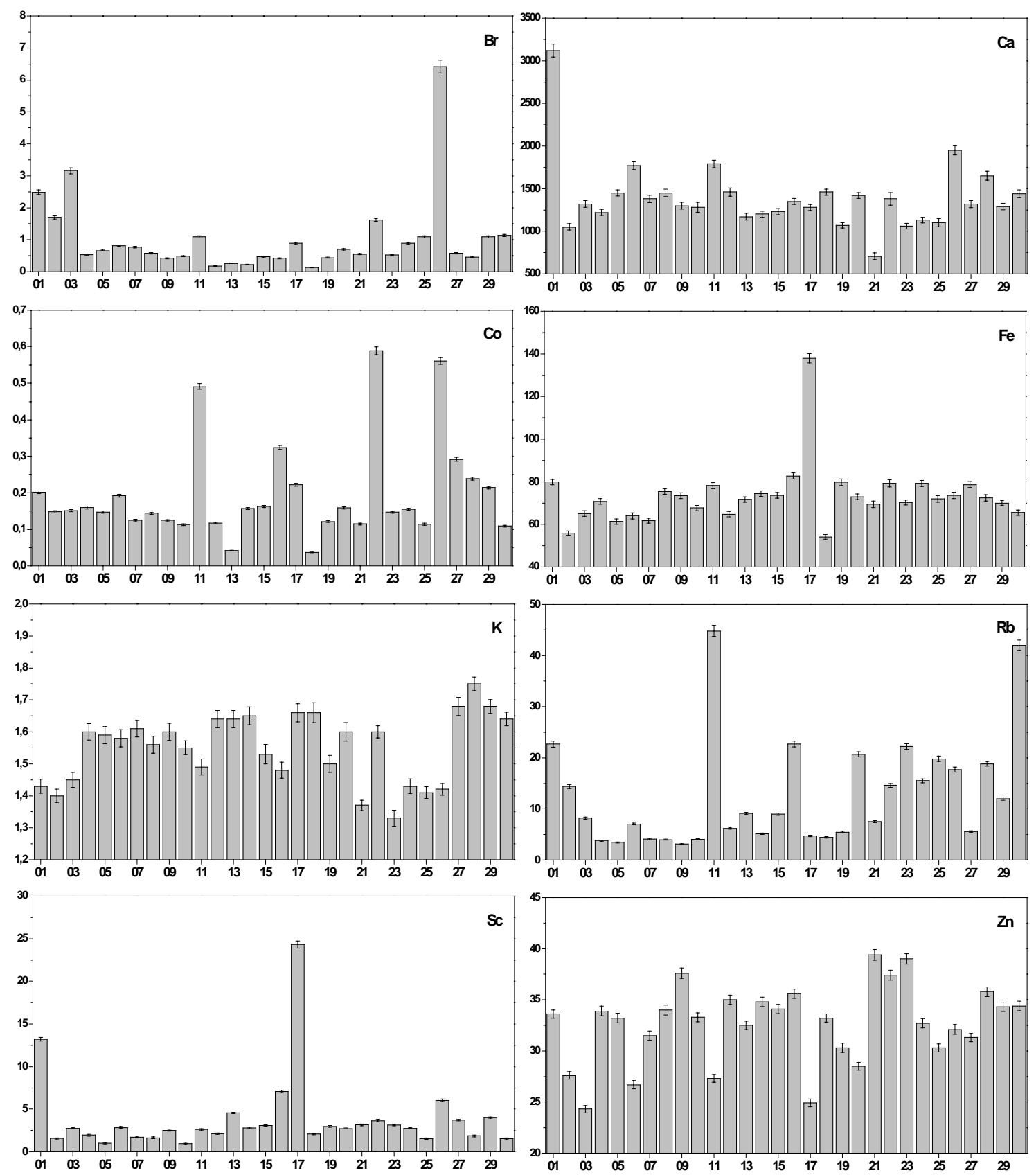

Figura 16 - Resultados individuais para os oito elementos químicos que foram determinados em todas as amostras de feijão. Barras de erros representam as incertezas combinadas dos valores obtidos, que estão expressos em $\mathrm{mg} \mathrm{kg}{ }^{-1}$, exceto Sc em $\mu \mathrm{g} \mathrm{kg}^{-1}$ e K em \% 
Para a amostra feijão-17 (carioca, Marcon), nota-se que as concentrações de Fe e Sc são muito superiores. Esses valores indicam ocorrência de contaminação com terra, pelas razões já discutidas anteriormente para amostras de batata. Também para o feijão-01 (adzuki, Super Grão) o teor de Sc aponta a presença de terra. Cabe lembrar que as amostras de grão não foram lavadas antes da análise, sendo portanto normal que se encontre alguma quantidade de impurezas. Além disso, é importante considerar que Sc é um traçador muito sensível, podendo apontar claramente a presença de terra em situações em que uma inspeção visual cuidadosa não notaria a contaminação.

Algumas amostras destacam-se pelas baixas concentrações apresentadas em relação às demais. O feijão-21 (fradinho, Camil) mostra baixa concentração de $\mathrm{Ca}, \mathrm{o}$ feijão-13 (carioca, Camil) tem pouco $\mathrm{Co}$, enquanto o feijão-18 é mais pobre principalmente em Co e Fe. Assim como para as concentrações elevadas, também não se conseguiu qualquer associação entre as concentrações baixas e o tipo de feijão.

\subsubsection{Outros grãos}

Os resultados obtidos na análise de ervilha, grão-de-bico e lentilha foram reunidos em um único conjunto de gráficos (Figura 17). Nove elementos $(\mathrm{Br}, \mathrm{Ca}, \mathrm{Co}$, $\mathrm{Fe}, \mathrm{K}, \mathrm{Na}, \mathrm{Rb}, \mathrm{Se}$ e $\mathrm{Zn}$ ) foram determinados em todas as amostras desse grupo. Percebe-se claramente que as amostras de lentilha separam-se das demais principalmente pelas concentrações de $\mathrm{Fe}, \mathrm{Na}$ e Se. As ervilhas destacam-se do grupo sobretudo pelas menores concentrações de $\mathrm{Br}$, enquanto as amostras de grão-de-bico podem ser facilmente segregadas, mormente pelos resultados mais elevados para $\mathrm{Br}, \mathrm{Ca}$ e Na. Em síntese, seria possível separar perfeitamente os três grãos apenas pela observação de $\mathrm{Na}$ e Se.

A variação da composição química dentro de cada produto não foi muito grande, conforme pode-se inclusive observar pelos baixos desvios padrões relativos apresentados na Tabela 12 para $\mathrm{Ca}, \mathrm{Co}, \mathrm{Fe}, \mathrm{K}$, Se e Zn em grão-de-bico e lentilha. As maiores dispersões entre os elementos apresentados na Figura 17 foram observadas para $\mathrm{Br}$ e $\mathrm{Na}$. Em grão-de-bico, por exemplo, o maior valor de $\mathrm{Br}$ foi cerca de três vezes superior ao menor. Principalmente no caso da ervilha, há de se considerar a restrição da amostragem realizada, que não permite avaliar a variabilidade da composição. 

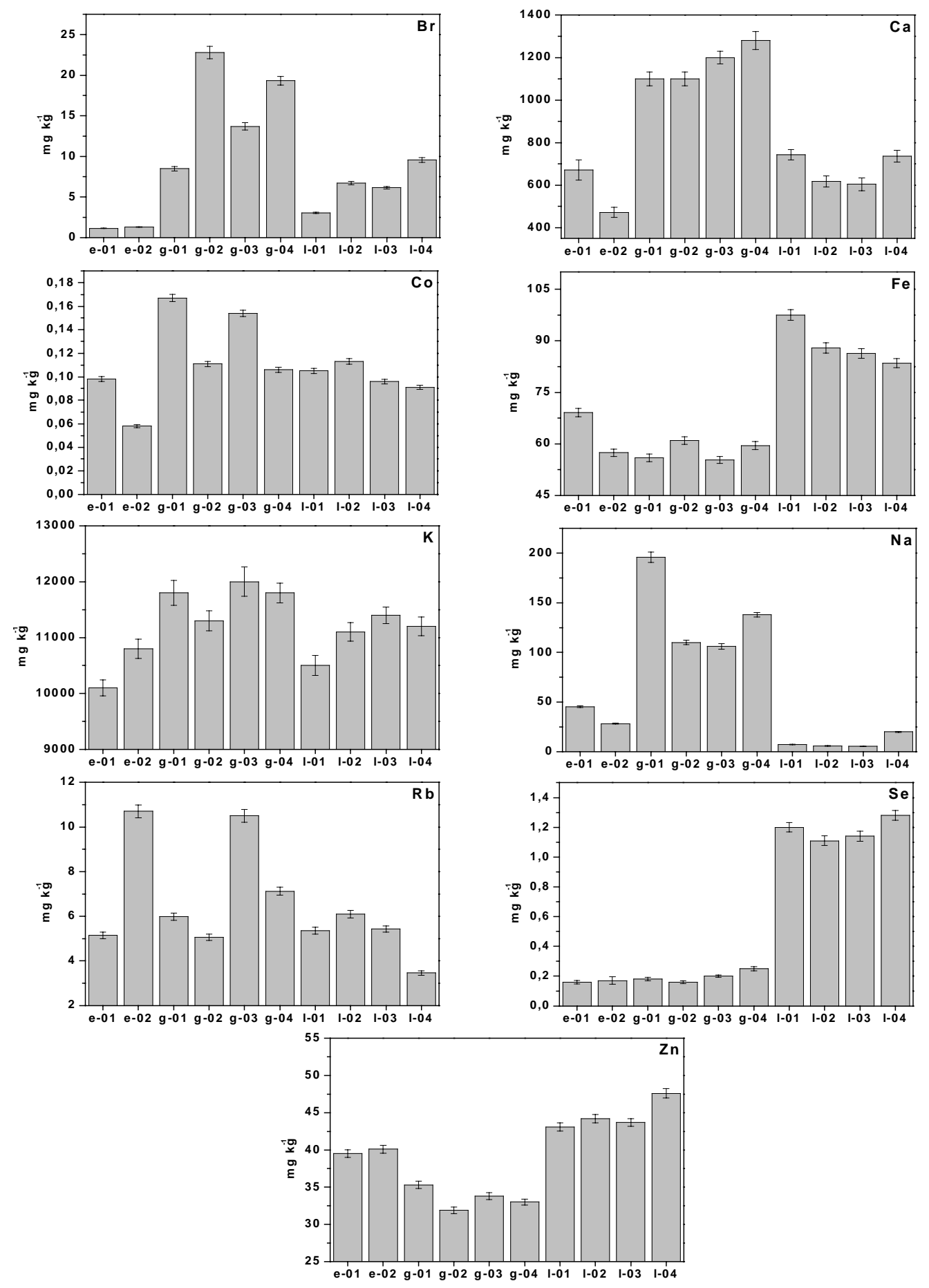

Figura 17 - Resultados individuais para os nove elementos químicos que foram determinados em todas as amostras de ervilha (e), grão-de-bico (g) e lentilha (l). Barras de erros representam as incertezas combinadas dos valores obtidos 


\subsection{Limites de detecção}

Os limites de detecção para os quinze elementos avaliados estão listados na Tabela 13, onde se encontra o valor médio para cada produto agrícola analisado. Pode-se afirmar que, em geral, as médias são representativas dos limites obtidos individualmente para cada amostra, pois a maior parte dos coeficientes de variação (66 em 90) se situa abaixo de 30 \%. A composição química provavelmente contribui para as variações nos limites de detecção, mas há que se considerar as diferenças ocorridas no procedimento experimental, principalmente para produtos em que os resultados provêm de dois lotes analíticos. Uma avaliação mais detalhada dos coeficientes de variação, mostra que valores abaixo de 20 \% são mais freqüentes para batata, cujos resultados foram obtidos em um único lote, e para ervilha, cujos resultados se originam de apenas duas amostras. No outro extremo, os coeficientes de variação tendem a ser mais elevados para arroz e feijão, onde várias amostras de diversos tipos foram analisadas, proporcionando uma maior diversidade na composição química. Além disso, as amostras de arroz e feijão foram divididas em dois lotes analíticos (Lote 2 e Lote 3), em que as condições de determinação foram diferentes, principalmente para as duas primeiras medições de radioatividade (vide item 4.3 .3 ).

Comparando-se os diferentes produtos, percebe-se que os menores limites de detecção foram, normalmente, obtidos para arroz. Essa maior sensibilidade, notada especialmente para elementos determinados na primeira e segunda medições, parece se explicar pela composição química do arroz, que apresenta concentrações de K pelo menos uma ordem de grandeza mais baixas do que as outras amostras avaliadas (vide Tabela 12). Da mesma forma, as maiores concentrações de $\mathrm{Br}$ e $\mathrm{Na}$ no grão-de-bico, e de $\mathrm{K}$ na batata, parecem ser as principais responsáveis pelos limites de detecção mais elevados para elementos como As, $\mathrm{Br}, \mathrm{Cd}$ e La, além de $\mathrm{K}$ e Na. A presença de $\mathrm{Br}, \mathrm{Na}$ e K são fatores conhecidos como diminuidores da sensibilidade analítica em INAA, pela formação de radionuclídeos $\left({ }^{82} \mathrm{Br},{ }^{24} \mathrm{Na} \mathrm{e}{ }^{42} \mathrm{~K}\right)$ emissores de raios gama que contribuem significativamente para a elevação da região Compton. 
Tabela 13. Limites de detecção médios e respectivos coeficientes de variação, para cada tipo de amostra analisada, calculados a partir de espectros com e sem supressão. Médias expressas em $\mu \mathrm{g} \mathrm{kg}^{-1}$, exceto $\mathrm{Ca}$, $\mathrm{Fe}$ e $\mathrm{K} \mathrm{em} \mathrm{mg} \mathrm{kg}{ }^{-1}$

\begin{tabular}{|c|c|c|c|c|c|c|}
\hline & $\begin{array}{c}\text { Arroz } \\
\mathrm{n}=9\end{array}$ & $\begin{array}{c}\text { Batata } \\
n=8\end{array}$ & $\begin{array}{c}\text { Ervilha } \\
\mathrm{n}=2\end{array}$ & $\begin{array}{c}\text { Feijão } \\
\mathrm{n}=30\end{array}$ & $\begin{array}{c}\text { Grão-de-bico } \\
n=4\end{array}$ & $\begin{array}{c}\text { Lentilha } \\
\mathrm{n}=4\end{array}$ \\
\hline As & $\begin{array}{l}13 \\
38\end{array}$ & $\begin{array}{l}58 \\
15\end{array}$ & $\begin{array}{l}29 \\
17\end{array}$ & $\begin{array}{l}25 \\
25\end{array}$ & $\begin{array}{c}140 \\
49\end{array}$ & $\begin{array}{l}29 \\
20\end{array}$ \\
\hline $\mathrm{Br}$ & $\begin{array}{l}12 \\
28\end{array}$ & $\begin{array}{l}52 \\
22\end{array}$ & $\begin{array}{c}21 \\
9\end{array}$ & $\begin{array}{l}20 \\
21\end{array}$ & $\begin{array}{l}81 \\
32\end{array}$ & $\begin{array}{l}26 \\
24\end{array}$ \\
\hline $\mathrm{Cd}$ & $\begin{array}{c}110 \\
38\end{array}$ & $\begin{array}{c}520 \\
13\end{array}$ & $\begin{array}{c}220 \\
7\end{array}$ & $\begin{array}{c}220 \\
17\end{array}$ & $\begin{array}{c}400 \\
24\end{array}$ & $\begin{array}{c}200 \\
9\end{array}$ \\
\hline Co & $\begin{array}{l}2,8 \\
60\end{array}$ & $\begin{array}{c}2,4 \\
19\end{array}$ & $\begin{array}{c}2,4 \\
21\end{array}$ & $\begin{array}{c}3,3 \\
32\end{array}$ & $\begin{array}{c}2,8 \\
12\end{array}$ & $\begin{array}{c}2,4 \\
33\end{array}$ \\
\hline $\mathrm{Cr}$ & $\begin{array}{l}48 \\
21\end{array}$ & $\begin{array}{c}56 \\
9\end{array}$ & $\begin{array}{l}68 \\
24\end{array}$ & $\begin{array}{l}85 \\
23\end{array}$ & $\begin{array}{l}50 \\
30\end{array}$ & $\begin{array}{c}80 \\
8\end{array}$ \\
\hline $\mathrm{Hg}$ & $\begin{array}{l}13 \\
41\end{array}$ & $\begin{array}{l}17 \\
19\end{array}$ & $\begin{array}{c}19 \\
9\end{array}$ & $\begin{array}{l}24 \\
24\end{array}$ & $\begin{array}{l}20 \\
13\end{array}$ & $\begin{array}{l}22 \\
30\end{array}$ \\
\hline $\mathrm{La}$ & $\begin{array}{l}1,8 \\
42\end{array}$ & $\begin{array}{l}11 \\
12\end{array}$ & $\begin{array}{c}2,0 \\
19\end{array}$ & $\begin{array}{c}2,4 \\
28\end{array}$ & $\begin{array}{c}6,2 \\
33\end{array}$ & $\begin{array}{l}2,1 \\
25\end{array}$ \\
\hline $\mathrm{Na}$ & $\begin{array}{l}66 \\
28\end{array}$ & $\begin{array}{c}720 \\
18\end{array}$ & $\begin{array}{c}320 \\
8\end{array}$ & $\begin{array}{c}320 \\
29\end{array}$ & $\begin{array}{c}480 \\
6\end{array}$ & $\begin{array}{c}370 \\
10\end{array}$ \\
\hline $\mathrm{Rb}$ & $\begin{array}{l}63 \\
13\end{array}$ & $\begin{array}{c}102 \\
15\end{array}$ & $\begin{array}{l}82 \\
10\end{array}$ & $\begin{array}{l}95 \\
19\end{array}$ & $\begin{array}{l}56 \\
32\end{array}$ & $\begin{array}{c}87 \\
6\end{array}$ \\
\hline $\mathrm{Sc}$ & $\begin{array}{c}0,23 \\
44\end{array}$ & $\begin{array}{c}0,24 \\
33\end{array}$ & $\begin{array}{c}0,23 \\
16\end{array}$ & $\begin{array}{c}0,32 \\
26\end{array}$ & $\begin{array}{c}0,21 \\
32\end{array}$ & $\begin{array}{c}0,31 \\
14\end{array}$ \\
\hline $\mathrm{Se}$ & $\begin{array}{l}44 \\
43\end{array}$ & $\begin{array}{l}44 \\
30\end{array}$ & $\begin{array}{c}71 \\
4\end{array}$ & $\begin{array}{l}76 \\
27\end{array}$ & $\begin{array}{l}66 \\
14\end{array}$ & $\begin{array}{l}63 \\
35\end{array}$ \\
\hline $\mathrm{Zn}$ & $\begin{array}{l}68 \\
49\end{array}$ & $\begin{array}{l}87 \\
27\end{array}$ & $\begin{array}{l}96 \\
13\end{array}$ & $\begin{array}{c}110 \\
25\end{array}$ & $\begin{array}{c}110 \\
5\end{array}$ & $\begin{array}{c}110 \\
30\end{array}$ \\
\hline $\mathrm{Ca}$ & $\begin{array}{l}74 \\
48\end{array}$ & $\begin{array}{c}570 \\
16\end{array}$ & $\begin{array}{c}100 \\
63\end{array}$ & $\begin{array}{c}140 \\
49\end{array}$ & $\begin{array}{l}85 \\
23\end{array}$ & $\begin{array}{l}62 \\
18\end{array}$ \\
\hline $\mathrm{Fe}$ & $\begin{array}{c}1,2 \\
19\end{array}$ & $\begin{array}{c}1,6 \\
14\end{array}$ & $\begin{array}{l}1,5 \\
17\end{array}$ & $\begin{array}{l}1,8 \\
20\end{array}$ & $\begin{array}{l}1,1 \\
31\end{array}$ & $\begin{array}{l}1,7 \\
10\end{array}$ \\
\hline $\mathrm{K}$ & $\begin{array}{l}4,7 \\
37\end{array}$ & $\begin{array}{l}67 \\
18\end{array}$ & $\begin{array}{l}26 \\
36\end{array}$ & $\begin{array}{l}25 \\
39\end{array}$ & $\begin{array}{l}40 \\
21\end{array}$ & $\begin{array}{l}38 \\
26\end{array}$ \\
\hline
\end{tabular}


Os limites de detecção conseguidos para As situam-se consideravelmente abaixo dos níveis máximos de contaminantes fixados para alguns alimentos pelo Ministério da Saúde, por meio da Portaria 685 (27/08/1998). Para cereais é estabelecido um valor máximo de $1,0 \mathrm{mg} \mathrm{kg}^{-1}$ para As, enquanto o mais elevado limite de detecção, encontrado para grão-de-bico, foi $0,14 \mathrm{mg} \mathrm{kg}^{-1}$. Embora a Portaria contenha limites de $\mathrm{Cd}$ e $\mathrm{Hg}$ apenas para produtos da pesca, também para esses elementos os limites se apresentaram abaixo do valor fixado $\left(1,0 \mathrm{mg} \mathrm{kg}^{-1}\right)$, uma vez que os piores limites de detecção foram respectivamente 0,52 e 0,02. Deve-se salientar que a Portaria trata de valores medidos em base úmida, enquanto os limites de detecção foram calculados em massa seca.

\subsection{Influência da supressão no limite de detecção}

A razão entre os limites de detecção calculados para espectros sem e com supressão foi o parâmetro adotado para avaliar o desempenho do sistema anti-Compton na análise das amostras. Pela observação das razões plotadas na Figura 18, fica claro que para $\mathrm{Br}, \mathrm{Co}, \mathrm{La}, \mathrm{Sc}$ e Se a utilização do sistema supressor não leva a qualquer vantagem, pois todas as razões encontradas são significativamente menores do que 1,0. Assim, esses elementos devem ser determinados a partir dos espectros sem supressão.

O baixo desempenho do supressor na determinação de Br, Co, La, Sc e Se é justificado, uma vez que os radionuclídeos medidos na quantificação desses elementos emitem raios gama em cascata no seu decaimento radioativo. Por essa razão, há acentuada perda de contagem nos fotopicos correspondentes por ocorrência de coincidência verdadeira, sobrepondo-se ao efeito benéfico da minimização da região Compton. A proporção de perda de contagem no fotopico depende do esquema de decaimento do radionuclídeo e do posicionamento da amostra em relação ao detector.

O uso de supressão também não apresenta vantagem clara para a determinação de $\mathrm{Na}$, mesmo que em alguns casos a razão tenha sido um pouco superior a 1,0. A detecção do radionuclídeo ${ }^{24} \mathrm{Na}$ está sujeita a efeitos de coincidência verdadeira, porém o problema é menor. Além disso, o radionuclídeo foi determinado na primeira medição, realizada à grande distância do detector. 

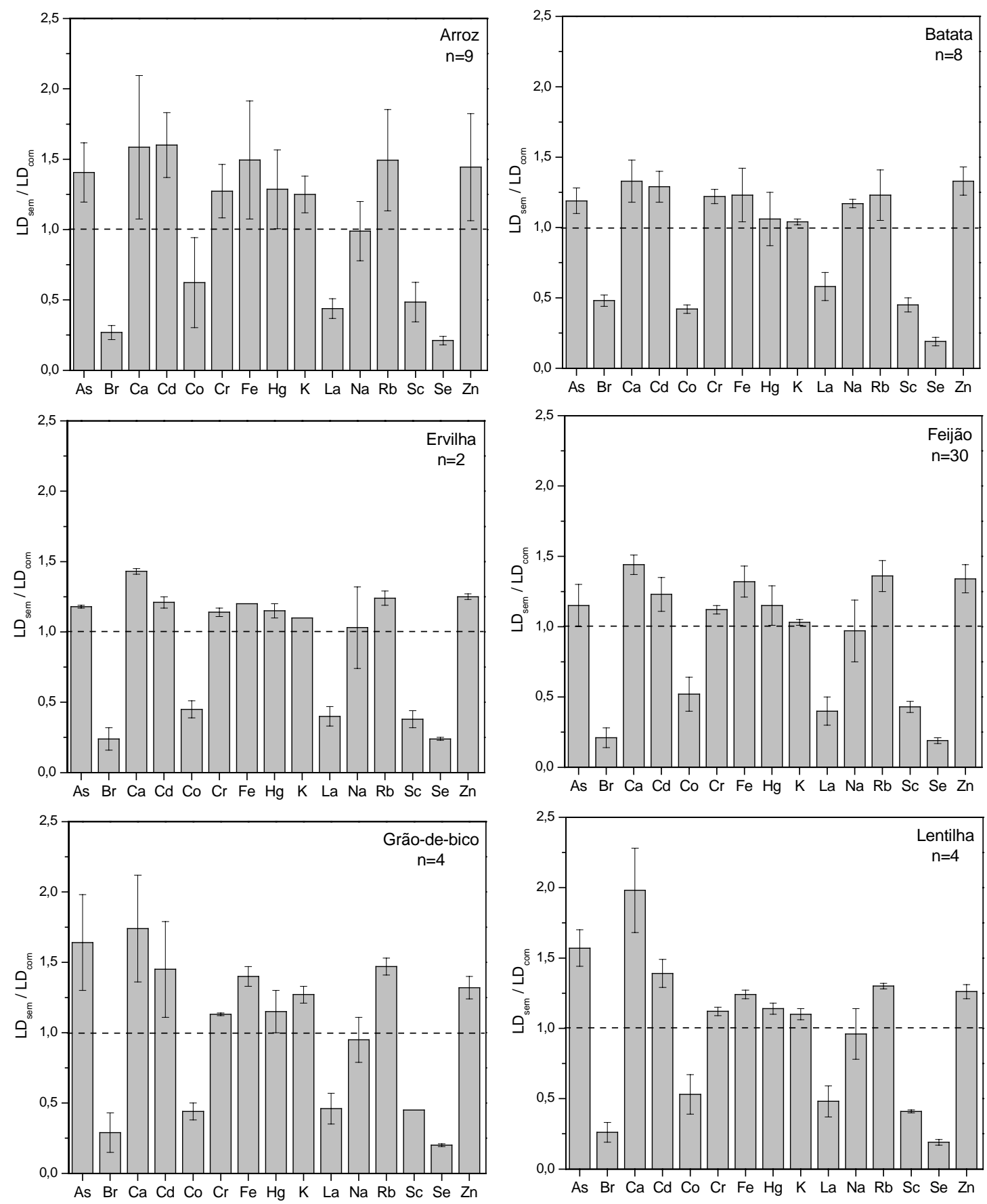

Figura 18 - Razão entre os limites de detecção calculados a partir de espectros sem e com supressão para os produtos agrícolas analisados. Valores representam média de várias amostras e barras de erros são os respectivos desvios padrões 
Para As, $\mathrm{Ca}, \mathrm{Cd}, \mathrm{Cr}, \mathrm{Fe}, \mathrm{Hg}, \mathrm{K}, \mathrm{Rb}$ e $\mathrm{Zn}$, as razões entre os limites de detecção sem e com supressão se mostraram iguais ou superiores a 1,0. Esse comportamento, a princípio, indica o uso de supressor Compton para a determinação desses nove elementos. Porém, o ganho real conseguido depende fortemente do material analisado e das condições experimentais empregadas. Na maioria dos casos, a razão ficou abaixo de 1,5, mas foram encontrados valores médios de até 1,98 (para $\mathrm{Ca}$ em lentilha). A maior freqüência de médias elevadas ocorre para arroz e grão-de-bico, que também apresentaram os maiores desvios padrões, demonstrando maior variabilidade entre as amostras tomadas para representar esses dois produtos.

Ainda pela observação da Figura 18, evidencia-se que o desempenho do supressor na redução dos limites de detecção para $\mathrm{Cr}$ e $\mathrm{Hg}$ foi quase sempre inferior ao conseguido para $\mathrm{Cd}$, embora os três elementos tenham sido quantificados por radiações gama de energias muito próximas. Ocorre que ${ }^{115} \mathrm{Cd}$ tem meia-vida bem mais curta, sendo determinado principalmente na segunda medição, quando a influência de elementos como $\mathrm{Br}, \mathrm{K}$ e $\mathrm{Na}$ pode ser bastante reduzida pelo supressor. Por sua vez, nas terceira e quarta contagens, quando foram determinados $\mathrm{Cr}$ e $\mathrm{Hg}$, os principais elementos gerando emissão de radiação em altas energias eram Co e Zn, cujas atividades de ${ }^{60} \mathrm{Co}$ e ${ }^{65} \mathrm{Zn}$ eram geralmente bem mais baixas.

Outro fator que colaborou para o fraco desempenho do supressor na determinação de $\mathrm{Cr}$ e $\mathrm{Hg}$ foi a intensa contribuição de radiação de freamento nas regiões de mais baixa energia dos espectros, sobretudo na terceira e quarta contagens. Esse fato fica evidente pelo melhor desempenho apresentado pelo supressor para elementos determinados a partir de raios gama com energias mais elevadas, como $\mathrm{Fe}, \mathrm{Rb}$ e $\mathrm{Zn}$. Dentre os emissores beta em alta energia, ${ }^{32} \mathrm{P}$ é o mais provável causador dessa contribuição indesejada, a partir da ativação do ${ }^{31} \mathrm{P}$.

A individualização dos resultados obtidos para duas amostras de arroz analisadas no mesmo lote (Figura 19) demonstra que o supressor apresentou consideráveis variações de desempenho na análise desse produto. Os limites de detecção são semelhantes para $\mathrm{As}, \mathrm{Br}$, La e Se, porém grandes diferenças são encontradas sobretudo para Fe, Rb e Zn. O arroz-09 apresenta concentração de Co cerca de cinco 
vezes superior ao arroz- 05 , dessa forma o bom desempenho do supressor se justifica pela redução da interferência da radiação Compton do ${ }^{60} \mathrm{Co}$ durante a terceira e quarta medições de radioatividade, quando $\mathrm{Fe}, \mathrm{Rb}$ e $\mathrm{Zn}$ foram quantificados.

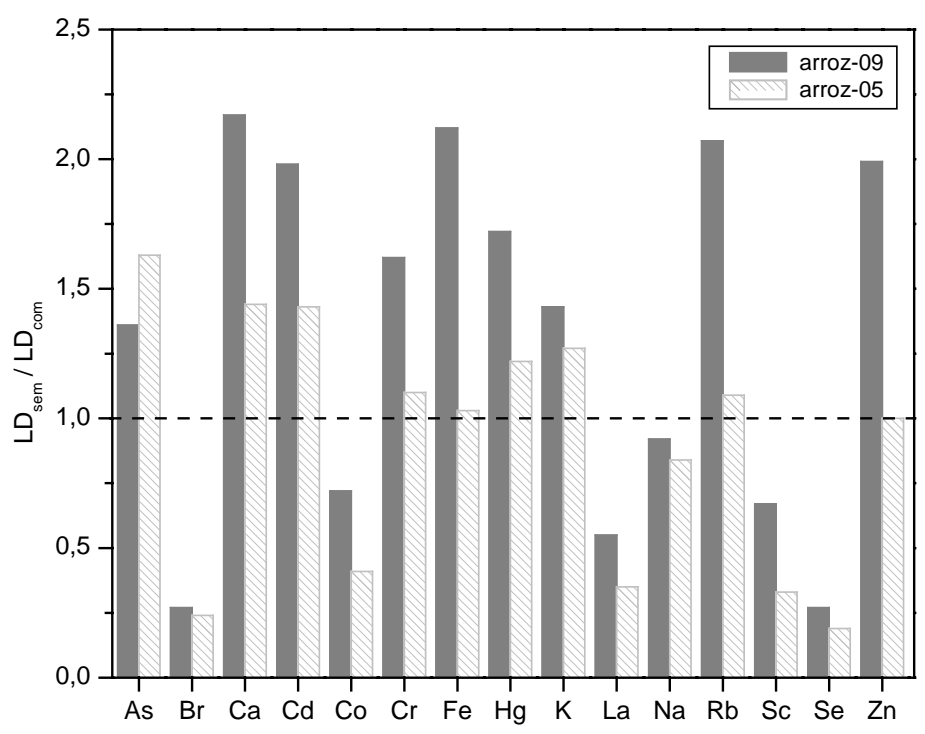

Figura 19 - Razão entre os limites de detecção calculados a partir de espectros sem e com supressão para duas amostras de arroz, em que o desempenho do supressor se mostra diferente

Em contraposição ao comportamento notado para as duas amostras de arroz, observa-se na Figura 20 que os limites de deteç̧ão para os elementos determinados na terceira e quarta medições não apresentam variação notável entre espectro com e sem supressão para as duas amostras de grão-de-bico. Por outro lado, para os elementos quantificados nas duas primeiras medições, o supressor conseguiu desempenho bem mais acentuado para a análise da amostra grão-de-bico-04, principalmente para determinação de $\mathrm{As}, \mathrm{Ca}$ e $\mathrm{Cd}$. É provavel que a concentração de $\mathrm{Br}$, duas vezes mais alta nessa amostra, justifique a diferença notada. Contudo, as duas amostras foram analisadas em lotes diferentes, portanto sob condições analíticas distintas, o que também contribui para um desempenho desigual. 


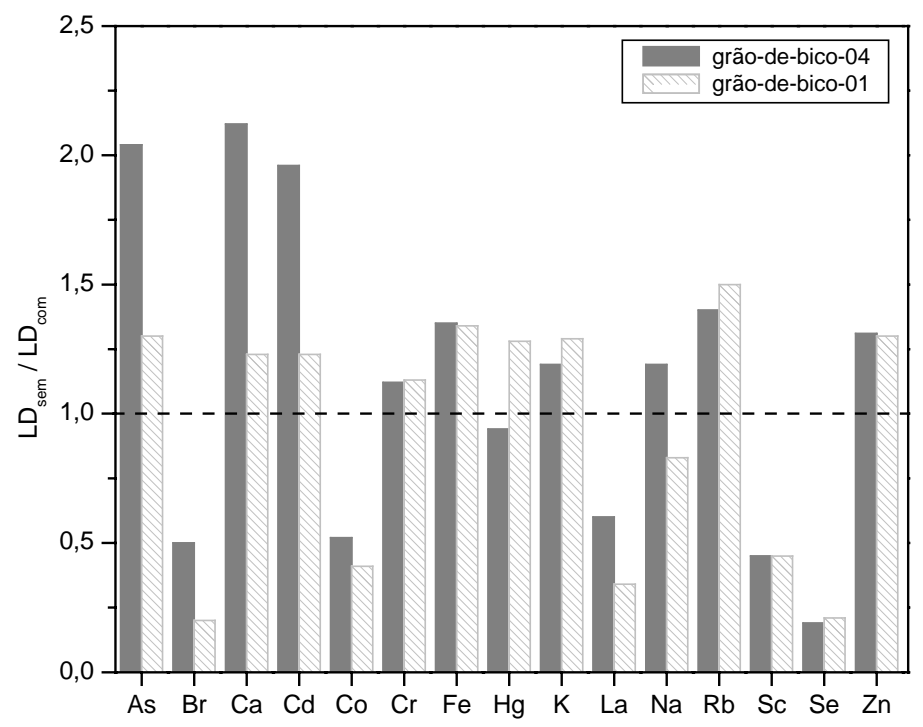

Figura 20 - Razão entre os limites de detecção calculados a partir de espectros sem e com supressão para duas amostras de grão-de-bico, em que o desempenho do supressor se mostra diferente

$\mathrm{Na}$ Figura 21, observa-se um melhor desempenho do supressor para a determinação de diversos elementos na amostra feijão-26 em comparação com o feijão-10. Esse comportamento é bem nítido para $\mathrm{As}$ e $\mathrm{Cd}$, determinados nas duas medições iniciais, e também para $\mathrm{Fe}, \mathrm{Rb}$ e $\mathrm{Zn}$, que foram quantificados na terceira e quarta medições. Considerando que nesse caso ambas as amostras foram analisadas em um mesmo lote, a única explicação para as diferenças parece ser as concentrações mais elevadas de $\mathrm{Br}$ (treze vezes) e Co (cinco vezes) no feijão-26. A interpretação das Figuras 19, 20 e 21 demonstra claramente que a composição química das amostras é muito importante para o desempenho da supressão Compton em INAA. Muitas vezes, mesmo um elemento presente em concentrações baixas, como o Co, pode ocasionar grande acúmulo de contagens na região Compton, favorecendo a ação do supressor. 


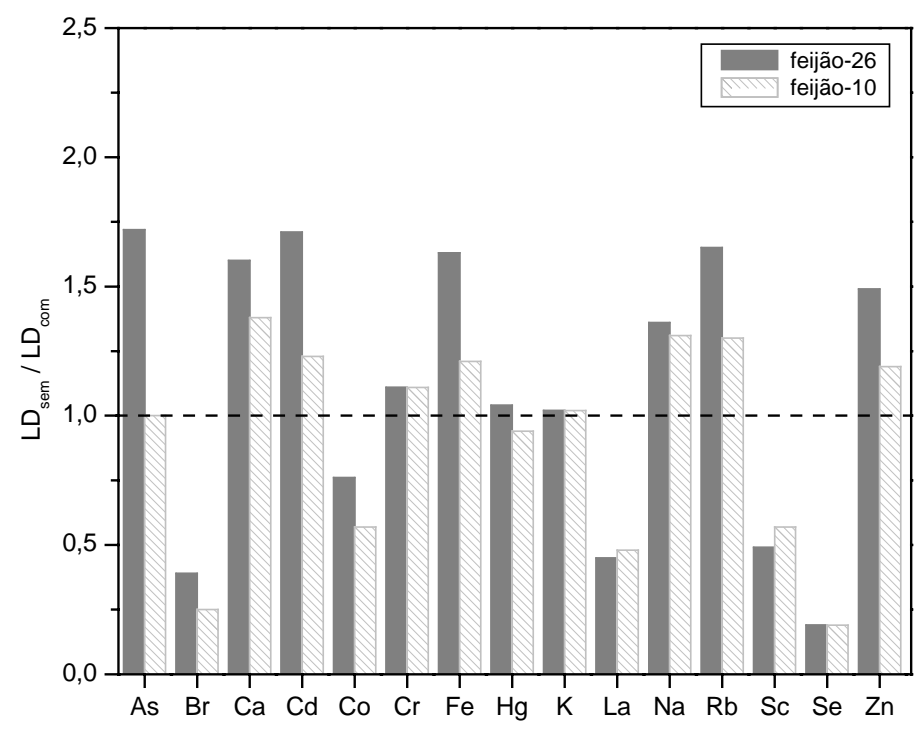

Figura 21 - Razão entre os limites de detecção calculados a partir de espectros sem e com supressão para duas amostras de feijão, em que o desempenho do supressor se mostra diferente

Pela observação do desempenho máximo e mínimo do supressor para a análise dos oito materiais de referência certificados (Figura 22), percebe-se a grande variação existente, que se deve principalmente às diferentes composições dos materiais. Para os elementos determinados por meio das duas primeiras medições, o melhor desempenho do supressor foi conseguido para os materiais Spinach Leaves (SRM1570a) e Tomato Leaves (SRM1573a), por conseqüência das elevadas concentrações de $\mathrm{Na}$ e $\mathrm{Br}$ respectivamente. Também para os elementos medidos na terceira e quarta contagens, o melhor desempenho foi, em geral, obtido para o material SRM1573a, pela influência da concentração mais elevada de Co.

As razões próximas a 4 , observadas para $\mathrm{Ca}$ e $\mathrm{Cd}$, apontam que um fator de supressão de aproximadamente 15 foi conseguido na região dos fotopicos utilizados para a determinação desses elementos, ou seja, 1296 e $336 \mathrm{keV}$. Assim, percebe-se que apesar da avaliação de desempenho realizada com fonte de ${ }^{137} \mathrm{Cs}$ ter medido fatores de supressão iguais ou inferiores a 6, efeitos de supressão mais acentuados podem ser conseguidos, dependendo, entre outros fatores, das energias do raio gama medido e dos raios gamas interferentes, que interagem por espalhamento Compton. 


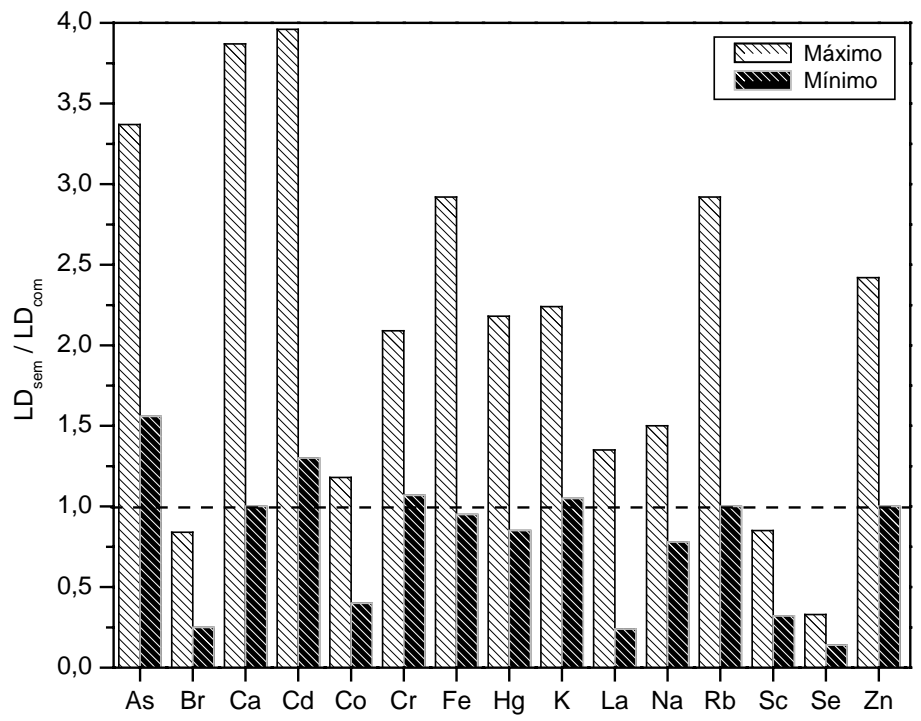

Figura 22 - Valores máximos e mínimos da razão entre os limites de detecção calculados a partir de espectros sem e com supressão para os oito materiais de referência certificados que foram analisados 


\section{CONCLUSÕES}

O desempenho do supressor Compton mostrou-se compatível com dados relatados em literatura para outros equipamentos similares. O fator de supressão para ${ }^{137} \mathrm{Cs}$ na região entre 358 e $382 \mathrm{keV}$ alcançou 5,97 no arranjo fonte-detector mais favorável, o que corresponde a uma razão pico-Compton de 795 no espectro com supressão. Para fonte colocada diretamente sobre o detector principal, o não uso do detector plug diminuiu o fator de supressão em $10 \%$. Em verificações periódicas realizadas durante vinte semanas, o equipamento demonstrou perfeita estabilidade quanto ao fator de supressão medido. Notou-se grande variação entre fatores de supressão calculados para diferentes energias da região Compton do ${ }^{137} \mathrm{Cs}$, com máximo em $450 \mathrm{keV}$. Os fatores de supressão medidos para ${ }^{137} \mathrm{Cs}$ e ${ }^{60} \mathrm{Co}$ diminuíram com o distanciamento da fonte em relação ao conjunto de detectores e com o aumento da taxa de contagem, situação em que a ocorrência de coincidência ocasional reduziu o número de eventos acumulados nos fotopicos. Os testes realizados evidenciaram a necessidade de definição da faixa de energia tomada e das condições experimentais adotadas para garantir a comparabilidade dos resultados obtidos.

Dos quinze elementos químicos estudados, apenas cinco foram determinados em todas as amostras, ou seja, Br, Co, K, Rb e Zn . Quatro elementos (Ca, Fe, Na e Sc) também puderam ser quantificados na maioria das amostras. Outros quatro (As, Cr, La e Se) normalmente se apresentaram abaixo do limite de deteçãa alcançado, enquanto Cd e Hg estiveram abaixo do limite de detecção em todas as amostras.

Diferenças na composição química foram encontradas entre os tipos de produtos analisados, sendo que alguns elementos (como $\mathrm{Rb}$ e $\mathrm{Zn}$ ) apresentaram pequenas variações, enquanto outros (como Br, Na e Sc) foram bastante variáveis. A presença de 
alguns elementos se mostrou característica de determinados grupos de amostras. Apenas em arroz foi possível determinar As, o que significa valores cerca de uma ordem de grandeza maior do que nos outros produtos. A concentração média de As em arroz (0,3 $\left.\mathrm{mg} \mathrm{kg}^{-1}\right)$ ficou relativamente próxima ao nível máximo estabelecido pela legislação brasileira (1,0 mg kg-1), embora nenhuma amostra o tenha excedido. Outros exemplos notórios de composição química característica foram os resultados bem mais elevados de Br e Na em grão-de-bico, e de Se em lentilha.

A contaminação superficial com terra foi evidenciada em duas amostras de feijão e nas amostras de casca de batata, devido à concentração mais alta de Sc. A boa correlação existente entre Fe e Sc nessas amostras ratificou a provável presença de terra. No caso da batata, percebe-se que o procedimento de lavagem utilizado não foi completamente eficiente, enquanto as amostras de feijão, assim como todos os grãos, realmente não foram lavados durante a preparação para análise.

Foram notadas diferenças na composição química elementar também entre amostras de um mesmo produto. As amostras de arroz integral, parboilizado e polido diferenciaram-se facilmente pelos resultados de $\mathrm{K}, \mathrm{Rb}$ e $\mathrm{Zn}$. Por sua vez, as cascas de batata apresentaram valores bem mais elevados para esses três elementos em comparação com a polpa. Outras diferenças foram encontradas dentro de cada grupo de produto estudado, entretanto não foi possível atribuí-las definitivamente a fatores como tipo, marca comercial ou procedência.

Houve grande influência de $\mathrm{Br}, \mathrm{K}$ e $\mathrm{Na}$ sobre os limites de detecção para elementos determinados na primeira e segunda medições, realizadas entre 3 e 8 dias após a irradiação. As amostras de arroz, que tiveram concentrações de K cerca de uma ordem de grandeza abaixo das demais, apresentaram os melhores limites de detecção para As, Br, Ca, Cd, K, La e Na. Por outro lado, a elevada concentração de Br e Na no grão-de-bico e K na batata prejudicou a sensibilidade para determinação desse mesmo grupo de elementos.

A razão entre os limites de detecção sem e com supressão mostrou claramente que a sensiblidade para determinação de Br, Co, La, Sc e Se não foi beneficiada pelo uso do supressor Compton, pois todos os valores calculados para esses elementos foram 
menores do que 1,0, enquanto para Na foi notada uma pequena melhora no limite de deteç̧ão. Na realidade, o fraco desempenho se deve à perda de contagens nos fotopicos correspondentes pela ocorrência de coincidência entre raios gama emitidos em cascata que chegam simultaneamente ao detector principal e a um detector secundário.

Por outro lado, as razões foram maiores do que 1,0 para As, Ca, Cd, Cr, Fe, Hg, $\mathrm{K}$, Rb e Zn, demonstrando a ação positiva do supressor Compton na determinação desses elementos. Observou-se, contudo, que o ganho real conseguido dependeu fortemente do material analisado e das condições experimentais empregadas. A maior redução média no limite de deteç̧ão foi encontrada para a determinação de Ca em lentilha (2,0), porém alguns valores foram encontrados entre 2,0 e 2,5 ao se tomarem amostras individuais. Percebeu-se, ainda, um grande acúmulo de contagens provenientes de interação de raios beta de alta energia (radiação de freamento) nas terceira e quarta medições, realizadas com tempos de decaimento entre 15 e 51 dias. Essa contribuição, provavelmente causada pelo ${ }^{32} \mathrm{P}$, prejudicou o desempenho do supressor nas regiões de mais baixa energia do espectro, o que foi especialmente notado para $\mathrm{Cr}$ e $\mathrm{Hg}$.

Confirmando que a composição química do material analisado influencia fortemente o desempenho do supressor Compton em INAA, reduções bem mais acentuadas nos limites de detecção foram conseguidas para alguns materiais de referência certificados. O máximo ganho de sensibilidade foi encontrado para Cd no SRM1573a (Tomato Leaves), onde a razão entre os limites de detecção foi 4,0. Nesse caso, o excelente desempenho do supressor se justifica pela alta concentração de $\mathrm{Br}$ no material $\left(1300 \mathrm{mg} \mathrm{kg}^{-1}\right)$. A maior redução conseguida $(4,0)$ equivale a um fator de supressão de aproximadamente 15, portanto bem mais elevado do que o medido com as fontes de ${ }^{137} \mathrm{Cs}$ e ${ }^{60} \mathrm{Co}$. Ainda para os materiais de referência certificados, ganhos acima de 3 foram atingidos também para os limites de detecção de As, Ca, Fe e Rb.

Os resultados aqui relatados corroboram a idéia de que o desempenho do supressor Compton na melhoria dos limites de detecção em INAA deve ser individualmente avaliado para cada tipo de amostra. Mesmo assim, considerando-se amostras de uma mesma composição matricial, diferenças na concentração de um único elemento químico podem ocasionar grande variação na supressão conseguida. 


\section{REFERÊNCIAS BIBLIOGRÁFICAS}

ALFASSI, Z.B. Chemical Analysis by Nuclear Methods, John Wiley \& Sons, Inc., 1994a, 556p.

ALFASSI, Z.B. Determination of Trace Elements, Balaban Publishers \& VCH., 1994b, 607p.

AMERICAN NATIONAL STANDARDS INSTITUTE - ANSI. IEEE Standard Test Procedures for Germanium Gamma-Ray Detectors, 1986. (ANSI/IEEE 325-1986).

BACCHI, M.A.; FERNANDES, E.A.N.; OLIVEIRA H. Brazilian experience on $\mathrm{k}_{0}$ standardized neutron activation analysis. Journal of Radioanalytical and Nuclear Chemistry, 245, 217-222, 2000a.

BACCHI, M.A.; FERNANDES, E.A.N.; FRANÇA, E.J. A semiempirical approach for the determination of HPGe detector photopeak efficiency aiming at $\mathrm{k}_{0}$-INAA. Journal of Radioanalytical and Nuclear Chemistry, 245, 209-215, 2000 b.

BACCHI, M.A.; FERNANDES, E.A.N. Quantu - design and development of a software package dedicated to $\mathrm{k}_{0}$-standardized NAA. Journal of Radioanalytical and Nuclear Chemistry, v.257, n.3, p.577-582, 2003. 
BODE, P. Detectors and detection limits in INAA: I. General theoretical relationships between detector specifications and detection limits. Journal of Radioanalytical and Nuclear Chemistry, v.222, n.1-2, p.117-125, 1997.

CARBONELL-BARRACHINA, A.A.; BURLO F.; LOPEZ E.; MARTINEZSANCHEZ F. Arsenic toxicity and accumulation in radish as affected by arsenic chemical speciation. Journal of Environmental Science and Health Part B Pesticides Food Contaminants and Agricultural Wastes, 34 (4), 661-667, 1999./Resumo.

CARPENTER, M.P.; KHOO, T.L.; AHMAD, I.; JANSSENS, R.V.F.; LAURITSEN,T.; ANNAN, G.A.; BAXTER, A.M.; BLEICH, M.E.; HARFENIST, S.; MOORE, E.F.; TORELLI, M.; VISSER, D.W. Test and performance of a BGO Compton-supression shield for gammasphere. Nuclear Instruments and Methods in Physics Research, v.A 353, p.234-238, 1994.

COOPER, J.A. Evaluation of $\mathrm{Ge}(\mathrm{Li})$ Compton suppression spectrometers for nondestructive radiochemical analysis. Journal of Radioanalytical Chemistry, v.6, p.177184, 1970.

COOPER, R.D.; BROWNELL, G.L. A large coaxial Ge(Li) detector with plastic anticoincidence scintillator for activation analysis. Nuclear Instruments Methods, v.51, p.72-76, 1967.

CORNETT, C.R.; SAMUDRALWAR, D.L.; EHMANN, W.D.; MARKESBERY, W.R. Sensitivity improvements in the determination of mercury in biological tissue by neutron-activation analysis. Journal of Radioanalytical and Nuclear ChemistryArticles, v.195, n.1, p.117-121, 1995.

CURRIE, L.A. Detection and quantification limits: origins and historical overview. Analytica Chimica Acta, v.391, p.127-134, 1999.

DE CORTE, F. The standardization of standardless NAA. Journal of Radioanalytical and Nuclear Chemistry, v.248, n.1, p.13-20, 2001. 
DEIBEL, M.A.; LANDSBERGER, S.; WU, D.; EHMANN, W.D. Non-destructive analysis of copper in human brain tissue by neutron activation analysis using coincidence and anti-coincidence techniques. Journal of Radioanalytical and Nuclear Chemistry, v.217, n.2, p.153-155, 1997.

D’LLIO, S.; ALESSANDRELLI, M.; CRESTI, R.; FORTE, G.; CAROLI, S. Arsenic content of various types of rice as determined by plasma-based techniques. Microchemical Journal, v.73, p.195-201, 2002.

EHMANN, W.D.; VANCE, D.E. Radiochemistry and Nuclear Methods of Analysis, John Wiley \& Sons, Inc., 1991, 531p.

EISBERG, R.; RESNICK, R. Física Quântica - Átomos, Moléculas, Sólidos, Núcleos e Partículas, Editora Campus, 1979, 928p.

EVANS, R.D. The Atomic Nucleus, McGraw-Hill, 1955, 972 p.

FERNANDES, E.A.N. Scandium as tracer in the sugar and alcohol agroindustry. Journal of Radioanalytical and Nuclear Chemistry, v.168, p.41-46, 1993.

FRANÇA, E.J.; FERNANDES, E.A.N.; BACCHI, M.A. Ni-Cr alloy as neutron flux monitor: composition and homogeneity assessment by NAA. Journal of Radioanalytical and Nuclear Chemistry-Articles, v.257, n.1, p.113-115, 2003.

FUKUDA, K; OHKUMA, J.; ASANO, T.; SATOH, Y. Performance of a Ge-BGO Compton-supression spectrometer and its application to photon activation analysis. Nuclear Instruments and Methods in Physics Research, v.B 114, p.379-386, 1996.

HARBOTTLE, G.; CUMMING, J.B. Performance and promise of the Compton suppression well counter. Nuclear Instruments and Methods in Physics Research, v.A 353, p.503-507, 1994.

HATSUKAWA, Y.; OSHIMA, M.; HAYAKAWA, T.; TOH, Y.; SHINOHARA, N. Application of multidimensional spectrum analysis for neutron activation analysis. Journal of Radioanalytical and Nuclear Chemistry, v.248, n.1, p.121-124, 2001. 
HATSUKAWA, Y.; OSHIMA, M.; HAYAKAWA, T.; TOH, Y.; SHINOHARA, N. Application of multiparameter coincidence spectrometry using a Ge detectors array to neutron activation analysis. Nuclear Instruments and Methods in Physics Research, v.A 482, p.328-333, 2002.

HIEN, D.S. Development of nuclear spectroscopy system using high resolution semicondutor detector. Nuclear Instruments and Methods in Physics Research, v.A 373, p.406-410, 1996.

INSTITUTO BRASILEIRO DE GEOGRAFIA E ESTATÍSTICA - IBGE. Levantamento Sistemático da Produção Agrícola. http://www.ibge.gov.br/home/estatistica/indicadores/agropecuaria/lspa/default.shtm (16 jan. 2004).

ISHIHARA, T.; KOBAYASHI, E.; OKUBO, Y.; SUWAZONO, Y.; KIDO, T.; NISHIJYO, M.; NAKAGAWA, H.; NOGAWA, K. Association between cadmium concentration in rice and mortality in the Jinzu River basin, Japan. Toxicology, 163 (1), 23-28, 2001./Resumo.

IYENGAR, G.V.; NAIR, P.P. Global outlook on nutrition and the environment: meeting the challenges of the next millennium. The Science of the Total Environment, v.249, p.331-346, 2000.

JAIN, C.K.; ALI, I. Arsenic: occurrence, toxicity and speciation techniques. Water Resources, v.34, n.17, p.4304-4312, 2000.

LAMONT, W. Concentration of inorganic arsenic in samples of white rice from the United States. Journal of Food and Analysis, v.16, p.687-695, 2003.

LANDSBERGER, S. Compton suppression neutron activation methods in environmental analysis. Journal of Radioanalytical and Nuclear ChemistryArticles, v.179, n.1, p.67-79, 1994.

LANDSBERGER, S.; LARSON, S. AND WU, D. Determination of airborne cadmium in environmental tabacco smoke by instrumental neutron activation analysis with a Compton suppression system. Analytical Chemistry, v.65, n.11, p.1506-1509, 1993. 
LANDSBERGER, S.; PESHEV, S.; BECKER, D.A. Determination of silicon in biological and botanical reference materials by epithermal INAA and Compton suppression. Nuclear Instruments and Methods in Physics Research, v.A353, p.601-605, 1994.

LANDSBERGER, S.; WU, D. An evaluation of thermal and epithermal neutron activation analysis Compton suppression methods for biological reference materials. Biological Trace Element Research, v.71-2, p. 453-461, 1999.

LANDSBERGER, S.; WU, D. The impact of heavy metals from environmental tobacco smoke on indoor air quality as determined by Compton suppression neutron activation analysis. The Science of the Total Environment, v.173-174, p.323-337, 1995.

LANDSBERGER, S.; BASUNIA, M.S.; ISKANDER F. Halogen determination in Artic aerosols by neutron activation analysis with Compton suppression methods. Journal of Radioanalytical and Nuclear Chemistry, v.249, n.2, p.303-305, 2001.

LEHNINGER, A.L. Princípios de bioquímica, Sarvier Editora de Livros Médicos Ltda., 1990, 725p.

LIN, X.; LIERSE, C.; WAHL, W. An innovative Compton suppression spectrometer and capability of evaluation in multi-elemental neutron activation analysis. Journal of Radioanalytical and Nuclear Chemistry, v.215, n.2, p.169-178, 1997.

MAUERHOFER, E. Improvement in the counting statistics and in the limit of detection with Compton suppression spectrometers - a contribution to instrumental neutron activation analysis. Applied Radiation and Isotopes, v. 47, n.7, p.649-658, 1996.

MAUERHOFER, E.; THARUN, U.; DENSCHLAG, H.O.; SCHMIDT, R.; KRATZ, J.V. A Compton suppression spectrometer for neutron activation analysis. Nuclear Instruments and Methods in Physics Research, v.A 371, p.465-471, 1996.

MEHARG, A.; RAHMAN, M. Arsenic contamination of Bangladesh paddy field soils: implications for rice contribution to arsenic consumption. Environmental Science and Technology, v.37, p.229-234, 2003. 
NRIAGU, J.O.; LIN, T.-S. Trace metals in wild rice sold in the United States. The Science of Total Environment, v.172, p.223-228, 1995.

PARRY, S.J. Activation Spectrometry in Chemical Analysis, John Wiley \& Sons, Inc., 1991, 243p.

PARUS, J.; KIERZEK, J.; RAAB, W.; DONOHUE, D. A dual purpose Compton suppression spectrometer. Journal of Radioanalytical and Nuclear Chemistry, v.258, n.1, p.123-132, 2003.

PETRA, M.; SWIFT, G.; LANDSBERGER, S. Design of Ge-NaI(Tl) Compton suppression spectrometer and its use in neutron-activation analysis. Nuclear Instruments and Methods Physics Research, v.A299, n.1-3, p.85-87, 1990.

PIZARRO, I.; GÓMEZ, M.; PALACIOS, M.A.; CÁMARA, C. Evaluation of stability of arsenic species in rice. Analytical and Bioanalytical Chemistry, v.376, n.1, p.102-109, 2003.

RIEDEL, T.; HENTIG, R.V.; FEILITZSCH, F.V. Anti-Compton spectrometer element studies. Applied Radiation and Isotopes, v.53, p.231-236, 2000.

ROSSBACH, M.; ZEISLER, R.; WOITTIEZ, J.R.W. The use of Compton suppression spectrometers for trace-element studies in biological materials. Biological Trace Element Research, v.26-27, p.63-73, 1990.

ROYCHOWDHURY, T.; UCHINO, T.; TOKUNAGA, H.; ANDO, M. Survey of arsenic in food composites from an arsenic-affected area of West Bengal, Índia. Food and Chemical Toxicology, v.40, p.1611-1621, 2002.

SATOH, Y.; FUKUDA, K.; OHKUMA, J.; ASANO, T.; TANIGUCHI, R.; FUJISHIRO, M. Multielement photon activation analysis of a bulk lanthanum sample by a Ge-BGO Compton suppression spectrometer. Applied Radiation and Isotopes, v.46, n.10, p.999-1002, 1995. 
SENESI, G.S.; BALDASSARRE, G.; SENESI, N.; RADINA, B.; Trace elements inputs into soils by anthropogenic activities and implication for human health. Chemosphere, v.39, n.2, p.343-377, 1999.

SERFOR-ARMAH, Y; NYARKO, B.J.B; HOLZBECHER, J.; AKAHO, E.H.K.; OSAE, E.K.; CHATT, A. Epithermal instrumental neutron activation analysis with Compton suppression spectrometry for the determination of iodine in food samples. Journal of Radioanalytical and Nuclear Chemistry, v.256, n.2, p.259-262, 2003.

SEVER, Y.; LIPPERT, J. A Compton-rejection germanium spectrometer. Nuclear Instruments \& Methods, v.33, n.2, p.347, 1965.

VOIGT, M.J.A.; BACELAR, J.C.; MICEK, S.L.; SCHOTANUS, P.; VERHOEF, B.A.W.; WINTRAECKEN, Y.J.E. VERMEULEN, P. A novel compact Ge-BGO Compton-supression spectrometer. Nuclear Instruments and Methods in Physics Research, v.A 356, p.362-375, 1995.

YONEZAWA, Ch; MATSUE, H.; YUKAWA, M. Non-destructive determination of trace amounts of iodine in biological samples by epithermal neutron activation and Compton suppression gamma-ray spectrometry. Journal of Radioanalytical and Nuclear Chemistry, v.255, n.1, p.105-109, 2003.

WAHL, W.; DEGERING, D.; LIERSE, C.; LIN, X. Enhancement of Compton suppression ratios in anti-Compton techniques: the Garching and Karlsruhe photon spectrometers. Nuclear Instruments and Methods in Physics Research, v.A 369, p. 627-633, 1996.

WAALKES, M.P. Cadmium carcinogenesis in review. Journal of Inorganic Biochemistry, v.79, p.241-244, 2000.

WESTPHAL, G.P. Real-time correction of chance coincidence losses in high-rate Compton suppression spectrometry. Nuclear Instruments and Methods in Physics Research, v.A416, p.536-538, 1998. 
WESTPHAL, G.P.; JÖSTL, K.; SCHRÖDER, P.; LAUSTER, R.; HAUSCH, E. Quantitative Compton suppression spectrometry at elevated counting rates. Nuclear Instruments and Methods in Physics Research, v.A422, p.347-351, 1999. 


\section{APÊNDICE 1}

Composição Química Elementar 


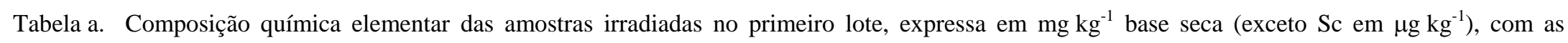
respectivas incertezas combinadas expressas em porcentagem

\begin{tabular}{|c|c|c|c|c|c|c|c|c|}
\hline & \multicolumn{8}{|c|}{ batata } \\
\hline & \multicolumn{2}{|c|}{ achat } & \multicolumn{2}{|c|}{ bintje } & \multicolumn{2}{|c|}{ slaney } & \multicolumn{2}{|c|}{ monalisa } \\
\hline & polpa & casca & polpa & casca & polpa & casca & polpa & casca \\
\hline As & $<0,050$ & $<0,073$ & $<0,050$ & $<0,064$ & $<0,051$ & $<0,067$ & $<0,054$ & $<0,058$ \\
\hline $\mathrm{Br}$ & $\begin{array}{c}1,11 \\
3,4\end{array}$ & $\begin{array}{c}3,73 \\
3,0\end{array}$ & $\begin{array}{c}1,72 \\
3,2\end{array}$ & $\begin{array}{c}3,88 \\
3,2\end{array}$ & $\begin{array}{c}0,81 \\
3,7\end{array}$ & $\begin{array}{c}2,88 \\
3,1\end{array}$ & $\begin{array}{c}1,41 \\
3,4\end{array}$ & $\begin{array}{c}2,62 \\
3,1\end{array}$ \\
\hline Ca & $\begin{array}{c}334 \\
14\end{array}$ & $\begin{array}{c}1150 \\
5,3\end{array}$ & $<503$ & $\begin{array}{c}596 \\
17\end{array}$ & $<517$ & $\begin{array}{c}945 \\
8,0\end{array}$ & $<548$ & $\begin{array}{c}646 \\
11\end{array}$ \\
\hline Cd & $<0,47$ & $<0,63$ & $<0,45$ & $<0,58$ & $<0,46$ & $<0,56$ & $<0,50$ & $<0,50$ \\
\hline Co & $\begin{array}{c}0,043 \\
2,9\end{array}$ & $\begin{array}{c}0,069 \\
2,6\end{array}$ & $\begin{array}{c}0,020 \\
3,5\end{array}$ & $\begin{array}{c}0,032 \\
3,7\end{array}$ & $\begin{array}{c}0,015 \\
4,6\end{array}$ & $\begin{array}{c}0,039 \\
3,2\end{array}$ & $\begin{array}{c}0,012 \\
5,1\end{array}$ & $\begin{array}{c}0,023 \\
3,0\end{array}$ \\
\hline $\mathrm{Cr}$ & $<0,55$ & $<0,70$ & $<0,52$ & $<0,66$ & $<0,59$ & $<0,65$ & $<0,60$ & $<0,50$ \\
\hline $\mathbf{F e}$ & $\begin{array}{c}27,8 \\
3,5\end{array}$ & $\begin{array}{c}139 \\
2,0\end{array}$ & $\begin{array}{c}26,1 \\
3,4\end{array}$ & $\begin{array}{c}150 \\
1,9\end{array}$ & $\begin{array}{c}23,0 \\
4,4\end{array}$ & $\begin{array}{c}199 \\
1,7\end{array}$ & $\begin{array}{c}26,0 \\
3,5\end{array}$ & $\begin{array}{c}69,0 \\
2,4\end{array}$ \\
\hline Hg & $<0,013$ & $<0,021$ & $<0,013$ & $<0,017$ & $<0,013$ & $<0,021$ & $<0,015$ & $<0,018$ \\
\hline $\mathbf{K}$ & $\begin{array}{c}23700 \\
1,4\end{array}$ & $\begin{array}{c}30000 \\
1,4\end{array}$ & $\begin{array}{c}24600 \\
1,6\end{array}$ & $\begin{array}{c}31200 \\
1,4\end{array}$ & $\begin{array}{c}21700 \\
1,5\end{array}$ & $\begin{array}{c}33500 \\
1,4\end{array}$ & $\begin{array}{c}20100 \\
1,6\end{array}$ & $\begin{array}{c}30800 \\
1,6\end{array}$ \\
\hline La & $<0,010$ & $\begin{array}{c}0,083 \\
5,4\end{array}$ & $<0,0098$ & $\begin{array}{c}0,067 \\
6,6\end{array}$ & $<0,011$ & $\begin{array}{c}0,098 \\
4,1\end{array}$ & $<0,011$ & $<0,0097$ \\
\hline $\mathrm{Na}$ & $\begin{array}{c}14,0 \\
4,0\end{array}$ & $\begin{array}{c}71,2 \\
2,4\end{array}$ & $\begin{array}{r}5,9 \\
8,3\end{array}$ & $\begin{array}{c}22,2 \\
3,2\end{array}$ & $\begin{array}{c}10,7 \\
5,2\end{array}$ & $\begin{array}{c}31,5 \\
2,5\end{array}$ & $\begin{array}{c}23,2 \\
3,1\end{array}$ & $\begin{array}{c}25,3 \\
2,9\end{array}$ \\
\hline $\mathbf{R b}$ & $\begin{array}{c}16,8 \\
2,8\end{array}$ & $\begin{array}{c}23,5 \\
2,8\end{array}$ & $\begin{array}{c}12,3 \\
2,8\end{array}$ & $\begin{array}{c}16,0 \\
2,8\end{array}$ & $\begin{array}{c}12,1 \\
2,9\end{array}$ & $\begin{array}{c}18,0 \\
2,8\end{array}$ & $\begin{array}{c}11,3 \\
2,8\end{array}$ & $\begin{array}{c}19,4 \\
2,7\end{array}$ \\
\hline Sc & $\begin{array}{c}1,57 \\
4,4\end{array}$ & $\begin{array}{c}36,1 \\
1,8\end{array}$ & $\begin{array}{c}1,68 \\
4,0\end{array}$ & $\begin{array}{c}39,6 \\
1,8\end{array}$ & $\begin{array}{c}1,25 \\
5,4\end{array}$ & $\begin{array}{c}55,7 \\
1,7\end{array}$ & $\begin{array}{c}0,97 \\
7,3\end{array}$ & $\begin{array}{c}16,8 \\
1,9\end{array}$ \\
\hline Se & $<0,030$ & $<0,056$ & $<0,032$ & $<0,051$ & $<0,031$ & $<0,051$ & $<0,038$ & $<0,048$ \\
\hline Zn & $\begin{array}{c}18,7 \\
2,8\end{array}$ & $\begin{array}{c}21,9 \\
2,9\end{array}$ & $\begin{array}{c}19,7 \\
2,5\end{array}$ & $\begin{array}{c}20,8 \\
2,9\end{array}$ & $\begin{array}{c}23,1 \\
2,4\end{array}$ & $\begin{array}{c}30,1 \\
2,2\end{array}$ & $\begin{array}{c}22,1 \\
2,6\end{array}$ & $\begin{array}{c}19,6 \\
2,5\end{array}$ \\
\hline
\end{tabular}


Tabela b. Composição química elementar das amostras irradiadas no segundo lote, expressa em $\mathrm{mg} \mathrm{kg}^{-1}$ base seca (exceto Sc em $\mu \mathrm{g} \mathrm{kg}{ }^{-1}$ ), com as respectivas incertezas combinadas expressas em porcentagem

\begin{tabular}{|c|c|c|c|c|c|c|c|c|c|}
\hline & \multicolumn{3}{|c|}{ arroz } & \multirow{2}{*}{ ervilha } & \multicolumn{5}{|c|}{ feijão } \\
\hline & integral & parboilizado & polido & & adzuki & bolinha & branco & carioca & fradinho \\
\hline & Ásia Lee & Uncle Bens & Prato Fino & Hikari & $\begin{array}{l}\text { Super } \\
\text { Grão }\end{array}$ & D'Guste & Yoki & $\begin{array}{l}\text { Broto } \\
\text { Legal }\end{array}$ & Camil \\
\hline As & $\begin{array}{c}0,27 \\
3,3\end{array}$ & $\begin{array}{c}0,25 \\
3,9\end{array}$ & $\begin{array}{c}0,11 \\
6,8\end{array}$ & $<0,025$ & $<0,031$ & $<0,016$ & $<0,017$ & $<0,017$ & $<0,023$ \\
\hline $\mathrm{Br}$ & $\begin{array}{c}0,59 \\
3,3\end{array}$ & $\begin{array}{c}0,83 \\
3,2\end{array}$ & $\begin{array}{c}1,43 \\
3,1\end{array}$ & $\begin{array}{c}1,15 \\
3,2\end{array}$ & $\begin{array}{c}2,49 \\
3,0\end{array}$ & $\begin{array}{c}1,70 \\
3,1\end{array}$ & $\begin{array}{c}0,49 \\
3,5\end{array}$ & $\begin{array}{c}0,18 \\
4,6\end{array}$ & $\begin{array}{c}0,55 \\
3,6\end{array}$ \\
\hline Ca & $<122$ & $<121$ & $<122$ & $\begin{array}{c}671 \\
7,0\end{array}$ & $\begin{array}{c}3120 \\
2,4\end{array}$ & $\begin{array}{c}1050 \\
3,5\end{array}$ & $\begin{array}{c}1280 \\
4,6\end{array}$ & $\begin{array}{c}1460 \\
3,2\end{array}$ & $\begin{array}{l}706 \\
5,6\end{array}$ \\
\hline Cd & $<0,21$ & $<0,16$ & $<0,13$ & $<0,23$ & $<0,21$ & $<0,16$ & $<0,18$ & $<0,18$ & $<0,24$ \\
\hline Co & $\begin{array}{c}0,020 \\
3,1\end{array}$ & $\begin{array}{c}0,047 \\
2,4\end{array}$ & $\begin{array}{c}0,069 \\
2,4\end{array}$ & $\begin{array}{c}0,098 \\
2,1\end{array}$ & $\begin{array}{c}0,202 \\
1,8\end{array}$ & $\begin{array}{c}0,148 \\
1,8\end{array}$ & $\begin{array}{c}0,113 \\
2,0\end{array}$ & $\begin{array}{c}0,117 \\
1,9\end{array}$ & $\begin{array}{c}0,115 \\
2,1\end{array}$ \\
\hline $\mathrm{Cr}$ & $<0,44$ & $<0,45$ & $<0,43$ & $\begin{array}{c}1,27 \\
14\end{array}$ & $<0,42$ & $<0,44$ & $<0,42$ & $<0,43$ & $<0,44$ \\
\hline $\mathbf{F e}$ & $\begin{array}{c}11,8 \\
4,6\end{array}$ & $\begin{array}{c}3,80 \\
10\end{array}$ & $<0,93$ & $\begin{array}{c}69,1 \\
1,8\end{array}$ & $\begin{array}{c}79,9 \\
1,6\end{array}$ & $\begin{array}{c}55,9 \\
1,8\end{array}$ & $\begin{array}{c}67,7 \\
1,8\end{array}$ & $\begin{array}{c}64,8 \\
1,9\end{array}$ & $\begin{array}{c}69,4 \\
2,1\end{array}$ \\
\hline Hg & $<0,017$ & $<0,013$ & $<0,011$ & $<0,018$ & $<0,014$ & $<0,019$ & $<0,022$ & $<0,019$ & $<0,027$ \\
\hline $\mathbf{K}$ & $\begin{array}{c}2400 \\
1,7\end{array}$ & $\begin{array}{c}1600 \\
1,6\end{array}$ & $\begin{array}{c}605 \\
1,6\end{array}$ & $\begin{array}{c}10100 \\
1,4\end{array}$ & $\begin{array}{c}14300 \\
1,5\end{array}$ & $\begin{array}{c}14000 \\
1,5\end{array}$ & $\begin{array}{c}15500 \\
1,4\end{array}$ & $\begin{array}{c}16400 \\
1,6\end{array}$ & $\begin{array}{c}13700 \\
1,2\end{array}$ \\
\hline La & $<0,0028$ & $<0,0028$ & $<0,0029$ & $\begin{array}{c}0,026 \\
5,9\end{array}$ & $\begin{array}{c}0,044 \\
3,5\end{array}$ & $\begin{array}{c}0,010 \\
6,0\end{array}$ & $<0,0019$ & $<0,0033$ & $\begin{array}{c}0,013 \\
12\end{array}$ \\
\hline $\mathrm{Na}$ & $\begin{array}{c}27,8 \\
2,0\end{array}$ & $\begin{array}{c}24,7 \\
2,4\end{array}$ & $\begin{array}{c}3,36 \\
5,4\end{array}$ & $\begin{array}{c}45,3 \\
1,6\end{array}$ & $\begin{array}{l}1,67 \\
10,7\end{array}$ & $<0,19$ & $\begin{array}{l}1,36 \\
12,1\end{array}$ & $<0,24$ & $\begin{array}{c}35,5 \\
1,7\end{array}$ \\
\hline $\mathbf{R b}$ & $\begin{array}{c}22,3 \\
2,6\end{array}$ & $\begin{array}{c}18,8 \\
2,6\end{array}$ & $\begin{array}{c}6,24 \\
2,8\end{array}$ & $\begin{array}{c}5,15 \\
2,9\end{array}$ & $\begin{array}{c}22,7 \\
2,6\end{array}$ & $\begin{array}{c}14,4 \\
2,6\end{array}$ & $\begin{array}{c}4,06 \\
2,9\end{array}$ & $\begin{array}{c}6,21 \\
2,8\end{array}$ & $\begin{array}{c}7,55 \\
2,9\end{array}$ \\
\hline Sc & $<0,14$ & $<0,13$ & $<0,13$ & $\begin{array}{c}1,73 \\
4,0\end{array}$ & $\begin{array}{c}13,2 \\
1,6\end{array}$ & $\begin{array}{c}1,58 \\
4,0\end{array}$ & $\begin{array}{c}0,97 \\
4,6\end{array}$ & $\begin{array}{c}2,13 \\
3,4\end{array}$ & $\begin{array}{c}3,17 \\
3,1\end{array}$ \\
\hline Se & $<0,054$ & $<0,041$ & $<0,033$ & $\begin{array}{c}0,16 \\
7,6\end{array}$ & $<0,052$ & $<0,059$ & $\begin{array}{c}0,34 \\
4,3\end{array}$ & $<0,059$ & $\begin{array}{c}0,23 \\
7,3\end{array}$ \\
\hline Zn & $\begin{array}{c}20,0 \\
1,3 \\
\end{array}$ & $\begin{array}{c}10,9 \\
1,7 \\
\end{array}$ & $\begin{array}{c}18,0 \\
1,4 \\
\end{array}$ & $\begin{array}{c}39,5 \\
1,3 \\
\end{array}$ & $\begin{array}{c}33,6 \\
1,2 \\
\end{array}$ & $\begin{array}{c}27,6 \\
1,3 \\
\end{array}$ & $\begin{array}{c}33,3 \\
1,3 \\
\end{array}$ & $\begin{array}{c}35,0 \\
1,3\end{array}$ & $\begin{array}{c}39,4 \\
1,3\end{array}$ \\
\hline
\end{tabular}


Tabela c. Composição química elementar das amostras irradiadas no segundo lote, expressa em $\mathrm{mg} \mathrm{kg}^{-1}$ base seca (exceto Sc em $\mu \mathrm{g} \mathrm{kg}{ }^{-1}$ ), com as respectivas incertezas combinadas expressas em porcentagem

\begin{tabular}{|c|c|c|c|c|c|c|c|c|}
\hline & \multicolumn{6}{|c|}{ feijão } & \multirow{3}{*}{$\begin{array}{c}\text { grão-de-bico } \\
\text { Yoki }\end{array}$} & \multirow{3}{*}{$\begin{array}{l}\text { lentilha } \\
\text { Kodilar }\end{array}$} \\
\hline & \multirow{2}{*}{$\begin{array}{c}\text { jalo } \\
\text { Camil }\end{array}$} & \multirow{2}{*}{$\begin{array}{c}\text { manteiga } \\
\text { Super Grão }\end{array}$} & \multirow{2}{*}{$\begin{array}{c}\text { mulatinho } \\
\text { Super Grão }\end{array}$} & \multirow{2}{*}{$\begin{array}{c}\text { preto } \\
\text { Namorado }\end{array}$} & \multirow{2}{*}{$\begin{array}{c}\text { rosinha } \\
\text { Grão de } \\
\text { Campo } \\
\end{array}$} & \multirow{2}{*}{$\begin{array}{c}\text { roxo } \\
\text { Super Cook }\end{array}$} & & \\
\hline & & & & & & & & \\
\hline As & $<0,028$ & $<0,024$ & $<0,032$ & $<0,032$ & $<0,033$ & $<0,029$ & $<0,041$ & $<0,021$ \\
\hline $\mathrm{Br}$ & $\begin{array}{c}1,62 \\
3,2\end{array}$ & $\begin{array}{c}1,09 \\
3,3\end{array}$ & $\begin{array}{c}6,42 \\
3,1\end{array}$ & $\begin{array}{c}0,46 \\
3,5\end{array}$ & $\begin{array}{c}1,09 \\
3,0\end{array}$ & $\begin{array}{c}1,14 \\
3,0\end{array}$ & $\begin{array}{c}19,33 \\
2,8\end{array}$ & $\begin{array}{c}6,14 \\
2,7\end{array}$ \\
\hline Ca & $\begin{array}{c}1380 \\
5,2\end{array}$ & $\begin{array}{c}1100 \\
4,4\end{array}$ & $\begin{array}{c}1950 \\
2,7\end{array}$ & $\begin{array}{c}1650 \\
3,1\end{array}$ & $\begin{array}{c}1290 \\
3,0\end{array}$ & $\begin{array}{c}1440 \\
3,1\end{array}$ & $\begin{array}{c}1280 \\
3,3\end{array}$ & $\begin{array}{c}604 \\
4,9\end{array}$ \\
\hline Cd & $<0,29$ & $<0,24$ & $<0,26$ & $<0,29$ & $<0,24$ & $<0,27$ & $<0,26$ & $<0,18$ \\
\hline Co & $\begin{array}{c}0,589 \\
1,8\end{array}$ & $\begin{array}{c}0,114 \\
2,3\end{array}$ & $\begin{array}{c}0,561 \\
1,7\end{array}$ & $\begin{array}{c}0,239 \\
1,8\end{array}$ & $\begin{array}{c}0,214 \\
1,8\end{array}$ & $\begin{array}{c}0,109 \\
2,1\end{array}$ & $\begin{array}{c}0,106 \\
2,1\end{array}$ & $\begin{array}{c}0,096 \\
2,0\end{array}$ \\
\hline $\mathrm{Cr}$ & $<0,48$ & $<0,49$ & $<0,43$ & $<0,47$ & $<0,42$ & $<0,46$ & $<0,46$ & $<0,42$ \\
\hline Fe & $\begin{array}{c}79,3 \\
2,1\end{array}$ & $\begin{array}{c}71,9 \\
2,1\end{array}$ & $\begin{array}{c}73,6 \\
2,1\end{array}$ & $\begin{array}{c}72,4 \\
2,0\end{array}$ & $\begin{array}{c}70,0 \\
1,7\end{array}$ & $\begin{array}{c}65,5 \\
2,0\end{array}$ & $\begin{array}{c}59,5 \\
2,0\end{array}$ & $\begin{array}{c}86,3 \\
1,6\end{array}$ \\
\hline Hg & $<0,032$ & $<0,025$ & $<0,025$ & $<0,024$ & $<0,023$ & $<0,023$ & $<0,022$ & $<0,025$ \\
\hline $\mathbf{K}$ & $\begin{array}{c}16000 \\
1,2\end{array}$ & $\begin{array}{c}14100 \\
1,3\end{array}$ & $\begin{array}{c}14200 \\
1,3\end{array}$ & $\begin{array}{c}17500 \\
1,2\end{array}$ & $\begin{array}{c}16800 \\
1,3\end{array}$ & $\begin{array}{c}16400 \\
1,3\end{array}$ & $\begin{array}{c}11800 \\
1,5\end{array}$ & $\begin{array}{c}11400 \\
1,3\end{array}$ \\
\hline La & $\begin{array}{c}0,018 \\
17\end{array}$ & $\begin{array}{c}0,014 \\
6,9\end{array}$ & $\begin{array}{c}0,017 \\
14\end{array}$ & $\begin{array}{c}0,012 \\
8,9\end{array}$ & $\begin{array}{c}0,016 \\
7,1\end{array}$ & $<0,0031$ & $\begin{array}{c}0,014 \\
9,7\end{array}$ & $\begin{array}{c}0,013 \\
5,4\end{array}$ \\
\hline $\mathrm{Na}$ & $<0,34$ & $\begin{array}{c}1,42 \\
14\end{array}$ & $\begin{array}{c}1,45 \\
17\end{array}$ & $\begin{array}{c}1,10 \\
18\end{array}$ & $<0,29$ & $\begin{array}{c}0,95 \\
19\end{array}$ & $\begin{array}{l}138 \\
1,6\end{array}$ & $\begin{array}{c}5,31 \\
3,9\end{array}$ \\
\hline $\mathbf{R b}$ & $\begin{array}{c}14,6 \\
2,7\end{array}$ & $\begin{array}{c}19,8 \\
2,6\end{array}$ & $\begin{array}{c}17,7 \\
2,8\end{array}$ & $\begin{array}{c}18,8 \\
2,4\end{array}$ & $\begin{array}{c}12,0 \\
2,5\end{array}$ & $\begin{array}{c}42,0 \\
2,4\end{array}$ & $\begin{array}{c}7,12 \\
2,5\end{array}$ & $\begin{array}{c}5,43 \\
2,6\end{array}$ \\
\hline Sc & $\begin{array}{c}3,65 \\
3,8\end{array}$ & $\begin{array}{c}1,55 \\
5,4\end{array}$ & $\begin{array}{c}6,03 \\
2,5\end{array}$ & $\begin{array}{c}1,86 \\
5,0\end{array}$ & $\begin{array}{c}4,02 \\
2,4\end{array}$ & $\begin{array}{c}1,57 \\
5,3\end{array}$ & $\begin{array}{c}4,77 \\
2,3\end{array}$ & $\begin{array}{c}4,24 \\
2,5\end{array}$ \\
\hline Se & $<0,11$ & $<0,093$ & $\begin{array}{c}0,23 \\
6,6\end{array}$ & $<0,096$ & $<0,10$ & $<0,095$ & $\begin{array}{c}0,25 \\
5,8\end{array}$ & $\begin{array}{c}1,14 \\
2,9\end{array}$ \\
\hline $\mathrm{Zn}$ & $\begin{array}{c}37,4 \\
1,3\end{array}$ & $\begin{array}{c}30,3 \\
1,3\end{array}$ & $\begin{array}{c}32,1 \\
1,5\end{array}$ & $\begin{array}{c}35,8 \\
1,3\end{array}$ & $\begin{array}{c}34,3 \\
1,3\end{array}$ & $\begin{array}{c}34,4 \\
1,4\end{array}$ & $\begin{array}{c}33,0 \\
1,2\end{array}$ & $\begin{array}{c}43,7 \\
1,2\end{array}$ \\
\hline
\end{tabular}


Tabela d. Composição química elementar das amostras irradiadas no terceiro lote, expressa em $\mathrm{mg} \mathrm{kg}^{-1}$ base seca (exceto Sc em $\mu \mathrm{g} \mathrm{kg}{ }^{-1}$ ), com as respectivas incertezas combinadas expressas em porcentagem

\begin{tabular}{|c|c|c|c|c|c|c|c|c|}
\hline & \multicolumn{6}{|c|}{ arroz } & \multirow{3}{*}{$\begin{array}{c}\text { ervilha } \\
\text { Yoki }\end{array}$} & \multirow{3}{*}{$\begin{array}{c}\text { feijão } \\
\text { bolinha } \\
\text { Grão de } \\
\text { Campo } \\
\end{array}$} \\
\hline & \multicolumn{2}{|c|}{ parboilizado } & \multicolumn{4}{|c|}{ polido } & & \\
\hline & Carrefour & $\begin{array}{c}\text { Super } \\
\text { Coradini }\end{array}$ & Carrefour & Coradini & Delta & Tio João & & \\
\hline As & $\begin{array}{c}0,43 \\
5,3\end{array}$ & $\begin{array}{c}0,33 \\
3,8\end{array}$ & $\begin{array}{c}0,47 \\
3,6\end{array}$ & $\begin{array}{c}0,40 \\
4,2\end{array}$ & $\begin{array}{c}0,32 \\
4,9\end{array}$ & $\begin{array}{c}0,16 \\
7,6\end{array}$ & $<0,032$ & $<0,018$ \\
\hline $\mathrm{Br}$ & $\begin{array}{c}1,89 \\
3,2\end{array}$ & $\begin{array}{c}1,74 \\
3,2\end{array}$ & $\begin{array}{c}0,99 \\
3,3\end{array}$ & $\begin{array}{c}0,95 \\
3,3\end{array}$ & $\begin{array}{c}0,42 \\
3,4\end{array}$ & $\begin{array}{c}1,75 \\
3,3\end{array}$ & $\begin{array}{c}1,31 \\
3,2\end{array}$ & $\begin{array}{c}3,16 \\
2,9\end{array}$ \\
\hline Ca & $<58$ & $<51$ & $<51$ & $<49$ & $\begin{array}{c}203 \\
13\end{array}$ & $\begin{array}{c}163 \\
14\end{array}$ & $\begin{array}{c}472 \\
4,9\end{array}$ & $\begin{array}{c}1320 \\
3,0\end{array}$ \\
\hline Cd & $<0,12$ & $<0,087$ & $<0,071$ & $<0,082$ & $<0,090$ & $<0,089$ & $<0,21$ & $<0,18$ \\
\hline Co & $\begin{array}{c}0,032 \\
3,7\end{array}$ & $\begin{array}{c}0,020 \\
3,4\end{array}$ & $\begin{array}{c}0,023 \\
3,3\end{array}$ & $\begin{array}{c}0,025 \\
2,9\end{array}$ & $\begin{array}{c}0,032 \\
2,4\end{array}$ & $\begin{array}{c}0,110 \\
2,2\end{array}$ & $\begin{array}{c}0,058 \\
2,3\end{array}$ & $\begin{array}{c}0,151 \\
2,2\end{array}$ \\
\hline $\mathrm{Cr}$ & $\begin{array}{c}1,46 \\
10\end{array}$ & $<0,38$ & $<0,40$ & $\begin{array}{c}0,75 \\
18\end{array}$ & $\begin{array}{c}1,09 \\
13\end{array}$ & $\begin{array}{c}1,20 \\
11\end{array}$ & $<0,41$ & $<0,44$ \\
\hline $\mathbf{F e}$ & $\begin{array}{c}15,1 \\
5,1\end{array}$ & $<1,4$ & $<1,3$ & $\begin{array}{c}7,19 \\
4,6\end{array}$ & $\begin{array}{c}13,6 \\
2,9\end{array}$ & $\begin{array}{c}19,4 \\
3,1\end{array}$ & $\begin{array}{c}57,4 \\
1,8\end{array}$ & $\begin{array}{c}65,1 \\
2,1\end{array}$ \\
\hline Hg & $<0,019$ & $<0,016$ & $<0,014$ & $<0,0051$ & $<0,0037$ & $<0,014$ & $<0,020$ & $<0,028$ \\
\hline $\mathbf{K}$ & $\begin{array}{c}1700 \\
1,5\end{array}$ & $\begin{array}{c}1670 \\
1,7\end{array}$ & $\begin{array}{c}622 \\
1,6\end{array}$ & $\begin{array}{c}583 \\
1,5\end{array}$ & $\begin{array}{c}659 \\
1,6\end{array}$ & $\begin{array}{c}580 \\
1,6\end{array}$ & $\begin{array}{c}10800 \\
1,6\end{array}$ & $\begin{array}{c}14500 \\
1,6\end{array}$ \\
\hline $\mathbf{L a}$ & $<0,0019$ & $<0,0011$ & $<0,0011$ & $<0,0011$ & $<0,0014$ & $<0,0016$ & $<0,0020$ & $\begin{array}{c}0,014 \\
7,1\end{array}$ \\
\hline $\mathrm{Na}$ & $\begin{array}{c}11,8 \\
3,5\end{array}$ & $\begin{array}{c}8,24 \\
2,9\end{array}$ & $\begin{array}{c}4,39 \\
4,3\end{array}$ & $\begin{array}{c}4,32 \\
4,2\end{array}$ & $\begin{array}{c}13,0 \\
2,3\end{array}$ & $\begin{array}{c}9,14 \\
2,7\end{array}$ & $\begin{array}{c}28,2 \\
2,0\end{array}$ & $\begin{array}{c}0,97 \\
19\end{array}$ \\
\hline Rb & $\begin{array}{c}15,7 \\
2,7\end{array}$ & $\begin{array}{c}14,5 \\
2,7\end{array}$ & $\begin{array}{c}6,31 \\
2,8\end{array}$ & $\begin{array}{c}6,80 \\
2,7\end{array}$ & $\begin{array}{c}7,35 \\
2,7\end{array}$ & $\begin{array}{c}8,82 \\
2,7\end{array}$ & $\begin{array}{c}10,7 \\
2,7\end{array}$ & $\begin{array}{c}8,23 \\
2,6\end{array}$ \\
\hline Sc & $<0,39$ & $<0,18$ & $<0,17$ & $<0,27$ & $\begin{array}{c}0,60 \\
7,7\end{array}$ & $\begin{array}{c}1,22 \\
6,0\end{array}$ & $<0,25$ & $\begin{array}{c}2,76 \\
3,1\end{array}$ \\
\hline Se & $<0,073$ & $<0,051$ & $<0,045$ & $<0,021$ & $<0,013$ & $<0,062$ & $\begin{array}{c}0,17 \\
15\end{array}$ & $<0,083$ \\
\hline $\mathbf{Z n}$ & $\begin{array}{c}7,85 \\
2,0 \\
\end{array}$ & $\begin{array}{c}7,61 \\
2,0 \\
\end{array}$ & $\begin{array}{c}15,5 \\
1,5 \\
\end{array}$ & $\begin{array}{c}14,7 \\
1,5 \\
\end{array}$ & $\begin{array}{c}15,8 \\
1,5 \\
\end{array}$ & $\begin{array}{c}14,1 \\
1,5 \\
\end{array}$ & $\begin{array}{c}40,1 \\
1,3 \\
\end{array}$ & $\begin{array}{c}24,3 \\
1,5 \\
\end{array}$ \\
\hline
\end{tabular}


Tabela e. Composição química elementar das amostras irradiadas no terceiro lote, expressa em $\mathrm{mg} \mathrm{kg}^{-1}$ base seca (exceto Sc em $\mu \mathrm{g} \mathrm{kg}{ }^{-1}$ ), com as respectivas incertezas combinadas expressas em porcentagem

\begin{tabular}{|c|c|c|c|c|c|c|c|c|}
\hline & \multicolumn{8}{|c|}{ feijão } \\
\hline & \multicolumn{6}{|c|}{ branco } & \multicolumn{2}{|c|}{ carioca } \\
\hline & Angélica & Camil & $\begin{array}{c}\text { Grão de } \\
\text { Campo }\end{array}$ & Hikari & Kodilar & Super Grão & Bico de Ouro & Camil \\
\hline As & $<0,019$ & $<0,020$ & $<0,021$ & $<0,022$ & $<0,023$ & $<0,015$ & $<0,023$ & $<0,025$ \\
\hline $\mathrm{Br}$ & $\begin{array}{c}0,53 \\
3,0\end{array}$ & $\begin{array}{c}0,66 \\
3,0\end{array}$ & $\begin{array}{c}0,81 \\
3,1\end{array}$ & $\begin{array}{c}0,77 \\
3,0\end{array}$ & $\begin{array}{c}0,58 \\
3,2\end{array}$ & $\begin{array}{c}0,42 \\
3,2\end{array}$ & $\begin{array}{c}1,09 \\
2,9\end{array}$ & $\begin{array}{c}0,26 \\
3,8\end{array}$ \\
\hline Ca & $\begin{array}{c}1220 \\
2,8\end{array}$ & $\begin{array}{c}1450 \\
2,4\end{array}$ & $\begin{array}{c}1770 \\
2,6\end{array}$ & $\begin{array}{c}1380 \\
3,1\end{array}$ & $\begin{array}{c}1450 \\
3,0\end{array}$ & $\begin{array}{c}1300 \\
3,0\end{array}$ & $\begin{array}{c}1790 \\
2,5\end{array}$ & $\begin{array}{c}1170 \\
3,3\end{array}$ \\
\hline Cd & $<0,20$ & $<0,20$ & $<0,21$ & $<0,21$ & $<0,23$ & $<0,14$ & $<0,19$ & $<0,22$ \\
\hline Co & $\begin{array}{c}0,160 \\
2,3\end{array}$ & $\begin{array}{c}0,147 \\
2,0\end{array}$ & $\begin{array}{c}0,192 \\
1,9\end{array}$ & $\begin{array}{c}0,125 \\
1,9\end{array}$ & $\begin{array}{c}0,144 \\
1,9\end{array}$ & $\begin{array}{c}0,125 \\
1,8\end{array}$ & $\begin{array}{c}0,491 \\
1,6\end{array}$ & $\begin{array}{c}0,042 \\
2,5\end{array}$ \\
\hline $\mathrm{Cr}$ & $<0,42$ & $<0,44$ & $<0,43$ & $<0,45$ & $<0,49$ & $<0,43$ & $<0,42$ & $<0,44$ \\
\hline $\mathbf{F e}$ & $\begin{array}{c}70,7 \\
1,9\end{array}$ & $\begin{array}{c}61,3 \\
2,0\end{array}$ & $\begin{array}{c}64,0 \\
2,2\end{array}$ & $\begin{array}{c}61,7 \\
1,8\end{array}$ & $\begin{array}{c}75,5 \\
1,8\end{array}$ & $\begin{array}{c}73,4 \\
1,8\end{array}$ & $\begin{array}{c}78,2 \\
1,8\end{array}$ & $\begin{array}{c}71,7 \\
1,8\end{array}$ \\
\hline Hg & $<0,028$ & $<0,029$ & $<0,030$ & $<0,016$ & $<0,020$ & $<0,019$ & $<0,019$ & $<0,018$ \\
\hline $\mathbf{K}$ & $\begin{array}{c}16000 \\
1,6\end{array}$ & $\begin{array}{c}15900 \\
1,7\end{array}$ & $\begin{array}{c}15800 \\
1,7\end{array}$ & $\begin{array}{c}16100 \\
1,6\end{array}$ & $\begin{array}{c}15600 \\
1,7\end{array}$ & $\begin{array}{c}16000 \\
1,7\end{array}$ & $\begin{array}{c}14900 \\
1,7\end{array}$ & $\begin{array}{c}16400 \\
1,6\end{array}$ \\
\hline $\mathbf{L a}$ & $<0,0025$ & $<0,0025$ & $\begin{array}{c}0,0092 \\
8,6\end{array}$ & $<0,0028$ & $<0,0029$ & $\begin{array}{c}0,0083 \\
6,3\end{array}$ & $\begin{array}{c}0,017 \\
5,1\end{array}$ & $<0,0020$ \\
\hline $\mathrm{Na}$ & $\begin{array}{c}2,47 \\
7,6\end{array}$ & $\begin{array}{c}1,65 \\
11\end{array}$ & $\begin{array}{c}2,46 \\
7,9\end{array}$ & $\begin{array}{c}1,77 \\
11\end{array}$ & $\begin{array}{c}5,18 \\
4,7\end{array}$ & $\begin{array}{c}2,17 \\
8,7\end{array}$ & 0,26 & 0,287 \\
\hline $\mathbf{R b}$ & $\begin{array}{c}3,82 \\
2,9\end{array}$ & $\begin{array}{c}3,46 \\
2,7\end{array}$ & $\begin{array}{c}7,06 \\
2,6\end{array}$ & $\begin{array}{c}4,11 \\
2,7\end{array}$ & $\begin{array}{c}3,99 \\
2,8\end{array}$ & $\begin{array}{c}3,13 \\
2,7\end{array}$ & $\begin{array}{c}44,8 \\
2,4\end{array}$ & $\begin{array}{c}9,13 \\
2,5\end{array}$ \\
\hline Sc & $\begin{array}{c}1,95 \\
6,1\end{array}$ & $\begin{array}{c}0,99 \\
7,7\end{array}$ & $\begin{array}{c}2,85 \\
3,3\end{array}$ & $\begin{array}{c}1,70 \\
4,2\end{array}$ & $\begin{array}{c}1,64 \\
6,5\end{array}$ & $\begin{array}{c}2,49 \\
3,3\end{array}$ & $\begin{array}{c}2,65 \\
3,4\end{array}$ & $\begin{array}{c}4,56 \\
2,2\end{array}$ \\
\hline Se & $\begin{array}{c}0,26 \\
11\end{array}$ & $<0,087$ & $\begin{array}{c}0,36 \\
7,5\end{array}$ & $\begin{array}{c}0,35 \\
3,7\end{array}$ & $\begin{array}{c}0,29 \\
5,6\end{array}$ & $\begin{array}{c}0,18 \\
8,7\end{array}$ & $<0,057$ & $<0,053$ \\
\hline Zn & $\begin{array}{c}33,9 \\
1,4\end{array}$ & $\begin{array}{c}33,2 \\
1,4\end{array}$ & $\begin{array}{c}26,7 \\
1,5\end{array}$ & $\begin{array}{c}31,5 \\
1,4\end{array}$ & $\begin{array}{c}34,0 \\
1,4\end{array}$ & $\begin{array}{c}37,6 \\
1,3\end{array}$ & $\begin{array}{c}27,3 \\
1,4\end{array}$ & $\begin{array}{c}32,5 \\
1,3\end{array}$ \\
\hline
\end{tabular}


Tabela f. Composição química elementar das amostras irradiadas no terceiro lote, expressa em $\mathrm{mg} \mathrm{kg}^{-1}$ base seca (exceto Sc em $\mu \mathrm{g} \mathrm{kg}{ }^{-1}$ ), com as respectivas incertezas combinadas expressas em porcentagem

\begin{tabular}{|c|c|c|c|c|c|c|c|c|}
\hline & \multicolumn{8}{|c|}{ feijão } \\
\hline & \multicolumn{7}{|c|}{ carioca } & \multirow{2}{*}{$\begin{array}{c}\text { jalo } \\
\text { Grão de } \\
\text { Campo } \\
\end{array}$} \\
\hline & Carrefour & $\begin{array}{c}\text { Grão de } \\
\text { Campo }\end{array}$ & Ki Grão & Marcon & Pantera & Vencedor & Zamunér & \\
\hline As & $<0,018$ & $<0,024$ & $<0,027$ & $<0,028$ & $<0,031$ & $<0,023$ & $<0,031$ & $<0,032$ \\
\hline Br & $\begin{array}{c}0,22 \\
3,8\end{array}$ & $\begin{array}{c}0,47 \\
3,2\end{array}$ & $\begin{array}{c}0,42 \\
3,2\end{array}$ & $\begin{array}{c}0,89 \\
2,9\end{array}$ & $\begin{array}{c}0,13 \\
4,4\end{array}$ & $\begin{array}{c}0,44 \\
3,1\end{array}$ & $\begin{array}{c}0,70 \\
3,0\end{array}$ & $\begin{array}{c}0,52 \\
3,0\end{array}$ \\
\hline Ca & $\begin{array}{c}1200 \\
3,0\end{array}$ & $\begin{array}{c}1230 \\
2,9\end{array}$ & $\begin{array}{c}1350 \\
2,6\end{array}$ & $\begin{array}{c}1280 \\
2,7\end{array}$ & $\begin{array}{c}1460 \\
2,5\end{array}$ & $\begin{array}{c}1070 \\
3,0\end{array}$ & $\begin{array}{c}1420 \\
2,4\end{array}$ & $\begin{array}{c}1060 \\
3,3\end{array}$ \\
\hline Cd & $<0,15$ & $<0,20$ & $<0,22$ & $<0,22$ & $<0,23$ & $<0,22$ & $<0,23$ & $<0,24$ \\
\hline Co & $\begin{array}{c}0,157 \\
1,8\end{array}$ & $\begin{array}{c}0,163 \\
1,8\end{array}$ & $\begin{array}{c}0,324 \\
1,7\end{array}$ & $\begin{array}{c}0,222 \\
1,7\end{array}$ & $\begin{array}{c}0,037 \\
2,7\end{array}$ & $\begin{array}{c}0,121 \\
2,0\end{array}$ & $\begin{array}{c}0,159 \\
1,9\end{array}$ & $\begin{array}{c}0,147 \\
1,8\end{array}$ \\
\hline $\mathrm{Cr}$ & $<0,43$ & $<0,40$ & $<0,40$ & $<0,40$ & $<0,43$ & $<0,44$ & $<0,40$ & $<0,41$ \\
\hline Fe & $\begin{array}{c}74,4 \\
1,8\end{array}$ & $\begin{array}{c}73,6 \\
1,8\end{array}$ & $\begin{array}{c}82,7 \\
1,8\end{array}$ & $\begin{array}{c}138 \\
1,6\end{array}$ & $\begin{array}{c}54,1 \\
2,0\end{array}$ & $\begin{array}{c}79,8 \\
1,9\end{array}$ & $\begin{array}{c}72,9 \\
1,8\end{array}$ & $\begin{array}{c}70,3 \\
1,7\end{array}$ \\
\hline Hg & $<0,025$ & $<0,024$ & $<0,025$ & $<0,028$ & $<0,026$ & $<0,028$ & $<0,025$ & $<0,0049$ \\
\hline $\mathbf{K}$ & $\begin{array}{c}16500 \\
1,7\end{array}$ & $\begin{array}{c}15300 \\
2,0\end{array}$ & $\begin{array}{c}14800 \\
1,7\end{array}$ & $\begin{array}{c}16600 \\
1,7\end{array}$ & $\begin{array}{c}16600 \\
1,9\end{array}$ & $\begin{array}{c}15000 \\
1,8\end{array}$ & $\begin{array}{c}16000 \\
1,8\end{array}$ & $\begin{array}{c}13300 \\
1,9\end{array}$ \\
\hline La & $\begin{array}{c}0,0086 \\
7,5\end{array}$ & $\begin{array}{c}0,011 \\
8,4\end{array}$ & $\begin{array}{c}0,011 \\
7,0\end{array}$ & $\begin{array}{c}0,053 \\
2,7\end{array}$ & $<0,0023$ & $<0,0021$ & $\begin{array}{c}0,012 \\
4,9\end{array}$ & $\begin{array}{c}0,0071 \\
11\end{array}$ \\
\hline $\mathrm{Na}$ & $<0,28$ & $<0,26$ & $<0,26$ & $\begin{array}{c}0,96 \\
18\end{array}$ & $<0,17$ & $<0,26$ & $<0,17$ & $<0,16$ \\
\hline $\mathbf{R b}$ & $\begin{array}{c}5,14 \\
2,6\end{array}$ & $\begin{array}{c}8,97 \\
2,6\end{array}$ & $\begin{array}{c}22,7 \\
2,4\end{array}$ & $\begin{array}{c}4,73 \\
2,6\end{array}$ & $\begin{array}{c}4,47 \\
2,7\end{array}$ & $\begin{array}{c}5,47 \\
2,6\end{array}$ & $\begin{array}{c}20,7 \\
2,4\end{array}$ & $\begin{array}{c}22,2 \\
2,4\end{array}$ \\
\hline Sc & $\begin{array}{c}2,82 \\
3,0\end{array}$ & $\begin{array}{c}3,09 \\
2,9\end{array}$ & $\begin{array}{c}7,08 \\
2,1\end{array}$ & $\begin{array}{c}24,3 \\
1,7\end{array}$ & $\begin{array}{c}2,07 \\
3,4\end{array}$ & $\begin{array}{c}2,98 \\
3,3\end{array}$ & $\begin{array}{c}2,74 \\
2,9\end{array}$ & $\begin{array}{c}3,14 \\
2,7\end{array}$ \\
\hline Se & $<0,082$ & $<0,068$ & $<0,074$ & $<0,080$ & $<0,070$ & $<0,078$ & $<0,069$ & $<0,017$ \\
\hline Zn & $\begin{array}{c}34,8 \\
1,3 \\
\end{array}$ & $\begin{array}{c}34,1 \\
1,3 \\
\end{array}$ & $\begin{array}{c}35,6 \\
1,3 \\
\end{array}$ & $\begin{array}{c}24,9 \\
1,5 \\
\end{array}$ & $\begin{array}{c}33,2 \\
1,2 \\
\end{array}$ & $\begin{array}{c}30,3 \\
1,5 \\
\end{array}$ & $\begin{array}{c}28,5 \\
1,3 \\
\end{array}$ & $\begin{array}{c}39,0 \\
1,3 \\
\end{array}$ \\
\hline
\end{tabular}


Tabela g. Composição química elementar das amostras irradiadas no terceiro lote, expressa em $\mathrm{mg} \mathrm{kg}^{-1}$ base seca (exceto Sc em $\mu \mathrm{g} \mathrm{kg}{ }^{-1}$ ), com as respectivas incertezas combinadas expressas em porcentagem

\begin{tabular}{|c|c|c|c|c|c|c|c|c|}
\hline & \multicolumn{2}{|c|}{ feijão } & \multirow{2}{*}{\multicolumn{3}{|c|}{ grão-de-bico }} & \multirow{2}{*}{\multicolumn{3}{|c|}{ lentilha }} \\
\hline & \multirow{2}{*}{$\begin{array}{c}\text { jalo } \\
\text { Super Cook } \\
\end{array}$} & \multirow{2}{*}{$\begin{array}{l}\text { preto } \\
\text { Camil } \\
\end{array}$} & & & & & & \\
\hline & & & Camil & Hikari & Kodilar & Camil & Hikari & Yoki \\
\hline As & $<0,033$ & $<0,035$ & $<0,20$ & $<0,16$ & $<0,18$ & $<0,028$ & $<0,032$ & $<0,034$ \\
\hline $\mathrm{Br}$ & $\begin{array}{c}0,89 \\
2,8\end{array}$ & $\begin{array}{c}0,58 \\
3,1\end{array}$ & $\begin{array}{c}8,48 \\
3,2\end{array}$ & $\begin{array}{c}22,8 \\
3,3\end{array}$ & $\begin{array}{c}13,7 \\
3,3\end{array}$ & $\begin{array}{c}3,05 \\
3,2\end{array}$ & $\begin{array}{c}6,70 \\
3,2\end{array}$ & $\begin{array}{c}9,56 \\
3,2\end{array}$ \\
\hline Ca & $\begin{array}{c}1130 \\
2,9\end{array}$ & $\begin{array}{c}1320 \\
3,2\end{array}$ & $\begin{array}{c}1100 \\
3,0\end{array}$ & $\begin{array}{c}1100 \\
3,0\end{array}$ & $\begin{array}{c}1200 \\
2,5\end{array}$ & $\begin{array}{c}743 \\
3,3\end{array}$ & $\begin{array}{l}618 \\
4,2\end{array}$ & $\begin{array}{c}736 \\
3,7\end{array}$ \\
\hline Cd & $<0,23$ & $<0,27$ & $<0,49$ & $<0,42$ & $<0,42$ & $<0,20$ & $<0,22$ & $<0,21$ \\
\hline Co & $\begin{array}{c}0,155 \\
1,8\end{array}$ & $\begin{array}{c}0,292 \\
1,7\end{array}$ & $\begin{array}{c}0,167 \\
1,9\end{array}$ & $\begin{array}{c}0,111 \\
2,0\end{array}$ & $\begin{array}{c}0,154 \\
1,8\end{array}$ & $\begin{array}{c}0,105 \\
2,2\end{array}$ & $\begin{array}{c}0,113 \\
2,0\end{array}$ & $\begin{array}{c}0,091 \\
1,9\end{array}$ \\
\hline $\mathrm{Cr}$ & $<0,39$ & $<0,39$ & $<0,45$ & $<0,37$ & $<0,42$ & $<0,38$ & $<0,38$ & $<0,39$ \\
\hline $\mathbf{F e}$ & $\begin{array}{c}79,2 \\
1,8\end{array}$ & $\begin{array}{c}78,7 \\
1,8\end{array}$ & $\begin{array}{c}55,9 \\
2,0\end{array}$ & $\begin{array}{c}61,0 \\
1,8\end{array}$ & $\begin{array}{c}55,3 \\
1,8\end{array}$ & $\begin{array}{c}97,5 \\
1,6\end{array}$ & $\begin{array}{c}87,9 \\
1,7\end{array}$ & $\begin{array}{c}83,5 \\
1,6\end{array}$ \\
\hline Hg & $<0,022$ & $<0,026$ & $<0,020$ & $<0,017$ & $<0,021$ & $<0,024$ & $<0,026$ & $<0,012$ \\
\hline $\mathbf{K}$ & $\begin{array}{c}14300 \\
1,6\end{array}$ & $\begin{array}{c}16800 \\
1,7\end{array}$ & $\begin{array}{c}11800 \\
1,9\end{array}$ & $\begin{array}{c}11300 \\
1,6\end{array}$ & $\begin{array}{c}12000 \\
2,2\end{array}$ & $\begin{array}{c}10500 \\
1,7\end{array}$ & $\begin{array}{c}11100 \\
1,5\end{array}$ & $\begin{array}{c}11200 \\
1,5\end{array}$ \\
\hline $\mathbf{L a}$ & $<0,0022$ & $\begin{array}{c}0,0127 \\
6,2\end{array}$ & $<0,0074$ & $<0,0079$ & $<0,0064$ & $\begin{array}{c}0,025 \\
3,9\end{array}$ & $\begin{array}{c}0,010 \\
9,0\end{array}$ & $\begin{array}{c}0,0096 \\
16\end{array}$ \\
\hline $\mathrm{Na}$ & $<0,293$ & $\begin{array}{c}2,61 \\
8,1\end{array}$ & $\begin{array}{l}196 \\
2,7\end{array}$ & $\begin{array}{l}110 \\
2,1\end{array}$ & $\begin{array}{l}106 \\
2,6\end{array}$ & $\begin{array}{c}7,25 \\
3,9\end{array}$ & $\begin{array}{c}5,78 \\
4,1\end{array}$ & $\begin{array}{c}19,9 \\
2,7\end{array}$ \\
\hline $\mathbf{R b}$ & $\begin{array}{c}15,5 \\
2,5\end{array}$ & $\begin{array}{c}5,54 \\
2,6\end{array}$ & $\begin{array}{c}5,98 \\
2,8\end{array}$ & $\begin{array}{c}5,06 \\
2,8\end{array}$ & $\begin{array}{c}10,5 \\
2,7\end{array}$ & $\begin{array}{c}5,35 \\
2,8\end{array}$ & $\begin{array}{c}6,10 \\
2,8\end{array}$ & $\begin{array}{c}3,46 \\
2,8\end{array}$ \\
\hline Sc & $\begin{array}{c}2,76 \\
3,1\end{array}$ & $\begin{array}{c}3,71 \\
2,5\end{array}$ & $\begin{array}{c}2,70 \\
3,1\end{array}$ & $\begin{array}{c}4,66 \\
2,5\end{array}$ & $\begin{array}{c}1,82 \\
3,8\end{array}$ & $\begin{array}{c}9,82 \\
1,8\end{array}$ & $\begin{array}{c}3,58 \\
2,8\end{array}$ & $\begin{array}{c}2,57 \\
3,0\end{array}$ \\
\hline Se & $<0,072$ & $\begin{array}{c}0,19 \\
9,4\end{array}$ & $\begin{array}{c}0,18 \\
7,1\end{array}$ & $\begin{array}{c}0,16 \\
6,3\end{array}$ & $\begin{array}{c}0,20 \\
4,5\end{array}$ & $\begin{array}{c}1,20 \\
2,6\end{array}$ & $\begin{array}{c}1,11 \\
2,9\end{array}$ & $\begin{array}{c}1,28 \\
2,6\end{array}$ \\
\hline Zn & $\begin{array}{c}32,7 \\
1,4 \\
\end{array}$ & $\begin{array}{c}31,3 \\
1,3 \\
\end{array}$ & $\begin{array}{c}35,3 \\
1,4 \\
\end{array}$ & $\begin{array}{c}31,9 \\
1,4 \\
\end{array}$ & $\begin{array}{c}33,8 \\
1,4 \\
\end{array}$ & $\begin{array}{c}43,1 \\
1,3 \\
\end{array}$ & $\begin{array}{c}44,2 \\
1,3 \\
\end{array}$ & $\begin{array}{c}47,6 \\
1,3 \\
\end{array}$ \\
\hline
\end{tabular}




\section{ERRATA}

\section{Página 8, linha 9}

Onde se lê:

$2,43 \times 10^{12} \mathrm{~m}$

Leia-se:

$2,43 \times 10^{-12} \mathrm{~m}$

\section{Página 41, Tabela 10}

Onde se lê:

${ }^{76} \mathrm{Rb}$

Leia-se:

${ }^{86} \mathrm{Rb}$

\section{Na dissertação}

Onde se lê:

Leia-se:

Sensibilidade e Sensibilidade analítica

Limite de detecção 